A CASE STUDY OF THE PROGRESSIVE IMPACT OF SCHOOL-WIDE POSITIVE BEHAVIOR SUPPORT ON FIVE SELECTED STUDENT

PERFORMANCE FACTORS IN A MISSOURI

K-12 ALTERNATIVE PUBLIC SCHOOL

A Doctoral Dissertation

Presented to

The Faculty of the Graduate School

University of Missouri-Columbia

In Partial Fulfillment

Of the Requirements for the Degree

Doctorate of Education

By

COLLEEN GILDAY BECKER

Dr. Phillip Messner, Supervisor

JULY 2013 
(C) Colleen Gilday Becker 2013

All Rights Reserved 
The undersigned, appointed by the dean of the Graduate School, have examined the Doctoral Dissertation entitled A CASE STUDY OF THE PROGRESSIVE IMPACT OF SCHOOL-WIDE POSITIVE BEHAVIOR SUPPORT ON FIVE SELECTED STUDENT PERFORMANCE FACTORS IN A MISSOURI K-12 ALTERNATIVE PUBLIC SCHOOL

Presented by Colleen Gilday Becker

A candidate for the degree of

\section{Doctorate of Education}

And hereby certify that, in their opinion, it is worthy of acceptance.

Professor Phillip Messner

Professor Carole Edmonds

Professor Rochelle Hiatt

Professor Kristina Alexander 


\section{DEDICATION}

First of all, I dedicate this scholarly work to all those students who have been told they cannot do something, or will never amount to anything, or will be a nobody in this world. Throughout my career I have worked for the Department of Mental Health, the Department of Corrections, and the Department of Elementary and Secondary Education. No matter in what job capacity I was employed there was a consistent theme of selfdeprecating behavior in those clients, inmates, patients, or students with whom I worked. I firmly believe that you can do anything you put your mind to doing, regardless of what others may say. My own personal life experience has taught me that this is true.

When I was in high school I was an average student and very introverted and quiet. When all of my friends were planning to go off to college, my high school advisor met with me and my parents and told us that she strongly advised that I not go to college as it would be a waste of time and money because I would not be successful. That was all I had dreamed of was going to college and someday getting my doctorate. I am so very thankful to my parents that they did not listen to that high school counselor. They always encouraged me to do my best and pursue my dreams and so I went to college. And now four college degrees later and finally achieving my doctorate 40 years since high school graduation, I am extremely proud of my academic and life accomplishments. And most of all I did not listen to someone who told me I could not achieve my goals.

With the support and encouragement of my parents, Robert and Constance Gilday, I have achieved my goal of attaining my doctorate. I dedicate this dissertation to them most of all. My only regret is that my father passed away right before I started the 
doctoral program and then my mother died very unexpectedly two years ago. I know they will be there in spirit, so it will be a bittersweet occasion.

I also dedicate my dissertation to my three wonderful children Paul, John, and Amy who have been patient, loving, and supportive throughout my academic career. As a parent, I have been involved in their pursuits with music, sports, education, families and careers. In retrospect, they have always known me as a mom who is employed and in pursuit of some kind of education, training, or additional professional certification or licensure. This has also been true for the next generation, as my grandchildren Terrence, Tevion, and Noah have experienced the same. I hope some day that my grandchildren will read this dissertation and be inspired to further their educational goals and dreams. I want them to know and experience the benefits of lifelong learning.

And last, but not least, I dedicate this dissertation to my identical twin sister Maureen. We were born premature and neither one of us was given much of a chance to live. She died the next day after we were born and I have often wondered what life would have been like had she lived. She has always been a part of my heart and spirit. At each milestone in my life, and other times as well, I have celebrated my life with her through a soulful connection. So Maureen, I share this great accomplishment with you!

In conclusion, I have some final thoughts regarding life accomplishments. I have always maintained the same mantra that education is knowledge and knowledge is power, and this kind of power allows you the opportunity to make wise choices in life.

Ultimately, education is something that no one can take away from you. So, believe in yourself, even if there may be those who are doubters. You are in control of you, and you can do anything you put your mind to doing. Always put forth your best effort and be 
persistent in your endeavors and you will be rewarded accordingly. Even though there will be obstacles along the way the journey is worth the ride.

At the end of each of my college graduation ceremonies, my mom would always take me aside and tell me how she was so proud of me. She also would say one more thing. My mom will not be here this time to say the one more thing, so I will say it "Well, you proved again that high school counselor was wrong. She should see you now." Thanks mom and dad for always believing in me! 


\section{ACKNOWLEDGEMENTS}

The road to the doctoral degree was not a solo journey. There were many people

along the way who gave assistance, support, guidance, encouragement, and they were all active participants in my doctoral achievement. I remember starting this process four years ago when the first group of people to help me with a great beginning was my Cohort 7 small group members Randy Caffey, Bryndyn Crutcher, Steven Himes, Natalie Precise, and Kris Schuler. I was so blessed to be a part of this group. We worked hard together, struggled together, succeeded together, and most importantly we laughed together. They will always be people I will be connected to because of a unique shared experience. I also want to give recognition to my NWMSU Cohort group especially Michelle Eppler, Tammy Bunch, Stephanie DeClue, Debbie Psychoyos, and Mary Laughlin. I am very thankful for their knowledge, wisdom, and support. I value their continued friendship.

I would also like to acknowledge Dr. Jerry Barnett and Dr. Julia Schmitz who helped me survive statistics. They successfully translated statistics into English so I could understand it! I also want to thank other friends as well as co-workers who have been so supportive and encouraging throughout this process. And finally, and most importantly, I want to thank various faculty members for their part in my doctoral journey. Dr. Maxcy was an amazing teacher who made me dig deep and think in ways that expanded my brain capacity! Dr. Piveral was always very encouraging and great at explaining concepts I did not understand. I also want to thank my faculty advisor Dr. Messner and the rest of my dissertation committee Dr. Edmonds, Dr. Hiatt, and Dr. Alexander for their time, commitment, and advice for a quality scholarly research product. 


\section{TABLE OF CONTENTS}

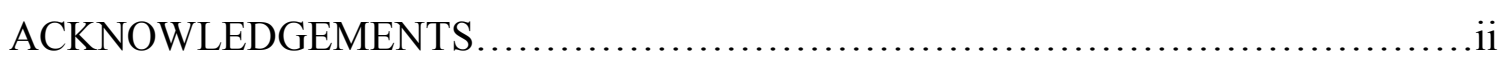

LIST OF TABLES ....................................................................

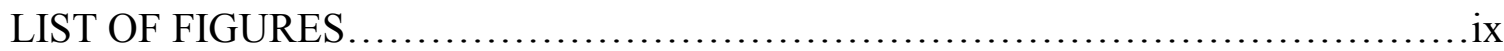

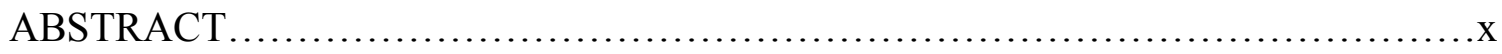

\section{CHAPTER}

I. INTRODUCTION TO THE CASE STUDY ............................................

History of Early Prevention Approaches .....................................

Elementary, Middle, and High School................................. 7

Alternative Public Schools..............................................9

Conceptual Framework ....................................................

Definitions of Key Terms ............................................ 20

Setting and Subjects..................................................... 24

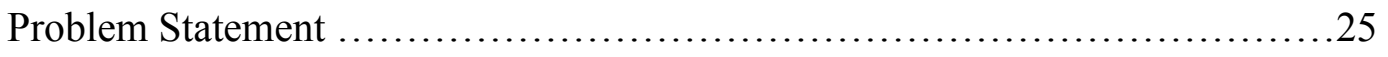

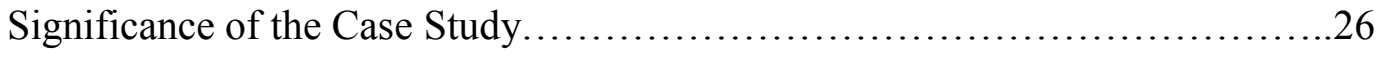

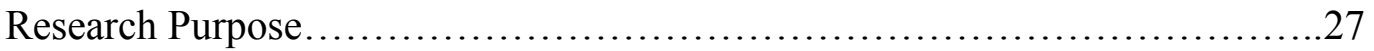

Research Questions and Null Hypotheses...................................28

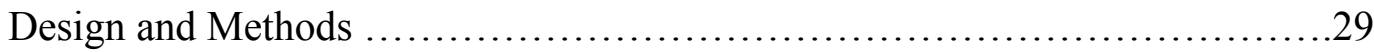

Limitations ...................................................................... 31

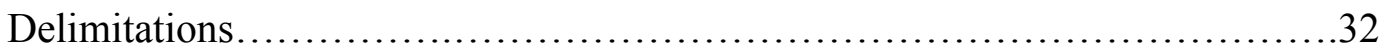

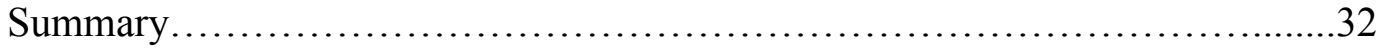

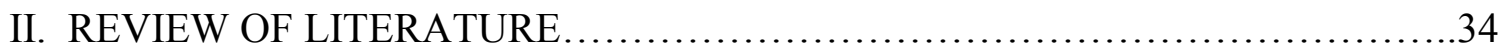

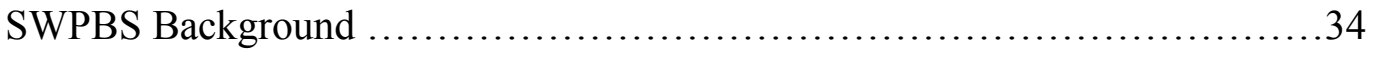


Conceptual Underpinnings of School-Wide Behavior Support. ...

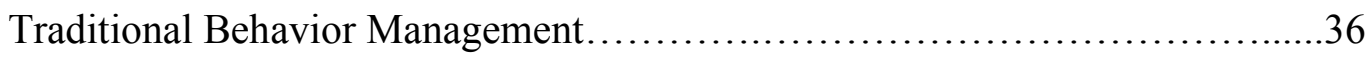

Overview of Positive Behavior Intervention and Support .....................38

School-Wide Positive Behavior Support..................................41

Three-Tiered Level System: Traditional Public School vs. K-12

Alternative Public School........................................57

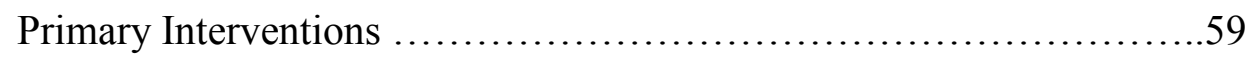

Secondary Interventions ....................................59

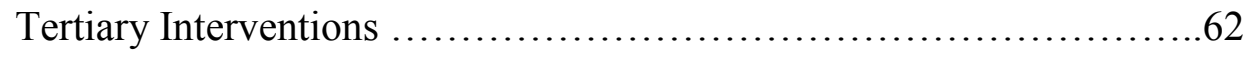

Traditional Public School SWPBS vs. Alternative Public School SWPBS.....65

Student Behavioral Data and Discipline..................................66

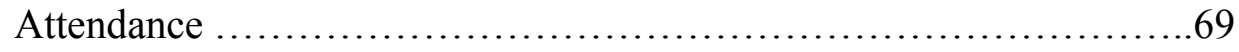

Academic Achievement ....................................... 70

Office Discipline Referrals ..................................72

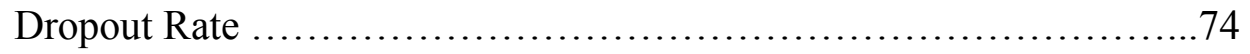

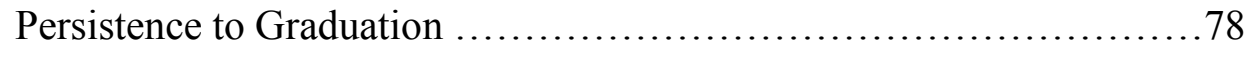

Literature Review Summary.......................................8 83

III. RESEARCH DESIGN AND METHODOLOGY ............................85

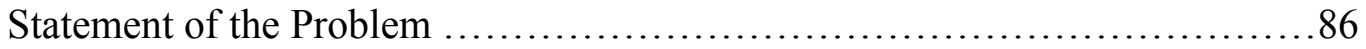

Research Methods................................................ 89

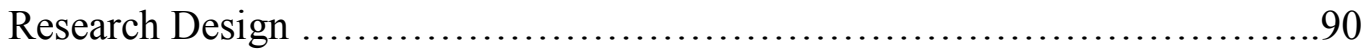

Research Questions .............................................90 
Population to Be Studied............................................... 91

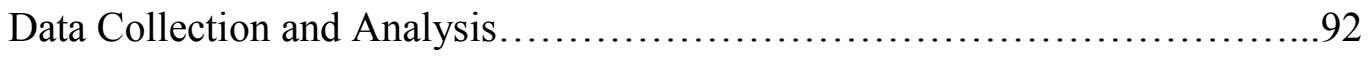

Measurements ................................................. 94

Academic Achievement ........................................94

Attendance ................................................ 94

Office Discipline Referrals ...................................94

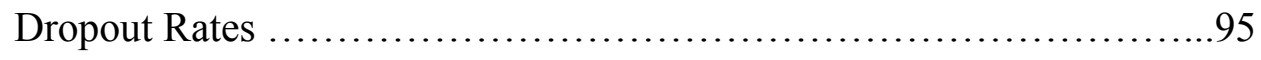

Graduation Rates .............................................95

Reliability and Validity............................................95

Ethical Considerations .............................................96

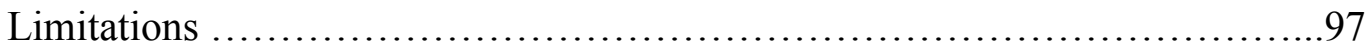

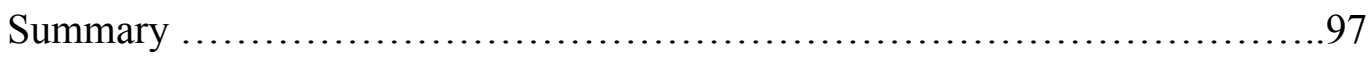

IV. RESULTS AND FINDINGS ........................................ 99

Case Study Data Organization....................................... 99

Research Questions............................................... 100

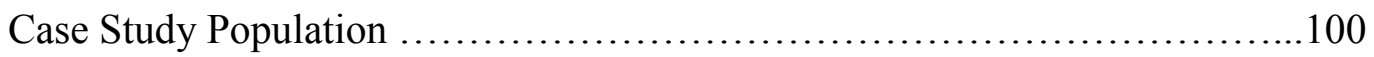

Analysis of Data .................................................. 101

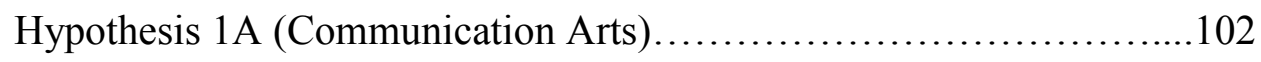

Elementary Grades $\left(\mathrm{K}-6^{\text {th }}\right)$ : SWPBS and CA Average \%..........103

High School $\left(7^{\text {th }}-12^{\text {th }}\right)$ : SWPBS and CA Average $\% \ldots \ldots \ldots \ldots \ldots . . . .104$

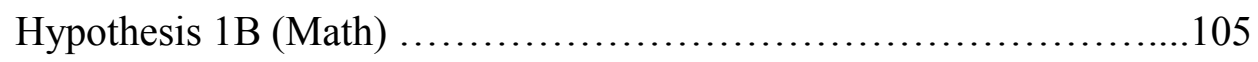

Elementary Grades $\left(\mathrm{K}-6^{\text {th }}\right)$ : SWPBS and Math Average \%........107

High School $\left(7^{\text {th }}-12^{\text {th }}\right)$ : SWPBS and Math Average $\% \ldots \ldots \ldots \ldots . . .107$ 
Hypothesis 2 (Attendance) 108

Elementary Grades $\left(\mathrm{K}-6^{\text {th }}\right)$ : SWPBS and Absence Average \%.109 High School $\left(7^{\text {th }}-12^{\text {th }}\right)$ : SWPBS and Absence Average \%........110

Hypothesis 3 (ODR's) ............................................111

Elementary Grades $\left(\mathrm{K}-6^{\text {th }}\right)$ : SWPBS and ODR's Average $\% \ldots 113$

High School $\left(7^{\text {th }}-12^{\text {th }}\right)$ : SWPBS and Absence Average $\% \ldots . .113$

Hypothesis 4 (Dropouts) ........................................114

High School $\left(9^{\text {th }}-12^{\text {th }}\right)$ : SWPBS and Dropouts Average $\% \ldots . . .116$

Hypothesis 5 (Graduates) ......................................117

High School $\left(12^{\text {th }}\right)$ : SWPBS and Graduates Average \% ........118

Summary of Data Analysis .................................................. 120

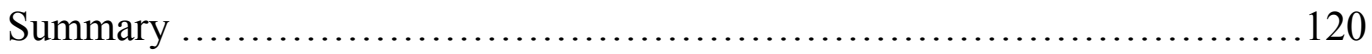

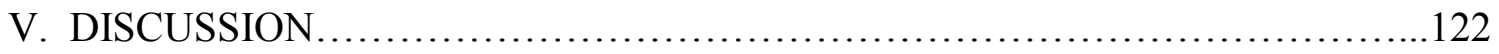

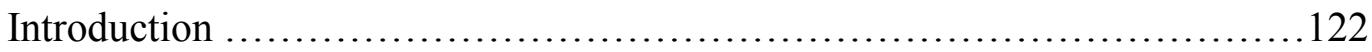

Overview of the Case Study............................................. 123

Review of Literature .............................................. 123

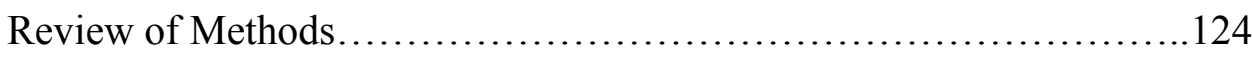

Discussion of the Findings ............................................... 125

Academic Achievement: SWPBS and Statistical Findings..............126

Academic Achievement: SWPBS and Findings in the Literature.........127

Attendance: SWPBS and Statistical Findings .......................128

Attendance: SWPBS and Findings in the Literature....................129

Office Discipline Referrals: SWPBS and Statistical Findings...........130 
Office Discipline Referrals: SWPBS and Findings in the Literature.....131

Dropout Rate: SWPBS and Statistical Findings.....................131

Dropout Rate: SWPBS and Findings in the Literature .................132

Graduation Rate: SWPBS and Statistical Findings..................132

Graduation Rate: SWPBS and Findings in the Literature...............133

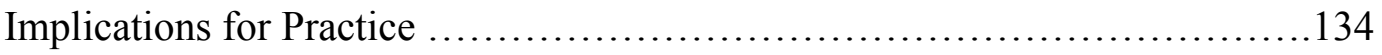

Recommendations ....................................................... 136

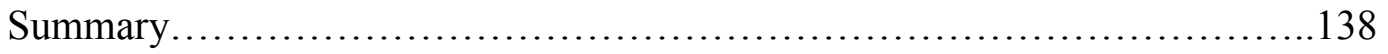

References................................................................ 141

Appendixes

A. K-12 Alternative School PBIS School Expectations Matrix ................163

B. SWIS Office Referral Definitions ...................................... 167

C. Permission for Using Summary of Features of PBS at Each Level of Implementation .............................................. 178

D. Permission for Using the Essential Dimensions of School Climate Chart ..................................................... 179

E. Permission for Using the Continuum of School-Wide Instructional and Positive Behavior Supports ...................................180

Permission for Using the Four PBS Elements Diagram ..................180

F. Permission for Using Summary of Interventions Continuum at the Secondary And Tertiary Levels of PBS ...........................181

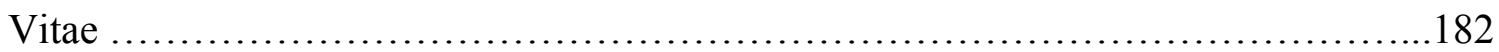




\section{LIST OF TABLES}

Table

Page

1. Examples of Strategies with Empirical Support for Decreasing School Dropouts.....6

2. Features of Positive Behavior Support .................................... 15

3. Summary of Features of PBS at Each Level of Implementation ......................39

4. Comparison of Traditional Behavior Management and PBIS ......................40

5. Four Essential Dimensions of School Climate $\ldots \ldots \ldots \ldots \ldots \ldots \ldots \ldots \ldots \ldots \ldots \ldots \ldots \ldots$

6. Summary Table of Interventions Continuum at the Secondary and Tertiary Levels of PBIS ..................................................63

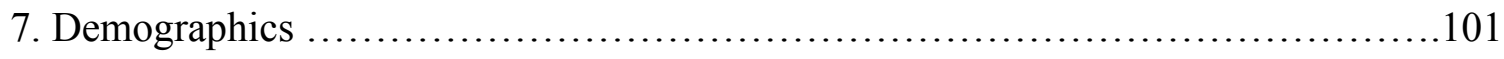

8. Summary Statistics for Communication Arts (CA) Passing Grades

(C or Higher) Between Years .......................................... 103

9. Average Percentages of Students Who Achieved "Passing Grades"

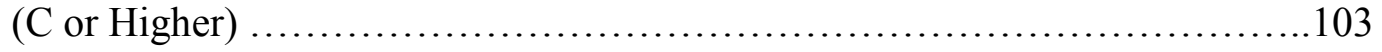

10. Summary Statistics for Math "Passing Grades" (C or Higher)

Between Years ....................................................... 106

11. Average Percentages for Math "Passing Grades" (C or Higher) by

Grouped Grade Levels ............................................ 106

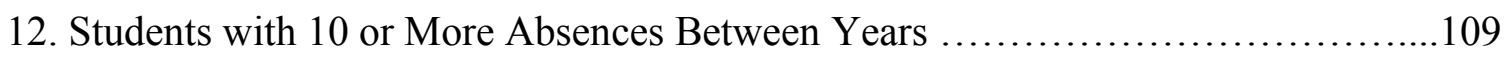

13. Average Percentages for Students with 10 or More Absences By Grouped

Grade Levels ....................................................... 109

14. Summary Statistics for Office Discipline Referrals Between Years ...............112

15. Average Percentage of Office Discipline Referrals Between Grouped

Grade Levels ...................................................113

16. Summary Statistics for Students Who Dropped Out $\left(9^{\text {th }}-12^{\text {th }}\right)$

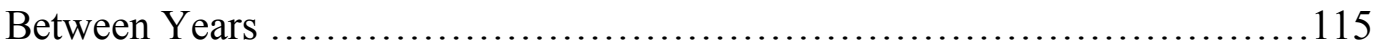

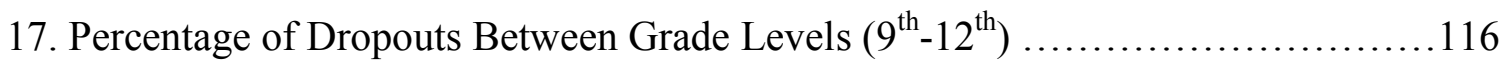

18. Summary Statistics for Students Who Graduated $\left(12^{\text {th }}\right.$ Grade) Per Year $\ldots . . . . . . .118$ 


\section{LIST OF FIGURES}

Figure

Page

1. Continuum of School-Wide Instructional and Positive Behavior Support ...........53

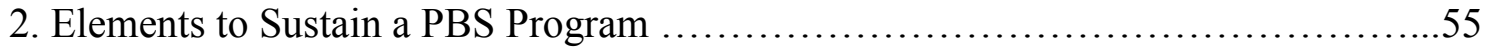

3. Multi-Tiered Levels for K-12 Alternative Public School ............................58

4. SWPBS Relationship to Research Questions ................................91

5. Elementary and High School Average CA Percentages ...........................105

6. Elementary and High School Average Math Percentages ........................108

7. Elementary and High School Average Absence Percentages ......................110

8. Elementary and High School Average ODR Percentages .......................114

9. High School Average Dropout Percentages ..................................117

10. High School Seniors and Total Number of Graduates..........................119

11. High School Percentage of Graduates .....................................119 
A CASE STUDY OF THE PROGRESSIVE IMPACT OF SCHOOL-WIDE POSITIVE BEHAVIOR SUPPORT ON FIVE SELECTED STUDENT

PERFORMANCE FACTORS IN A MISSOURI

K-12 ALTERNATIVE PUBLIC SCHOOL

\author{
By \\ Colleen Gilday Becker \\ Dr. Phillip Messner, Dissertation Supervisor
}

\begin{abstract}
The purpose of this case study was to examine the School-Wide Positive Behavior Support (SWPBS) impact on five selected student performance factors. A literature review revealed there have been many SWPBS research studies regarding traditional public schools. However, there have not been any published empirical SWPBS studies involving K-12 alternative public schools. Addressing this gap in the literature a Midwestern K-12 alternative public school involving 1,164 students was studied 2007-08 through 2010-11. Data were collected through several school information systems including School Administration Student Information System (SASI), School-Wide Information System (SWIS), and Power School. The independent variable SWPBS was investigated regarding its impact on the five dependent variables academic achievement, attendance, office discipline referrals, dropout rate, and persistence to graduation. Frequencies and percentages of each variable were analyzed using the Chi-square “goodness of fit" test (Field, 2009).

Previous studies at traditional public schools reported SWPBS positively impacted the five student performance factors, however this case study did not yield any
\end{abstract}


significant findings at the K-12 alternative public school. Specifically, there were no significant differences between the first year when there was no SWPBS and the fourth year when SWPBS was fully implemented. These outcomes raised more questions than answers. (a) Do the students at K-12 alternative public schools require a different threetiered level system as compared to those in the traditional public schools? (b) Does the process of advancing from one level to another take a longer time for these students? (c) Does professional development need to focus more on how to provide SWPBS strategies to at-risk and special needs students at K-12 alternative public schools? (d) Does the plan of gradually working through the SWPBS initial stages to full implementation take more years for the K-12 alternative public schools to achieve?

Since there are no empirical studies for K-12 alternative public schools to use as guides, future research is essential to answers these questions. The findings and conclusions of this case study will guide building level and school district leaders as they continue the quest for programs and strategies to enhance positive student behavior and academic success. Implications are addressed and recommendations made for further research. The dissertation findings will also add to the gap in the literature and provide a springboard for future research regarding SWPBS effects at alternative public schools. 


\section{CHAPTER ONE}

\section{INTRODUCTION TO THE CASE STUDY}

According to the National Center for Education Statistics (n.d.), approximately one in three students in the United States failed to graduate from high school. The state of Missouri had a 4.7\% dropout rate (Kittle, 2011). The purpose of this case study was to examine one approach known as School-Wide Positive Behavior Support (SWPBS). SWPBS was known to help maintain students in traditional public schools (Sugai \& Horner, 2002) and also had a positive effect on student performance and behavior (Stoiber \& Gettinger, 2011; Lassen, Steele, \& Sailor 2006). The literature review revealed SWPBS resulted in increased academic achievement and attendance as well as decreased office discipline referrals and dropout rates, and impacted graduation rates (Simonsen et al., 2012; Townsend, 2011; Sherrod, Getch, \& Ziomek-Daigle, 2009; the State Education Resource Center, 2009; Landis \& Reschly, 2010). However, what was not known was the impact SWPBS had at the K-12 alternative public school.

Since there were no known empirical studies found in the literature regarding SWPBS effects at a K-12 alternative public school, this case study specifically investigated the SWPBS impact involving five selected categorical variables: (a) academic achievement, (b) attendance, (c) office discipline referrals, (d) dropout rates, and (e) persistence to graduation. The unit of analysis was a K-12 alternative public school in Missouri. In this case study, the student gender and ethnicity at the K-12 alternative public school was described for the sole purpose of providing demographic information. The archival data set revealed there was a total 1,164 students who attended the K-12 alternative public school 2007-08 through the 2010-11 school years. The 1,164 
students included 870 males and 294 females. The ethnicity of the population revealed there were 942 Caucasian students, 147 African-American students, 70 Hispanic students, and five Indian students.

The case study setting involved a K-12 alternative public school in a Midwest urban community of approximately 77,185 residents according to the 2011 U.S. Census Bureau. There were three high schools, four middle schools, sixteen elementary schools, and two alternative schools within the public school district. The original K-12 alternative education program began in 1995 with about 40 students. Then $7^{\text {th }}$ and $8^{\text {th }}$ grade students with specific juvenile delinquency issues were added to the student population. This was followed by the addition of K-6 students who originally attended for a six to eight week intense social skills training. This format changed years ago and these students remained as long as needed to assist them in behavior management. In more recent years this particular group was increased to include $7^{\text {th }}$ through $12^{\text {th }}$ grades. As this population increased the $7^{\text {th }}$ through $10^{\text {th }}$ grades remained and the $11^{\text {th }}$ and $12^{\text {th }}$ grades expanded into another building. The $7^{\text {th }}$ through $10^{\text {th }}$ grades also included those students who resided at the local county juvenile center and were bussed to the K-12 alternative public school.

When the alternative program originally began there were about 40 students enrolled yearly. The average for the past several years was 55 to 60 severely emotionally disturbed students each year with Axis I and/or Axis II diagnoses as described in the Diagnostic and Statistical Manual of Mental Disorders known as the DSM-IV-TR (American Psychiatric Association, 2000). These students also had IEP's and were in special education classes and were the only ones involved in a Special Education 
program. The other students in the building also had IEP's, however their educational needs were met through working with different Special Education staff. Many students at the K-12 alternative public school also had 504 plans that allowed modifications for students with mental or physical disabilities. There were a total 1,164 students attending the K-12 alternative public school or approximately 291 students per case study year.

As further clarification, the students who attended the K-12 alternative public school were ages five through 18 and some students had a disability that required an Individual Education Plan (IEP). Various disabilities included mental or emotional issues found within the DSM-IV-TR. Other disabilities included learning disabilities (LD), emotional and behavioral disorders (EBD) or other health impaired (OHI). There was also a small group of students at the alternative school who were court adjudicated and resided at the local county juvenile residential facility. These students may have had IEP's, but most were diagnosed with conduct disorder, oppositional defiant disorder (ODD), or attention deficit hyperactivity disorder (ADHD). Once these students completed the program at the local county juvenile facility, some continued their enrollment at the K-12 alternative public school and others returned to their school of origin.

All students at the K-12 alternative public school participated in School-Wide Positive Behavior Support (SWPBS). SWPBS is a continuum of support involving all students striving for both behavioral and academic success. SWPBS involved proactive strategies used to create positive school environments (Bradshaw, Mitchell, \& Leaf, 2010; Ervin, Schaughency, Matthews, Goodman, \& McGlinchey, 2007). SWPBS is not a program or a model, but rather a systems approach that involved all staff, teachers, 
administrators and students. It is a framework that allowed all schools to develop their own practices built on their strengths toward a broad systems change. The focus was providing support and encouraging positive behavior for all students in every area of the school environment including classroom and non-classroom settings.

A three-tiered approach, SWPBS was designed to improve behavior and academic performance that included all students. In the traditional public school setting, Tier I consisted of approximately $80 \%$ of the student population, Tier II consisted of approximately $15 \%$ of the student population, and Tier III consisted of approximately $5 \%$ of the population. The Tier II and Tier III students were typically those who were presenting the most behavior problems, were failing in school, had problems with authority, and were credit deficient, etc.

Intensive interventions and individualized supports were a part of this approach that best met the needs of at-risk students who presented challenging behaviors. SWPBS is research-validated and utilized behavior management practices and principles, developed safe schools, and increased the success of all students. SWPBS is an approach that evolved from an applied behavior analysis framework. Spaulding, Horner, May, and Vincent (2008) reported that out of 100,627 U.S. schools 7,953 schools used SWPBS. Two years later Upreti, Liaupsin, and Koonce (2010) reported approximately 10,000 U.S. schools used SWPBS. This number rapidly increased and changed monthly. The PBIS web master and data analyst reported 16,000 U.S. schools were using SWPBS as of December 2011 (L. Riffel, personal communication, December 5, 2011). According to the PBIS website, as of May 28, 2013 there were 18,277 schools using SWPBS. 


\section{History of Early Prevention Approaches}

School prevention programs began in the United States about 40 years ago. From 1960 to 1980 early prevention programs were devised to give information as well as induce some fear regarding negative consequences of making inappropriate choices related to drug abuse and delinquent behaviors. These approaches were not very effective due to limited implementation or the curriculum being taught by untrained professionals. Then from 1980 to 2008 emphasis was on the underlying causal factors related to behavioral problems. The focus shifted from identifying risk factors such as poverty, drug abuse, and family conflicts to focusing on protective factors such as caring relationships with adults, level of school commitment, social support from non-family members (Jenson, 2010).

The literature during a 20-year period (1982-2002) revealed there was limited research published in counseling journals regarding evidence-based school dropout interventions. Prevatt and Kelly (2003) reviewed 217 articles and found only 18 articles that met their criteria of an evidence-based school dropout intervention. The four criteria were: (a) published in a peer-reviewed journal, (b) identified an intervention as a measure of dropout prevention (c) used dropout as one of the dependent variables, and (d) intervention effectiveness determined by empirical analyses.

Some school-wide prevention programs included the Project Achieve (Knoff, 2000) and the Olweus Bullying Prevention Program (Olweus et al., 2007). In addition to these programs, White and Kelly (2010) investigated counseling programs and found these more fully implemented programs correlated to lower dropout rates. They identified 
strategies with empirical support for decreasing school dropout rates. Table 6 depicted these strategies. Some of these strategies were used in the K-12 public alternative school.

Table 1

Examples of Strategies with Empirical Support for Decreasing School Dropout

Domain $\quad$ Specific Strategies

Addressing protective factors

- Social support

- Monitoring and mentoring

Institute a peer mentoring system or buddy system.

Assign socially skilled, academically successful mentors to support and coach at-risk students.

Develop a helping culture and encourage peer support within the school.

Assign adult monitors or advocates to identified at-risk students to and follow up with parents.

Partner with volunteers from the community, local colleges and to identify capable and motivated adult members.

- Personal and social skill development

Provide explicit social skills instruction.

Teach relevant coping and problemsolving skills (e.g., time management with part time jobs and school, caring for family members while in school).

- Parent Involvement

Involve parents in dropout prevention programs (e.g., provide information on student's participation in school-based programs, offer parent training).

Add ressing risk factors

- Academic Instruction

Assist teachers in providing more academic instruction and spending less time on behavior management.

Provide teacher training on effective and efficient classroom management strategies. 
- Academic Support

Offer after-school study skills and time management classes.

Implement adult/peer tutoring programs at times convenient for the students.

(White \& Kelly, 2010, p.229)

\section{Elementary, Middle, and High Schools}

School-wide positive behavior support was an emerging prevention program first developed by Sugai and Horner (1999) and started in the schools in Oregon. Most SWPBS research was found at the elementary and middle school level. A review of the literature revealed there was very limited SWPBS research at the high school level. As a result, Bohanon, Fenning, Eber, and Flannery (2007) investigated high school secondary and tertiary supports. Their intent was developing a roadmap of support for high school students involved in SWPBS, especially at the secondary and tertiary levels. Typically when high school personnel applied SWPBS interventions, the majority of the supports were only within the primary level interventions. It was only recently that the secondary and tertiary levels were included in the high schools.

The authors recommended six components necessary to provide effective secondary and tertiary level interventions. The components were: (a) include selfdetermination in the primary intervention level curriculum, (b) increase educator ability to teach function-based approaches, (c) identify individual student needs through function-based assessments, (d) provide future planning, (e) establish wraparound services for behaviors requiring additional resources, and (f) develop a system to identify students who require steps two through five.

Tertiary supports at the high school level required several key elements to make a positive difference in behavioral and academic functioning (Scott, Eber, Malloy, \& 
Cormier, 2005). The authors identified several key elements as: (a) the choice of the student and the family, (b) a strength-based team process, (c) a comprehensive plan of action, and (d) a support plan both within and outside the school setting to involve community agencies. The authors also indicated there were several factors that were barriers to the implementation of these elements. These factors included (a) a lack of staff involvement due to multiple responsibilities and large caseloads, (b) not enough time to plan the interventions and implement them, (c) administrative influences such as limited funding support and various regulations, and (d) a lack of options for students to earn course credit and limited alternatives to suspension and expulsion (Bohanon, Fenning, Eber, \& Flannery, 2007). Some of these same barriers were experienced at the K-12 alternative public school.

Guest (2011) conducted a case study of high school students $\left(9^{\text {th }}-12^{\text {th }}\right.$ grade) and investigated SWPBS impact on behavior and achievement outcome trends. The descriptive analysis included grade point average (GPA), course credits completed, and attendance rate. There was also a decrease in ODR's, suspensions and expulsions. These variables were similar to those being investigated in this current case study.

Looking at the middle school level, there was also limited research on the effectiveness of Tier II interventions. Through a nationwide survey Hoyle, Marshall, and Yell (2011) determined there was a need for research to determine the best way to evaluate middle school Tier II interventions. It was noted that high fidelity SWPBS implementation was difficult to maintain at the high school level (Bohanon, Fenning, Eber, \& Flannery, 2007). These were important factors to assess in the current case study. 


\section{Alternative Public Schools}

Prior to 1970, only one in five students with disabilities were educated in the school system in the United States. Many students were actually excluded from receiving an education. These students had disabilities such as emotional disturbances, mental retardation, or were blind or deaf. With the passing of the Education for All Handicapped Children Act (Public Law 94-142) on November 29, 1975, these student's rights were protected to receive an education that would best meet their needs (OSEP, 2011).

Alternative schools were designed to fulfill a variety of purposes. Raywid (1999) described this best as she explained "They've functioned almost as an empty glass to be filled with any sort of liquid - or even used for something other than a glass" (p. 47). The first alternative schools began in the 1960's and were found mostly in urban and suburban communities. The urban school purpose was assisting minority and poor students who were struggling in school to be successful. The suburban alternative schools had a different emphasis and attempted to develop new and innovative ways to educate students.

To determine whether or not an alternative school was successful was dependent upon the specific focus of the alternative school. For example, if the emphasis was helping students with behavior problems be successful, then the measure of success was completing high school, graduating, and possibly obtaining a job. Another example of success involved whether or not the alternative school provided an innovative, meaningful education. In this case, the measure of success was the student's attitudes toward school as evidenced by their effort and behavior. Additional success measures 
were related to the alternative schools purpose such as a deterrent to juvenile delinquency, dropout prevention, or possibly desegregation (Raywid, 1999).

Although the alternative schools originated with different agendas, they were divided into three types depending upon what they were attempting to change as described by Gagnon, Rockwell, and Scott (2008). The types were: (a) changing the student, (b) changing the school, and (c) changing the educational system. Many people perceived alternative schools as the last opportunity a student had to be successful in school. Some of these schools were punitive and others were very structured environments. Examples of early punitive schools were those that used time out rooms and in-school suspension (ISS). This example described the K-12 alternative public school prior to using SWPBS.

Alternative schools that emphasized changing the school rather than the student had a much different focus, created more innovative approaches, and possessed a more positive school climate. There was a significant difference between the outcomes of these two types of alternative schools. The punitive oriented schools rarely had any success changing student behavior. Alternative schools that tried to change the educational system provided a different curriculum and a different school climate.

Gagnon, Rockwell, and Scott (2008) indicated alternative school settings needed a research-based intervention approach such as SWPBS if the students were to be successful in the school, the community, and the workforce. Franklin, Streeter, Kim, and Tripodi (2007) found alternative schools that focused on student strengths were much more successful in dropout prevention than those schools that did not address student 
strengths. These researchers conducted a study and found that solution-focused public alternative schools were effective for dropout prevention.

Booker and Mitchell (2011) conducted a study to determine the probability of a student being placed in a different kind of alternative school, a Disciplinary Alternative Education Program (DAEP). The DAEP was a school designed for students who had difficulty functioning in their home school and required alternative school placement for either mandatory or discretionary reasons. These were some of the same reasons students were referred to the K-12 public alternative school being studied. Also, the procedure for student placement at the DAEP and the K-12 public alternative school were similar in that both schools required the students had an administrative referral from their home school.

Within the alternative school setting, Kilian and Kilian (2011) found ODR's were the best measure of student discipline problems. The teachers completed the ODR's, and the students displaying disruptive behaviors were sent to the office. Making poor behavioral choices and not following school rules were addressed by the administration. In addition to the ODR's, these researchers also found that within the alternative school environment, at-risk students were capable of earning average or better than average grades. Using school-based interventions also had a positive impact on other areas such as improved academics.

Only one study was found involving an alternative school setting. Although the school was not a public school, the at-risk students were similar to those being researched in the current case study. Simonsen, Britton, and Young (2010) conducted a three-year, single-subject case study that investigated the use of SWPBS in a non-public alternative 
school setting. The SWPBS effects resulted in a decrease in serious incidents. Students who typically engaged in serious physical aggression, an increase occurred in the percentage of students who refrained from these behaviors. When dealing with at-risk students in an alternative school setting it was important to provide structure and develop a program for successful learning. As part of the design for success, Ducharme and Shecter (2011) identified four key behavior areas that needed to be addressed in the classroom. These four areas were: (a) compliance, (b) social skills, (c) on-task behavior, and (d) communication. These were critical factors for success within the K-12 alternative public school.

Some at-risk students were identified as having emotional and behavioral disorders (EBD). Wagner, Kutash, Duchnowski, Epstein, and Sumi (2005) analyzed the data from a national longitudinal study and determined that emotionally disturbed (ED) children in special education came from family environments that had multiple risk factors. The researchers also determined that $50 \%$ of the students diagnosed as EBD dropped out of school and only $40 \%$ of these students who remained actually graduated. Similar results were found when EBD students were compared to students with other disabilities (Kauffman, Mock, \& Simpson, 2007). Results indicated EBD students had more failed courses and lower graduation rates. The student population at the K-12 alternative public school had EBD students and the impact SWPBS had on academic achievement, dropout and graduation rates were explored further in this research paper.

\section{Conceptual Framework}

The works of Skinner (1974) and Watson (1913) formed the conceptual basis for this case study. Behaviorism founded by John B. Watson, challenged the epistemological 
roots of human behavior where the use of consciousness was left to the philosophers. He believed behavior should be viewed according to the experience in which it occurred. If psychology was to be scientific, then the subject matter needed to be measured. The subject matter was identified as behavior. Behavior was studied so inferences could be made about the process that causes the behavioral changes being observed. In this instance, the process was learning. Most learning theorists believed behavioral changes were the result of learning (Hergenhahn, 1976).

Positive Behavior Intervention and Support (PBIS), was based upon behavioral theory where "problem behavior continues to occur because it is consistently followed by the child getting something positive or escaping something negative. By focusing on the contexts and outcomes of the behavior, it is possible to determine the functions of the behavior, make the problem behavior less effective and efficient, and make the desired behaviors more functional" (Cohn, 2001, p.29).

Skinner (1974) was the originator of a science of behavior known as the experimental analysis of behaviors. He applied an empirical approach together with a philosophy of this science to form radical behaviorism (Morris, Smith, \& Altus, 2005). This integration led to the formulation of a new discipline of psychology known as behavior analysis. "His many books and papers on applied technology led to the field of applied behavior analysis" (Pierce \& Cheney, 2004, p. 10). In tracing the history of SWPBS, from a broad spectrum of behaviorism to learning theory, to applied behavioral analysis (ABA), to positive behavior support, SWPBS has a theoretical and applied heritage.

Positive behavior support was an evolution of an applied science, specifically, 
applied behavior analysis. As the "father of behavior analysis", Skinner influenced the five dimensions of ABA through his methodology and experimental practices. These dimensions were: (a) the style and content of his science, (b) his interpretations of typical and atypical behavior, (c) implications drawn from his science for application, (d) his descriptions of possible applications, and (e) his own applications to human and nonhuman behavior (Morris et al., 2005).

Baer, Wolf, and Risley (1968) identified a feature unique to applied behavior analysis. They described the participant's behavior as the causal factor for behavioral change, rather than an indirect measure of change such as a change on a standardized test. The observable behavior change was due directly to the intervention and not due to some other variable. Furthermore, Baer and Wolf (1987) emphasized the importance of appropriately identifying an analytic intervention. An intervention was only perceived as analytic "when it demonstrates convincingly how to make specified changes and when its behavior-change methods make systematic, conceptual sense" (p. 318).

Anderson and Kincaid (2005) further explained the conceptual links between the philosophy of applied behavior analysis and SWPBS implementation. First, essential SWPBS components were decision-making and data based assessments, specifically functional behavioral assessments (FBA). Second, interventions were designed for a certain school rather than an individual. This was correlated to the same focus from a behavior analytic perspective. Third, various intervention components were taken directly from behavior analysis research. Some of these components included instruction of appropriate behavioral expectations, reinforcement, and token economy systems. 
Carr et al. (2002) identified Applied Behavioral Analysis (ABA) as the foundation for PBIS. Each of these ten features was a critical component necessary for the success of SWPBS at the K-12 alternative public school. Table 1 shows these features that exemplify PBIS.

Table 2

Features of Positive Behavior Support

1. Comprehensive lifestyle changes and improved quality of life were goals of any intervention and were only defined based on the values of those receiving support.

2. Interventions and supports were to be seen and implemented from a long- term, life span perspective.

3. Interventions must possess ecological validity, in that, strategies of interventions and support must be feasible in, relevant to, and effective in reallife settings, and situations.

4. Principal stakeholders (such as parents, teachers, friends, employers, and siblings) functioned as collaborators and partners in the development, and implementation of interventions and support plans.

5. Social validity was a primary and pervasive criterion of effective procedures and intended outcomes.

6. Interventions were developed with an understanding that ensuring fidelity with respect to support and sustainability required attention to systems variables. 
7. Support plans were developed with a comprehensive emphasis on prevention, and an acknowledgement that active and functional intervention occurred when problem behaviors were not present.

8. Support plans were (a) based on assessment of medical, behavioral, and educational variables; (b) guided by principles drawn from behavioral and biomedical science; and (c) evaluated through overt measurement impact.

9. An appreciation that optimal effectiveness required utilization of knowledge derived from a variety of methodological practices.

10. A pragmatic understanding that contributions to the development of effective interventions and supports came from multiple theoretical perspectives.

SWPBS occurred when PBIS (Positive Behavior Intervention and Support, 2009) was used with the entire student body and involved all staff in the implementation. PBIS methodology was used within the public education system the past 15 years. SWPBS applications evolved from an applied behavior analysis framework in working with developmental disabilities (Baer, Wolf, \& Risley, 1968). Studies involving SWPBS were conducted over the past 15 years. For example, a study by Filter, Tincani, and Fung (2009) indicated PBIS was scientifically based and made a significant contribution to the field of behavioral analysis. Results of a study conducted by Nelson (1996) showed a decrease in office discipline referrals (ODR's) and an increase in the academic performance of disruptive students when strategies similar to PBIS were used. There was an increased focus within the schools on PBIS and the effects of SWPBS on behavior and ODR's. Clonan, McDougal, Clark, and Davison (2007); Irvin, Tobin, Sprague, Sugai, 
and Vincent (2004); and Warren and Halpern-Manners (2007) indicated SWPBS interventions decreased ODR's. These studies showed the positive impact of the use of SWPBS in the traditional school settings. The current case study determined if the same positive effects would be gained through the use of SWPBS using ODR's as one of the indicators.

In addition to the reduction in ODR's, researchers investigated other SWPBS outcomes directly related to the variables being researched in this current case study at the K-12 alternative public school. For example, Curtis, Van Horne, Robertson, and Karvonen (2010); Flannery, Sugai, and Anderson (2009); Lane, Wehby, Robertson, and Rogers (2007); Nelson et al. (2009); and Walker, Cheney, and Stage (2009) found SWPBS decreased behavioral problems. McIntosh, Flannery, Sugai, Braun, and Cochrane (2008) studied SWPBS and the relationship between academics and behavior problems. A unique SWPBS component was the interpersonal relationships developed between students and adults. In relation to this social dynamic, Johnson, Rice, Edington, and Williams (2005) found students were more successful academically when they developed connections with teachers. Suh and Suh (2007) found the probability of a student dropping out decreased by one-half when there was close teacher involvement and support. "Successful alternative programs focus on the development of positive relationships and connections to school" (Cornelius-White, 2007, p. 127). This finding, supported in the research by Janosz, Archambault, Morizot, and Pagani (2008), found school engagement was one of the best predictors of academic achievement as well as a dropout deterrent. Appleton, Christenson, and Furlong (2008) also found a connection between engagement, achievement, and school behavior. They stated, "Laws may 
regulate the structure of the educational system, but student perspectives and experiences substantially influence academic and social outcomes" (p. 369). In the Missouri K-12 public alternative school it was observed when positive relationships were established, students developed a sense of belongingness.

Since SWPBS was first introduced into the public education system 15 years ago, SWPBS data based research was consistently increased. Additional studies were also conducted in areas such as dropout rates and graduation. Thornburgh (2006) investigated dropout rates. Irvin, Tobin, Sprague, Sugai, and Vincent (2004), Sugai, Sprague, Horner, and Walker (2000) and Vincent, Swain-Brady, Tobin, and May (2011) investigated the SWPBS effects on office discipline referrals. Algozzine, Wang, and Violette (2011) and Luiselli, Putnam, Handler, and Feinberg (2005) studied PBIS effects on academic achievement. Reinke, Herman, and Stormont (2013) found teachers using SWPBS related to positive interactions with students had more effective classroom management. Wickham, Griggs, and Beech (2006) conducted a case study on SWPBS effects regarding behaviors that interfered with learning. Lehr, Hansen, Sinclair, and Christenson (2003) conducted a literature review on intervention studies that addressed dropout rate and school completion. Landis and Reschly (2010) examined high school dropout and graduation rates. Lewis, Jones, Horner, and Sugai (2010) identified SWPBS implications for prevention, identification, and intervention involving students exhibiting emotional and behavioral disorders. Childs, Kincaid, and George (2010) identified a statewide evaluation model of universal Tier I positive behavior supports. Kern and Manz (2004) and Sasso (2004) investigated validity issues of SWPBS. 
These research findings highlighted the importance of PBIS in schools. These studies showed the positive impact of SWPBS in various settings, different populations, and investigated a multitude of variables. Yet, none of the studies researched the use of SWPBS in a K-12 public alternative school environment. The current case study addressed the use of SWPBS in this setting and answered the question whether or not SWPBS had any positive impact on academic achievement, attendance, office discipline referrals, dropout rate, and persistence to graduation.

In addition, it was also important to note that both Federal and State entities recognized the use of PBIS in the schools. Richter (2008) identified that PBIS was in compliance with No Child Left Behind (NCLB), Individuals with Disabilities Education Improvement Act (IDEA), Missouri School Improvement Plan (MSIP), Missouri State Support Plan (MSSP), the Missouri Comprehensive Guidance Curriculum, and the National Staff Development Council Standards for Staff Development.

Historically, American schools had a tendency to start the latest school improvement innovation without first investigating student needs, the underlying causes of recurring problems, or building a plan for long-term use. As a result, school improvement plans for student learning lasted approximately two years. This was a different scenario among schools that measured and analyzed the impact of new approaches (Bernhardt, 2005). SWPBS strategies were successful because the student needs were reviewed, teams were designed to focus on persistent problems, and all staff focused on both present and long term use of SWPBS strategies. The SWPBS framework was designed for implementation over a period of time. 
All staff participated in professional development training in SWPBS for an entire year prior to the implementation of SWPBS. This was true for both the traditional public schools and for the K-12 alternative public school being researched in this case study. The reason the SWPBS approach lasted longer than the two years described was due to the fidelity and sustainability of the SWPBS approach. This approach offered a checks and balances system as well as the utilization of data collection and analyses that were deemed crucial aspects of the success and longevity of SWPBS (Scott, et al., 2010).

\section{Definitions of Key Terms}

Applied Behavioral Analysis (ABA). "Applied Behavior Analysis is the design, implementation, and evaluation of environmental modifications to produce socially significant improvement in human behavior. $\mathrm{ABA}$ includes the use of direct observation, measurement, and functional analysis of the relations between environment and behavior. $\mathrm{ABA}$ uses antecedent stimuli and consequences, based on the findings of descriptive and functional analysis, to produce practical change" (Shaping Behavior, 2011). "Based on principles established through basic laboratory research, behavior analysts demonstrated that positive, appropriate behavioral repertoires of people with developmental disabilities could be shaped, strengthened, and maintained by rearranging environmental contingencies" (Beach Center on Disability, 2011).

Alternative Public School. "A public elementary/secondary school that addresses the needs of students that typically cannot be met in regular school, provides nontraditional education, serves as an adjunct to a regular school, or falls outside the categories of regular, special education, or vocational education" (USDOE, 2002, p.5). At the K-12 alternative public school studied, the students had the opportunity to participate 
in smaller class sizes for group instruction. For some courses, they also had the opportunity to use a computer in a classroom setting that was designed for individual work, completed at their own pace. The goal for all students was to complete the necessary coursework, advance to the next grade level, and eventually earn academic credits to graduate.

At-risk. This term described students who were credit deficient and in jeopardy of not earning enough credits to graduate. In addition, some students had issues such as domestic violence, alcohol, drugs, discipline, legal issues, teen pregnancy/parenting, homelessness, and possible verbal, physical, or sexual abuse. Within the K-12 alternative public school, students were considered at-risk due to academic as well as behavior issues. They were usually referred by their school principal or vice principal. There were also students referred by the school district central administration as a result of serious school violations such as property damage at school, physical assault, serious threats of harm toward staff or students, etc.

Dropout. In the traditional public school a dropout was described as "a student who was enrolled at any time during the previous school year who is not enrolled at the beginning of the current school year and who has not completed school" (Stillwell \& Hoffman, 2009, p.1). This did not include students who missed school due to illness, transferred to another school, or those students who died. At the K-12 alternative public school studied, a dropout was a student enrolled during the school year, who then left at any time during the school year, did not enroll at another school, or graduate.

Functional Behavioral Assessment (FBA). This assessment involved collecting information that pinpointed the function of a problem behavior as well as the antecedent 
events to the problem (Sugai et al., 2000). The functional behavior assessment specifically identified two important factors (a) antecedent conditions when the behavior occurred and when the behavior did not occur, and (b) consequences that maintained the behavior (Turton, Umbreit, \& Mather, 2011; Fox \& Duda, 2011). When the Individuals with Disabilities Education Improvement Act (IDEA) was reauthorized in 2004, the Functional Behavioral Assessment (FBA) and Positive Behavior Support (PBS) were encouraged to be used with students with disabilities who also exhibited challenging behavioral issues (Hieneman et al., 2005).

Function-Based Intervention. Once the functional behavioral assessment was completed, a function-based intervention was developed. This involved reviewing the FBA data and designing an appropriate intervention that addressed the problem behavior's function (Turton, Umbreit, \& Mather, 2011).

Office Discipline Referral (ODR). An ODR was a document showing a student violated a specific school rule or expectation. The student was sent to the office as the teacher or staff member completed the ODR form. The incidents occurred in the classroom, hallway/stairway, cafeteria, bathroom, playground, assemblies, bus, parking lot, and other areas outside on school property. These incidents were defined in six different categories including (a) fighting and harassment, (b) violent acts against persons, (c) property destruction, (d) alcohol, tobacco, or drug possession, (e) firearms or other weapons possession, and (f) disorderly conduct or other non-violent offenses. They were divided into major and minor ODR's. A major ODR required the administrator's attention to enforce a consequence. A minor ODR was not as serious and did not require 
administrative intervention. Appendix B showed office referral definitions (Todd, Horner, \& Tobin, 2010).

Positive Behavior Intervention and Support (PBIS). "An applied science that uses educational and systems change methods (environmental redesign) to enhance quality of life and minimize problem behavior" (Carr et al., 2002, p. 4). PBIS was an approach used to improve negative behaviors (Sugai \& Horner, 2002). PBIS was first introduced in the education system in the 1980's in response to the Individuals with Disabilities Education Act (IDEA) requirements. The inception of IDEA was a result of the need for providing a better response to the disciplinary practices of special education students (Crone \& Horner, 2003). "PBIS is neither a curriculum nor a program of prescribed strategies. Rather, it can be conceptualized as a framework under which systems identify predictable problems, select logical strategies to improve outcomes, facilitate consistent implementation, and use data to evaluate their success" (Scott, Alter, Rosenberg, \& Borgmeier, 2010, p. 515).

Power School. A Student Information System (SIS) provided by the local school district. Power School was a computer software system capable of managing student schedules, academic grades, attendance, dropouts, graduates, transcripts, personal/family information, history of schools attended, medical information, etc. At the K-12 public alternative school studied, Power School was the SIS used during the 2009-10 and 201011 school years.

School Administration Student Information System (SASI). This was a computer based software program developed by Pearson School Systems used in educational settings. SASI was able to compile schedules, academics, demographics, grades, etc. At 
the alternative school being studied, SASI was used during the 2007-08 and 2008-09 school years before the school district upgraded from SASI to Power School. School-Wide Information System (SWIS). This was a web-based application system developed by the SWPBS creators to assist school personnel in entering office discipline referral data (SWIS, n.d.). The data generated from SWIS was used for making decisions regarding student interventions as well as for school-wide interventions. The SWIS program indicated the dates and times of when behaviors occurred as well as the specific locations. The SWIS program also had the capability of identifying the behavior of one specific student and groups of students. This allowed school personnel to devise appropriate school-wide interventions to best meet the needs of the students both academically and socially (May et al., 2003).

School-Wide Positive Behavior Support (SWPBS). SWPBS was the use of PBIS as a process for developing safe schools. PBIS was not a program or a model. It was a systems approach using a three-tiered approach that involved all staff, teachers, administrators and students in a school setting. The focus was on providing support and encouraging positive behavior for all students in every area of the school environment including classroom and non-classroom settings. SWPBS involved educators being trained in "systems change, effective behavior management principles and practices, and applications of research-validated instruction and management practices" (PBIS, 2011).

\section{Setting and Subjects}

This case study setting involved at-risk students at a Missouri K-12 alternative public school. During the identified four years there were a total of 1,164 students in attendance averaging approximately 291 students per school year. The students at the K- 
12 alternative public school represented a very diverse and transient group. The student population involved those students referred to the alternative school by the local public schools. The reasons why students attended the K-12 alternative public school involved a myriad of issues, problems, behaviors, credit deficiencies, etc.

Consequently, there were students from one end of the spectrum who needed credit recovery to the other end of the spectrum who were diagnosed as severely emotionally disturbed who required IEP's. In addition, other students had IEP's due to learning disabilities (LD), emotional and behavioral disorders (EBD) or other health impaired (OHI). These students typically remained at the K-12 alternative public school. There was also a group of students attending the K-12 alternative public school that were court adjudicated and resided at the local county juvenile residential facility. Once these students completed the program at the local county juvenile facility, some continued their enrollment at the K-12 alternative public school and others returned to their school of origin.

\section{Problem Statement}

There was evidence in the literature SWPBS strategies being used in traditional public schools positively affected student academic achievement, attendance, office discipline referrals, dropout rate, and persistence to graduation. However, what was not known was the SWPBS impact on the performance factors at a K-12 alternative public school, as this was not addressed in the literature. Previous studies focused on the five identified research variables in the traditional public school system. However, the research was very limited at the traditional high school level. Bohanon et al., (2006) reported only a few case studies conducted regarding SWBPS at the high school level and 
subsequently indicated a need for research. There was very little known regarding how traditional high school students were impacted by SWPBS relative to academic achievement, attendance, office discipline referrals, dropout rate, and persistence to graduation. This was partially due to the fact that most schools that implemented PBIS strategies were at the elementary school level.

Additionally, there was no evidence in the literature where research was conducted at a K-12 alternative public school pertaining to the five categorical variables identified in this current case study specifically related to the impact of SWPBS implementation. The main website for PBIS (PBIS, 2009) as well as the International Association for Positive Behavior Support (APBS) website did not have any information or research in this area. This writer attended numerous PBIS conferences during the past three years and was unable to find any alternative public schools implementing SWPBS. This may explain why there was no evidence in the literature, as it appears there were no K-12 alternative public schools using SWPBS. It was also possible that K-12 alternative public schools were using SWPBS, however had not implemented the approach for enough years to publish any research.

\section{Significance of the Case Study}

This research case study was the first, or one of the first contributing to the literature regarding SWPBS effects at a K-12 alternative public school setting. Therefore, this case study represented a significant addition to, and expansion of the SWPBS literature. According to Simonsen, Britton, and Young (2010) “... no studies have explicitly examined the implementation of SWPBS in an alternative educational setting" (p. 181). Therefore, the current case study research results contributed to practice. 
Knowledge gained through data analyses and statistical findings provided future research implications regarding SWPBS effects at a K-12 alternative public school environment (Ervin et al., 2007). Specifically, this research contributed valuable information to the alternative public school being studied by identifying the specific SWPBS effects regarding academic achievement, attendance, office discipline referrals, dropout rate, and persistence to graduation.

Not only did this case study benefit the school being studied and contributed to the literature, but additionally expanded educational leadership and policy analysis research. Results assisted other alternative school administrators and leaders regarding PBIS policies, decision-making, and programming. As there was no previous SWPBS research involving a K-12 alternative public school setting, a review of this current case study may lead to other alternative public school leaders considering SWPBS implementation at their alternative schools.

This case study also provided the outcome data educational leaders needed to evaluate the SWPBS benefits for their students. Many studies, as discussed previously, showed positive student behavior by using SWPBS. Positive outcomes were reported regarding academic achievement, attendance, office discipline referrals, dropout rate, and persistence to graduation. These studies were found at traditional public school systems and other programs such as juvenile justice programs. However, there was no published research regarding these variables at a K-12 alternative public school.

Data from research studies allowed educational leaders the opportunity to make appropriate informed decisions for programming and policy-making. On the one hand, if the current case study showed a correlation between the five variables and SWPBS, 
administrators determined the feasibility of SWPBS for their schools. On the other hand, if the results did not support SWPBS usage as a means to improve student behavior factors, then the current case study would be a springboard for future SWPBS research at alternative public schools. No matter what the results, this case study provided educational leaders, policy makers, and other interested stakeholders, the knowledge to improve alternative education policies and practices.

\section{Research Purpose}

The purpose of this case study was two-fold: (a) it responded to an information gap in the literature, and (b) investigated whether or not SWPBS strategies decreased the dropout rate and discipline referrals, as well as increased academic performance, attendance, and persistence to graduation within a K-12 alternative public school setting during the years 2007-08, 2008-09, 2009-10, and 2010-11.

\section{Research Questions and Null Hypotheses}

The research questions that guided this case study are listed below:

RQ1 - What are the summary statistics for academic achievement by grade level, by course, and by each study year as measured by the number of passing grades? $\mathrm{H}_{0} 1$ - There is no significant difference in the number of passing grades by the end of each of the following school years 2007-08, 2008-09, 2009-10, and 2010-11.

RQ2 - What are the summary statistics for attendance by grade level and by study year? $\mathrm{H}_{0} 2$ - There are no significant differences in attendance at this K-12 alternative public school during the study years 2007-08, 2008-09, 2009-10, or 2011. 
RQ3 - Is there a difference in the number and percent of office discipline referrals by grade level for the school years 2007-08, 2008-09, 2009-10, and 2010-11? $\mathrm{H}_{0} 3$ - There is no significant difference in the number of office discipline referrals by the end of each of the identified school years.

RQ4 - Is there a difference in the number and percent of dropouts by grade level for the school years 2007-08, 2008-09, 2009-10, and 2010-11?

$\mathrm{H}_{0} 4$ - There is no significant difference in the number and percent of dropouts by grade level by the end of each of the identified school years.

RQ5 - Is there a difference in the number and percent of graduates for the school years 2007-08, 2008-09, 2009-10 and 2010-11?

$\mathrm{H}_{0} 5$ - There is no significant difference in the number and percent of graduates in the identified study years.

The five categorical variables were investigated using the statistical analyses Chisquare "Goodness of Fit" test. Specifically, the Chi-square test was used to analyze RQ1, RQ2, RQ3, RQ4, and RQ5 as well as determine the status of each null hypothesis. The Chi-square tests for each dependent variable are explained in more detail in Chapter 3 of this case study.

\section{Design and Methods}

Research design of this case study was quantitative, non-experimental. A nonexperimental case study involved no manipulation of the variables and no random assignment of subjects to groups. In this case study, the unit of analysis was the Missouri K-12 alternative public school. School data was studied including four identified years 2007-08, 2008-09, 2009-10, and 2010-11. This case study was a trend analysis using 
descriptive summary statistics to investigate the SWPBS impact on the five categorical variables academic achievement, attendance, office discipline referrals, dropout rate, and persistence to graduation. The year 2007-08 data analysis revealed statistical results when SWPBS strategies were not implemented. The year 2008-09 data analysis revealed statistical results during the first year when SWPBS strategies were emerging. The 200910 data analysis revealed statistical results when SWPBS strategies were established. The year 2010-11 data analysis revealed statistical results during a year when SWPBS strategies were fully implemented.

The Chi-square test was used to analyze the variables academic achievement, attendance, office discipline referrals, dropout rate and persistence to graduation. The data was imported into the Statistical Package for Social Sciences (IBM SPSS) version 20.0 and the vassarstats.net website for statistical computation was also used (Lowry, 2012). Once the data were imported the statistical analyses were conducted.

The Institutional Review Board (IRB) informed consent process was followed in accordance with local public school district practices and the University of Missouri Columbia. According to Mertens (2005) "an IRB is a committee mandated by the National Research Act, Public Law 93-348” (p. 332) and every university that had human subjects as a part of behavioral research was required to have an IRB. The IRB was needed to approve all research. As part of the expectation of the IRB, privacy of subjects was kept confidential and remained anonymous, as there was no identifying information attached to the data.

Archival data was retrieved from the K-12 alternative public school database through accessing Power School, SWIS, and SASI with local public school district 
administration permission. The data included information concerning 1,164 students from the 2007-08, 2008-09, 2009-10, and 2010-11 school years and student names remained anonymous. The school district staff member who retrieved the data blinded names of the students prior to giving the data to the researcher. In compliance with FERPA regulations, the local public school district as well as the researcher sent a "Memo of Understanding" to the University IRB indicating three expectations to be followed: (a) the names of the students were blinded prior to giving the data to the researcher, (b) the purpose of the data was for use by the researcher for the dissertation, and (c) once the dissertation was completed the data was destroyed.

The data identified the dependent variables of academic achievement, attendance, office discipline referrals, dropout rate, and persistence to graduation for each student. The independent variable, SWPBS, was studied to determine the impact on the dependent variables: academic achievement, attendance, office discipline referrals, dropout rate, and persistence to graduation.

\section{Limitations}

(a) The ability to draw inferential conclusions from the data to a larger group was a limitation since the case study only involved 1,164 students.

(b) Another limitation was generalizability of the data results to another alternative school due to the size of the population and number of case study years.

(c) The four-year time frame investigating the use of SWPBS at the K-12 alternative public school was also a limitation. A longitudinal case study was possibly needed. 
(d) Finally, a limitation of this study involved researcher bias as described by Creswell (2009). The researcher is employed as the guidance counselor at the K-12 alternative public school being studied and has assigned duties related to SWPBS at the school.

\section{Delimitations}

(a) The data gathered from this case study only represented one K-12 alternative public school in one Midwest state.

(b) The statistical data from this case study regarding office discipline referrals were collected from SWIS per grade level, per case study year.

(c) The statistical data regarding academic achievement, attendance, and persistence to graduation were collected from Power School per grade level, per case study year.

(d) The case study results reflected data retrieved from the 2007-08, 2008-09, 2009-10, and 2010-11 school years.

(e) Missouri State Department of Education descriptive data was used to determine if there was a relationship between SWPBS use and student outcomes.

\section{Summary}

Chapter One described this trend analysis case study. The goal of this case study was to research the SWPBS impact on five variables: academic achievement, attendance, office discipline referrals, dropout rate, and persistence to graduation. The unit of analysis was a K-12 alternative public school. Information resulting from this case study was significant because there was no research found in the literature that explored 
SWPBS use at an alternative public school setting. Therefore, the findings of the case study not only filled a gap in the literature, but also determined the SWPBS impact on five specific categorical variables.

In Chapter Two, the literature review started with the history of behavioral data, discipline, and an evolutionary process to the implementation of PBIS. It was followed by a presentation of traditional behavior management versus SWPBS. Next, there was a PBIS overview and then a discussion of comprehensive SWPBS components. In addition, SWPBS was explored in the traditional public school and the alternative public school environments. Finally, any findings in the literature regarding the five variables in this case study were addressed.

Chapter Three included the design and methods used in this case study. The chapter started with the research method, a description of the setting and participants, the data collection, and methods of analysis. The chapter ended with ethical considerations and limitations. Chapter Four presented the final results of the case study and Chapter Five provided discussion and conclusions, implications, and recommendations. 


\section{CHAPTER TWO \\ REVIEW OF LITERATURE}

The number of at-risk students seems to be increasing and more families are living at or below the poverty level. Society changed dramatically from the family of the 1960's, and with the struggling economy, the high rate of joblessness, and people losing their homes, the life of the modern family has become chaotic. In addition, the school climate has changed. For example, in the 2009-10 school year one-third of all public schools in the U.S. had armed security. According to the National Center for Education Statistics this accounted for approximately 23,000 schools (No Author, 2013). The situation became further complicated when children came from single parent homes, suffered abuse, witnessed domestic violence, and were impacted by alcohol and drug abuse, yet children were expected to attend school and be successful. Consequently, students arrived at school carrying a great deal of emotional baggage and also had safety concerns especially regarding the aftermath of school shootings, the most recent being the Sandy Hook Elementary School senseless killings of students and staff. These descriptions of at-risk students were those typically found within the alternative public school researched in this current case study.

\section{SWPBS Background}

SWPBS is a systems approach that introduced strategies to all students as a way of achieving success in a safe learning environment. It was a team-based process that utilized behavior management practices and principles in an effective learning environment. "The goal is to establish a positive school and classroom climate in which expectations for students are predictable, directly taught, consistently acknowledged, and 
actively monitored" (Osher et al., 2010, p. 50). Traditionally, SWPBS was used, in part, by the regular public school to prevent students from attending an alternative public school. Yet, once the student was in an alternative school environment, SWPBS was not a part of the school culture. This seemed to be somewhat of an irony as this was the environment where SWPBS was needed the most for these students to be successful. There were no published SWPBS research studies concerning K-12 alternative public schools. Therefore, another purpose of this case study was to investigate whether or not SWPBS was successful at a K-12 alternative public school environment.

\section{Conceptual Underpinnings of SWPBS}

In behaviorism, a model of behavioral theory, was a theory of discipline where behaviors were acquired through conditioning. The conditioning occurred through interaction with the environment. Applied Behavior Analysis (ABA) was a systematic application of interventions that were based on learning theory to improve behavior. The PBIS approach emerged from an applied behavior analysis framework through work with developmentally disabled children. In the 1950’s, applied behavior analysis was influential in making a difference with people who were developmentally disabled. Applied behavior analysis looked at the antecedent effects of negative behaviors, and encouraged an approach that used individual interventions (Sugai \& Horner, 2002). The focus was originally from a pathology-based model and progressed to an educational and systems change method. SWPBS was a behavior-based approach and included researchvalidated practices designed to positively affect desired behaviors.

According to Johnston, Foxx, Jacobsen, Green, and Mulick (2006), there was a conceptual link between applied behavior analysis and SWPBS. First, SWPBS used 
data based assessments in making decisions. Second, interventions were designed for the entire school population. And third, interventions were taken from the research in applied behavior analysis. Examples of these interventions were teaching expected behaviors, token economies, and other reinforcements. "Were it not for the past 35 years of research in analysis, PBS could not have come into existence" (Carr et al., 2002, p. 5).

Traditional Behavior Management

Historically, behavioral management in the educational system involved office discipline referrals, after school detention, in-school suspension (ISS), out-of-school suspension (OSS), and expulsion. This behavioral management approach was found both in the traditional educational setting as well as in the alternative public school in this case study. The focus was on punitive measures that arose out of reaction rather than proaction. Also, school settings possessed many practices that contributed to student negative behaviors that led to these punitive measures. In order to understand how SWPBS impacted educational settings, it was necessary to first look at numerous practices found within the traditional school setting as described by Sprague and Walker (2004). These included:

1. Ineffective instruction that resulted in academic failure;

2. Inconsistent and punitive classroom and behavior management practices;

3. Lack of opportunity to learn and practice pro-social and interpersonal skills

4. Unclear rules and expectations regarding appropriate behavior;

5. Failure to effectively correct rule violations;

6. Failure to reward adherence to rules;

7. Failure to individualize instruction and support to adapt to individual 
differences (e.g., ethnic/cultural, gender, disability);

8. Failure to assist students from at-risk (e.g. poverty, racial/ethnic minority members) backgrounds to bond with the schooling process

9. Disagreement and inconsistency of implementation among staff members; and

10. Lack of administrator involvement, leadership and support (Sprague \& Walker, 2004, p.13).

As a result of traditional behavior management, legislative demands placed upon schools to devise a plan that increased academic performance. These demands required replacing more punitive measures of suspension and expulsion with positive measures. "Teaching and acknowledging appropriate behaviors as a prevention-oriented basis, rather than reacting through suspension once a problem occurs, may be the first step in turning the tide toward safer schools designed for keeping students in school and experiencing success" (Morrisey, Bohanon, \& Fenning, 2010, p. 27). In response to this legislative demand, the alternative public school in this case study implemented the School-Wide Positive Behavior Support (SWPBS) approach.

The National Center for Education Statistics (2011) compiled data from 1972 to 2009 regarding trends in dropout rates and graduation rates. These trends showed the importance of SWPBS to increase school attendance and persistence to graduation. Herlihy and Quint (2008) agreed research-based programs designed to assist students academically were the most successful when special supports were in place. This case study of the K-12 alternative public school revealed whether or not the three levels of SWPBS had a positive impact on academic achievement, attendance, office discipline 
referrals, dropout rate and persistence to graduation.

\section{Overview of Positive Behavior Intervention and Support}

Scott et al. (2010) explained it was best to view PBIS as a continuum or a sequence of practices and processes rather than three separate levels. They proposed four steps from school-wide implementation through more intensive individual interventions. These four components were: (a) prediction, (b) high probability interventions, (c) consistency, and (d) assessment. In regard to decision-making it was essential to predict specific problem behaviors and the contexts in which they occurred. Second, through high-probability interventions of instruction and behavior management, student success was increased. Third, teachers and staff consistently maintained a consensus to adhere to SWPBS practices. Finally, assessment was a critical component in the decision-making process. The K-12 alternative public school in this case study implemented these four proposed steps and they are addressed further in this research paper.

As a means of ensuring these proposed steps were followed as a continuum of practice, it was imperative to focus on outcomes to make data based decisions regarding intervention effectiveness. Hieneman, Dunlap, and Kincaid (2005) investigated the use of PBS strategies with behavioral disordered students in general education settings.

Developing insight into the levels of SWPBS was a critical component as it related to behavior-disordered students like those found at the K-12 alternative public school. The authors described school-wide PBS, classroom PBS, and individualized PBS. These three levels were shown in Table 3 as an abbreviated summary of PBS features. 
Table 3

Summary of Features of PBS at Each Level of Implementation

\begin{tabular}{|c|c|c|c|}
\hline Question & Individual & Classroom & School-wide \\
\hline Who is involved? & $\begin{array}{l}\text { Students, parents } \\
\text { teachers, direct } \\
\text { support providers }\end{array}$ & $\begin{array}{l}\text { Teachers, para- } \\
\text { professionals, } \\
\text { administration }\end{array}$ & $\begin{array}{l}\text { Administrators, } \\
\text { grade-level and } \\
\text { discipline specific }\end{array}$ \\
\hline $\begin{array}{l}\text { How are variables } \\
\text { identified? }\end{array}$ & $\begin{array}{l}\text { Context (setting), } \\
\text { individual beh., } \\
\text { from FBA }\end{array}$ & $\begin{array}{l}\text { Classroom } \\
\text { management, } \\
\text { problem routines }\end{array}$ & $\begin{array}{l}\text { Observations, } \\
\text { surveys, and } \\
\text { patterns in ODR's }\end{array}$ \\
\hline \multirow[t]{2}{*}{$\begin{array}{l}\text { How are strategies } \\
\text { implemented? }\end{array}$} & $\begin{array}{l}\text { Modify tasks, } \\
\text { teach replacement } \\
\text { behaviors, }\end{array}$ & $\begin{array}{l}\text { Modify routines, } \\
\text { modify instruction } \\
\text { methods, }\end{array}$ & $\begin{array}{l}\text { More supervision, } \\
\text { implement } \\
\text { continuum } \\
\text { of consequences, }\end{array}$ \\
\hline & $\begin{array}{l}\text { Address lifestyle } \\
\text { supports }\end{array}$ & $\begin{array}{l}\text { Implement rewards } \\
\text { and time-outs }\end{array}$ & $\begin{array}{l}\text { View staff } \\
\text { incentives, and } \\
\text { org. policies }\end{array}$ \\
\hline \multirow[t]{2}{*}{$\begin{array}{l}\text { What will be used to } \\
\text { measure outcomes? }\end{array}$} & $\begin{array}{l}\text { Increase/decrease in } \\
\text { target behaviors }\end{array}$ & $\begin{array}{l}\text { Increase in academic } \\
\text { engagement }\end{array}$ & $\begin{array}{l}\text { Improvement in: } \\
\text { grades/attend }\end{array}$ \\
\hline & $\begin{array}{l}\text { Skills have replaced } \\
\text { problem behaviors }\end{array}$ & $\begin{array}{l}\text { Fewer ODR's and } \\
\text { more rewards }\end{array}$ & $\begin{array}{l}\text { Fewer ODR's and } \\
\text { crisis intervention }\end{array}$ \\
\hline
\end{tabular}

In addition to how PBIS functions at each level, it was important to look at specific studies that implemented SWPBS. Dunlap et al. (2010) determined PBIS research most often involved short-term studies restricted to only one or two wellcontrolled settings lasting three to five months. As a result of these findings, the researchers completed a two-year examination of positive behavior support with a diverse group of 21 participants from five different geographical locations. They found a reduction in problem behavior, however the decrease was not dramatic over the long term.

Netzel and Ebel (2003) conducted a study involving an elementary school using SWPBS and determined there were three important lessons learned: (a) administrator 
buy-in and follow through were essential for success, (b) successful SWPBS usage required team self-evaluation, (c) the staff and administration needed to participate in a shift in thinking toward a shared philosophy leading to a systems change, and (d) a long term commitment by building staff, administration, and district administrators was necessary for SWPBS sustainability. These were critical lessons that were pursued in this current research involving SWPBS at the K-12 alternative public school.

Schools across the nation investigated new approaches for handling student behavior and disciplinary problems. The education system was moving away from the traditional, more punitive approaches to models and approaches that included more positive interventions such as SWPBS. As shown in Table 4, Liaupsin, Jolivette, and Scott (2004) provided a comparison of the traditional management approaches and PBIS. Table 4 clearly indicated how SWPBS was not only perceived by the K-12 public alternative school, but also how SWPBS was designed to function in this environment.

Table 4

Comparison of Traditional Behavior Management and PBIS

Traditional Behavior Management

PBIS

Views individual as "the problem"

Views systems, settings, and skill deficiencies as "the problem"

Attempts to "fix" the individual

Attempts to "address" contributing issues within systems, settings, and skills

Extinguishes behavior

Creates new contacts, experiences, relationships, and skills

Sanctions aversives

Sanctions positive approaches

Takes days or weeks to "fix" a

single behavior

Takes years to create responsive systems, personalized settings, appropriate/empowering skills 
Implemented by a behavioral specialist often in atypical settings

Often resorted to when systems are inflexible
Implemented by a dynamic and collaborative team using personcentered planning in typical settings

Flourishes when systems are flexible

\section{School-Wide Positive Behavior Support}

SWPBS was not totally an original approach as it had its roots in behavioral theory. Skinner (1974) first described antecedent-behavior-consequence events in the 1950's. He used principles of reinforcement as a means to change behavior. For example, the students at the K-12 alternative school English class were asked to read quietly (antecedent event). However, some students were texting on their phones and others were talking to their neighbors (behavior). The teacher told them if they were texting they must take their phone to the office for the remainder of the day (consequence).

SWPBS was not a method or a program and even though it was used in the classroom, it was not a curriculum. SWPBS was a systems approach that involved all students in the school at the primary level and students with more challenging behaviors on an individual basis. All administrators, teachers, and staff were involved in SWPBS. Educators were involved in a team-based approach and received professional development regarding systems change and effective management practices. In addition, they learned instructional procedures that were validated through research.

It was important to note that SWPBS was not implemented all at once. It was a very systematic approach that took two to three years to develop and put into action within the school schedule. The three behavioral levels of support (primary, secondary, and tertiary) were conceptualized as three inter-related systems. Before the SWPBS 
approach was started, the school spent one year in the development phase. SWPBS was a very deliberate, methodical approach designed to best meet the needs of all students through the appropriate level of intensity. This structured design also involved the same level of precision allowing administrators, teachers, and other staff to receive SWPBS professional development training. Initial preparation and readiness was crucial and laid the foundation for SWPBS to be successful and maintained with fidelity.

Coaching was shown to improve the fidelity of the evidence-based approach. Kretlow and Bartholomew (2010) searched the literature over the past 20 years and identified 13 studies that indicated coaching improved the accuracy of the evidence-based SWPBS practices performed by teachers. In addition to the coaching aspect of SWPBS, O'Dell et al. (2011) analyzed research studies published in the Journal of Positive Behavior Interventions during the first ten years in publication (from 1998 to 2008) and found other important factors. For example, the authors found studies focused on (a) preventive measures, (b) improved school climate, (c) early intervention with young children, (d) school-aged children were the most researched, and (e) children with autism were the most common group researched. Overall, research showed student outcomes were positively affected by SWPBS interventions and practices. "It is critical that prevention and intervention efforts are derived from what is known about children's developmental needs and the programs selected are derived from sound research" (Whitted, 2011, p. 14). SWPBS was data based and met the critical need of prevention and intervention components.

SWPBS originated as a result of the need for school disciplinary measures to be a preventive approach rather than a reactionary approach. Too often the reactionary 
approach resulted in punitive measures such as students being suspended or expelled. The K-12 alternative public school in this case study was an example of a school that used this type of reactionary approach prior to the implementation of SWPBS. Sugai and Horner (2002) further described these disciplinary measures as: (a) a repetition and restatement of the consequences, (b) increased consequences to become more aversive, (c) established a zero tolerance level, (d) did not allow the student to attend the school by enforcing OSS or expelling the student, and (e) possible referral to alternative school placement.

In response to improved school disciplinary practices, Lane, Little, Menzies, Lambert, and Wehby (2010) recommended all school staff, teachers, and administrators worked together to create a comprehensive system that was more preventive than reactionary. The authors suggested the best approach was a SWPBS three-tiered comprehensive approach created by both general and special education personnel. This suggestion was put into practice by the K-12 alternative public school in this research case study.

The focus of SWPBS evolved to an adoption of more preventive disciplinary practices. From this, SWPBS emerged as an approach based upon three core features. McIntosh, Filter, Bennett, Ryan, and Sugai (2010) investigated these critical features through a "prevention science lens." They first described the integration of systems, practices, and data to facilitate achieved SWPBS outcomes. This process involved various stakeholders such as students, teachers, parents, and community participants. Second, SWPBS was designed to meet student needs at various levels such as individuals, groups, and whole-school approaches. In addition, different locations such as 
the classroom and non-classroom settings were identified. The expectations for the K-12 alternative public school being studied were shown in the PBIS Expectations Matrix found in Appendix A. And third, SWPBS provided an ongoing support system by initially involving all students in the interventions using a three-tiered support system.

There were three main SWPBS themes that included prevention, multi-tiered support, and data based decision-making. SWPBS was data based and met the critical need of prevention and intervention components. Prevention included three specific areas: (a) teaching positive behavioral expectations, (b) acknowledging expected behaviors, and (c) implementing consequences. The consequences included re-teaching the appropriate behaviors and responses. A SWPBS approach at the K-12 alternative public school was chosen as it allowed school personnel to design the behavior and intervention supports that best met the unique needs of these students.

It was shown that an important aspect of positive change in student behavior was related to changing the school climate. A SWPBS approach required a positive climate and when the positive climate was lacking, SWPBS was not as effective. Bradshaw, Koth, Thornton, and Leaf (2009) stated, “... schools that are less organizationally healthy, chaotic, and have staff who feel they have limited efficacy may be at an increased risk for poor implementation fidelity" (p.109). The authors described implementation fidelity as the ability of a program to put into practice what it set out to accomplish, specifically in regard to the quality of program delivery as well as the responses of the participants.

Good, McIntoch, and Gietz (2011) reinforced this idea and explained, “The overarching goal of SWPBS is to cultivate a safe, positive, and successful school culture" 
(p.55). The school culture played an important role in setting up any new initiative. These initiatives that supported tiered interventions at the high school level involved a shift in the school culture. "For example, staff members may need to collaborate in new ways, examine data together regularly and think about implications for instructional practice, and agree that the success of all students is the responsibility of all staff members" (National High School Center, 2010, p. 10). This level of responsibility was implemented at the K-12 alternative public school in this case study.

The National School Climate Center (NSCC) (2007) developed the Comprehensive School Climate Inventory (CSCI). An adaptation of the CSCI included four essential dimensions of school climate as shown in Table 5. In order for the K-12 alternative public school to become SWPBS successful, it was necessary to have a basic understanding of these dimensions in order to visualize a SWPBS connection and the need for positive supports in the schools.

Table 5 Four Essential Dimensions of School Climate

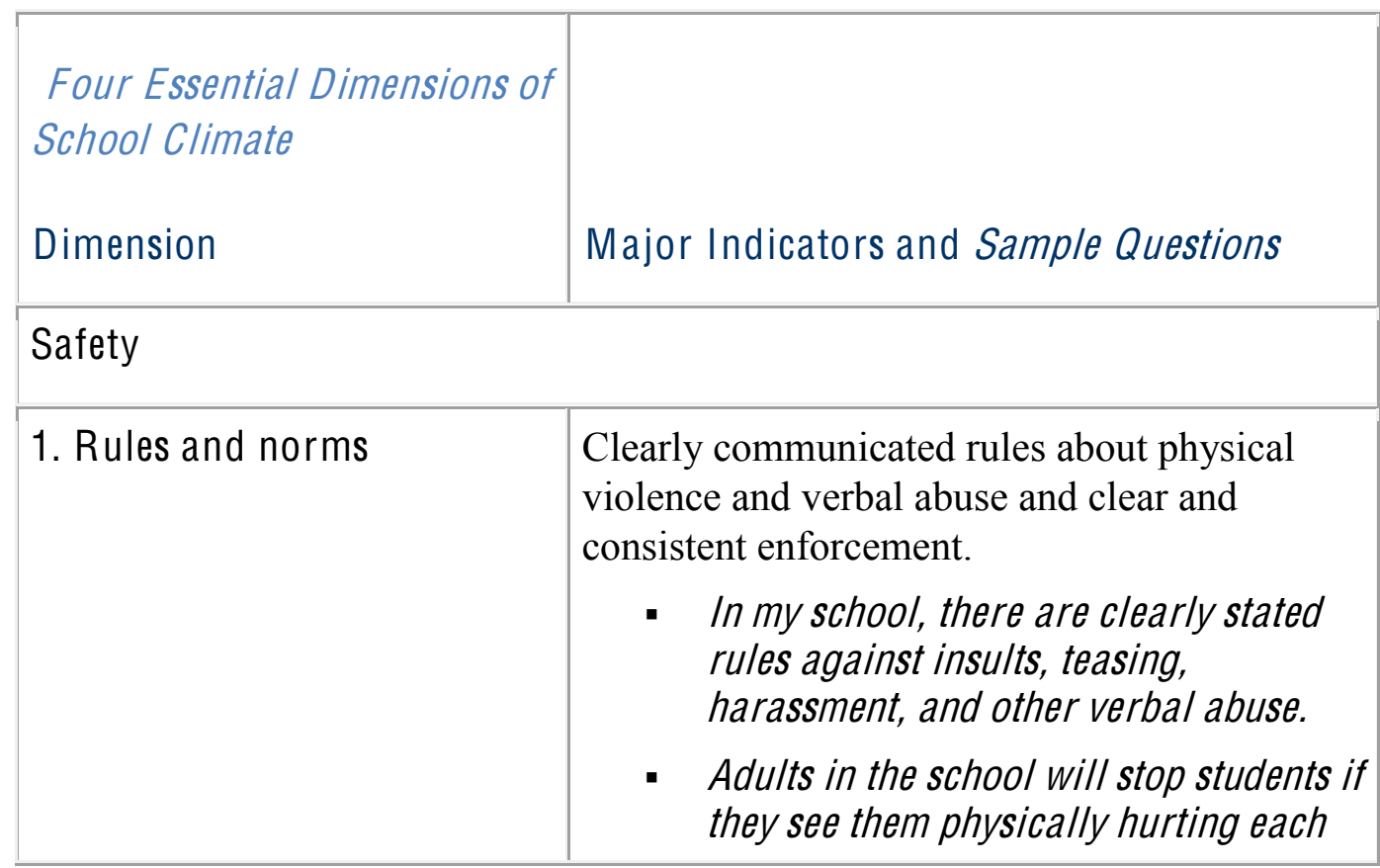




\begin{tabular}{|c|c|}
\hline & $\begin{array}{l}\text { other (for example, pushing, slapping, } \\
\text { or punching). }\end{array}$ \\
\hline 2. Physical safety & $\begin{array}{l}\text { Sense that students and adults feel safe from } \\
\text { physical harm in the school. } \\
\text { - I feel physically safe in all areas of the } \\
\text { school building. } \\
\text { - I have seen other students being } \\
\text { physically hurt at school more than } \\
\text { once (for example, pushed, slapped, } \\
\text { punched, or beaten up }\end{array}$ \\
\hline $\begin{array}{l}\text { 3. Social and emotional } \\
\text { security }\end{array}$ & $\begin{array}{l}\text { Sense that students feel safe from verbal } \\
\text { abuse, teasing, and exclusion. } \\
\text { - I have been insulted, teased, harassed } \\
\text { or otherwise verbally abused more } \\
\text { than once in this school. } \\
\text { - There are groups of students in the } \\
\text { school who exclude others and make } \\
\text { them feel bad for not being a part of } \\
\text { the group. }\end{array}$ \\
\hline \multicolumn{2}{|l|}{ Teaching and Learning } \\
\hline 1. Support for learning & $\begin{array}{l}\text { Supportive teaching practices, such as } \\
\text { constructive feedback and encouragement for } \\
\text { positive risk taking, academic challenge, } \\
\text { individual attention, and opportunities to } \\
\text { demonstrate knowledge and skills in a variety } \\
\text { of ways. } \\
\text { - My teachers show me how to learn } \\
\text { from my mistakes. } \\
\text { - My teachers encourage me to try out } \\
\text { new ideas (think independently). } \\
\text { - My teachers help me figure out how I } \\
\text { learn best. }\end{array}$ \\
\hline
\end{tabular}




\begin{tabular}{|c|c|}
\hline 2. Social and civic learning & $\begin{array}{l}\text { Support for the development of social and } \\
\text { civic knowledge and skills, including effective } \\
\text { listening, conflict resolution, reflection and } \\
\text { responsibility, and ethical decision-making. } \\
\text { - In my school, we have learned ways to } \\
\text { resolve disagreements so that everyone } \\
\text { can be satisfied with the outcome. } \\
\text { - In my school, we talk about the way } \\
\text { our actions will affect others. }\end{array}$ \\
\hline \multicolumn{2}{|l|}{ Interpersonal Relationships } \\
\hline 1. Respect for diversity & $\begin{array}{l}\text { Mutual respect for individual differences at all } \\
\text { levels of the school-student-student; adult- } \\
\text { student; adult-adult. } \\
\text { - Students in this school respect one } \\
\text { another's differences (for example, } \\
\text { gender, race, culture). } \\
\text { - Adults in this school respect one } \\
\text { another's differences (for example } \\
\text { gender, race, and culture). }\end{array}$ \\
\hline 2. Social support-adults & $\begin{array}{l}\text { Collaborative and trusting relationships among } \\
\text { adults and adult support for students in terms } \\
\text { of high expectations for success, willingness to } \\
\text { listen, and personal concern. } \\
\text { - Adults in my school seem to work well } \\
\text { with one another. } \\
\text { - If students need to talk to an adult in } \\
\text { school about a problem, there is } \\
\text { someone they trust who they could talk } \\
\text { to. }\end{array}$ \\
\hline 3. Social support—students & Network of peer relationships for academic \\
\hline
\end{tabular}




\begin{tabular}{|c|c|}
\hline & $\begin{array}{l}\text { and personal support. } \\
\text { - Students have friends at school they } \\
\text { can turn to if they have questions about } \\
\text { homework. } \\
\text { - Students have friends at school they } \\
\text { can trust and talk to if they have } \\
\text { problems. }\end{array}$ \\
\hline \multicolumn{2}{|l|}{ Institutional Environment } \\
\hline $\begin{array}{l}\text { 1. School } \\
\text { connectedness/engagement }\end{array}$ & $\begin{array}{l}\text { Positive identification with school, sense of } \\
\text { belonging, and norms for broad participation } \\
\text { in school life for students and families. } \\
\text { - I feel good about what I accomplish in } \\
\text { school. } \\
\text { - I think my parents/guardians feel } \\
\text { welcome at my school. My school } \\
\text { encourages students to get involved in } \\
\text { other things than schoolwork (for } \\
\text { example, sports, music/drama clubs). }\end{array}$ \\
\hline 2. Physical surroundings & $\begin{array}{l}\text { Cleanliness, order, and appeal of facilities and } \\
\text { adequate resources and materials. } \\
\text { - My school is physically attractive } \\
\text { (pleasing architecture, nicely } \\
\text { decorated, etc.). } \\
\text { - My school building is kept in good } \\
\text { condition. } \\
\text { - My school has up-to-date computers } \\
\text { and other electronic equipment } \\
\text { available to students. }\end{array}$ \\
\hline $\begin{array}{l}\text { Source: Adapted from the Co } \\
\text { the (NSCC) National School } \\
\text { by NSCC. Authorization for }\end{array}$ & $\begin{array}{l}\text { ehensive School Climate Inventory (CSCI) by } \\
\text { hate Center (2007), New York: NY. Copyright } \\
\text { granted on } 12 / 5 / 11 \text { by NSCC }\end{array}$ \\
\hline
\end{tabular}


The four essential dimensions of school climate described in the above chart included the dimensions of safety, teaching and learning, interpersonal relationships, and institutional environment. Each of these dimensions was a direct correlation to the components of SWPBS. First, the dimension of safety included rules and norms, physical safety, and social/emotional security. The SWPBS approach regarded these factors of safety to be of high importance. The safety and well being of students and staff was reflected in the SWPBS approach. There was continuous monitoring of student behavior in following clearly identified norms and rules. Second, the dimension of teaching and learning included support for learning, and social/civic learning. SWPBS was a means of providing instruction for students to learn both academic and social skills. Third, the dimension for interpersonal relationships included respect for diversity, social support (adults) and social support (students). The focus of interpersonal relationships was an integral piece of the foundation of SWPBS. Fourth, the dimension of the institutional environment involved school connectedness/engagement and the physical surroundings. In a similar fashion, the SWPBS approach was designed to create and maintain a positive school climate. It was important for teachers to develop rapport with students to build the foundation of a safe school environment where there was mutual respect between students and teachers. "Connection through human relationships is a central component of a culture of safety and respect" (No Author, 2013).

These dimensions were also reflective of the SWPBS approach used specifically at the K-12 alternative public school in this current case study. As part of the SWPBS plan the students and staff identified specific behavioral expectations as well as places where these behaviors occurred. Both are articulated in the K-12 alternative public school 
PBIS matrix (Appendix A). The behavioral expectations stated the students were to be: (a) honest, (b) respectful, (c) responsible, and (d) in control. The specific identified areas where these behaviors occurred were: (a) hallways, (b) classrooms, (c) cafeteria, (d) bathrooms, (e) playground, (f) assemblies, (g) bus, and (h) parking lot.

Not only was it important to delineate the behavioral expectations and where they were to occur, it was also necessary to specify how they occurred. Safran and Oswald (2003) described how disciplinary practices were reshaped through the use of positive behavior supports. The authors described SWPBS as a more holistic and collaborative approach designed to be a preventive strategy rather than a punitive disciplinary reaction to student misbehavior. The etiology of the behavior was perceived as an interaction between the student and the school environment. Therefore, in order for behavioral change to occur, there needed to be a shift not only in the thinking of students, but also in the thinking of staff, teachers, and administrators. SWPBS interventions were designed to be positive and proactive and required teams to be collaborative in designing, implementing, and evaluating SWPBS strategies. This collaborative team effort was part of the initial phase of preparation for SWPBS established at the K-12 public alternative school.

Before any interventions were implemented, the school personnel needed to understand that (a) it should not be assumed that students possessed necessary social skills, (b) the student's social culture with their peers must be considered, (c) not all students had the ability to take responsibility for their own successes or failures in learning and in life, (d) not all students responded to natural consequences by making appropriate behavior changes, and (e) students were not always self-motivated by social 
or academic success (Sugai, Flannery, \& Bohanon-Edmonson, 2004). These were critical factors that needed to be taken into consideration when applying SWPBS interventions at the K-12 alternative public school.

In order for a positive behavior support intervention to be comprehensive it included nine specific components (Carr et al., 2002). These components included (a) emphasis on prevention, (b) lifestyle changes and quality of life, (c) interventions with multiple components, (d) systems change, (e) stakeholder participation, (f) multiple theoretical perspectives, (g) ecological validity, (h) social validity, (i) flexible scientific practices, and (j) experimental control. These components were applicable to the K-12 alternative school being studied in order for SWPBS to be successful.

To determine the effectiveness of SWPBS Miramontes, Marchant, Heath, and Fischer (2011) conducted a qualitative study to evaluate a statewide PBIS initiative of elementary and middle schools in a western state. The study involved 35 schools in 16 school districts that were representative samples of the general population in urban, rural and suburban areas. The researchers found the majority of teachers, administrators, and service providers observed improvement in school climate once SWPBS was started statewide. Overall, the stakeholders indicated an investment in the statewide SWPBS initiative was worth the time and effort.

Although the state of Missouri, where the K-12 alternative public school was located, had not instituted a statewide initiative for SWPBS it had adopted a Response to Intervention (RtI) initiative that was consistent with the SWPBS approach. The Individuals with Disabilities Act (IDEA) was the only place where RtI was mentioned and it only referred to students with specific learning disabilities (SLD). IDEA relegated 
the authority to each state to determine how they would identify SLD students and implement RtI. As a result, Missouri mandated RtI as a state board of education policy (Zirkel \& Thomas, 2010). RtI was "the practice of providing high-quality instruction and interventions matched to student need, monitoring progress frequently to make decisions about changes in instruction or goals, and applying child response data to important educational decisions" (Batsche et al., 2005).

There was often a misconception that RtI was for academics and PBIS was for behavior. However, according to Sugai, Horner, Fixsen, and Blase (2010), PBIS was an integration of both behavior and academic supports on a three-tiered system. PBIS was consistent with the RtI approach by establishing a continuum of behavior support (Sugai \& Horner, 2009). Just as RtI was mandated for education in Missouri, the value of SWPBS was seen in its more widespread use across the United States in recent years. In addition, some states also mandated the use of PBIS in their schools. For example, in 2006 the State Board of Education in Michigan mandated "It is the policy of the State Board of Education that each school in Michigan implement a system of school-wide positive behavior support strategies" (Dunlap, Goodman, McEvoy, \& Paris, 2010, p. vii). This mandate was reflective of a more widespread PBIS usage in the United States during recent years. It was also indicative of the value stakeholders placed on SWPBS.

In order to best understand the SWPBS approach used at the K-12 alternative public school, it was necessary to look at the SWPBS key components. The main areas explored included the continuum of prevention, the four PBS elements, and the SWPBS approach in traditional versus alternative schools. The first key component addressed was the three-tiered triangle that depicted the continuum of SWPBS levels of prevention. This 
continuum was represented by a three-tiered triangle as shown below in Figure 1 and was used by the K-12 alternative public school in this case study. A multi-tiered triangle specifically used for the alternative school did not exist. The bottom portion of the triangle represented the SWPBS primary prevention interventions. This area was also referred to as the universal level because these interventions were applied to the entire school. Interventions at this level were effective with approximately $80 \%$ to $90 \%$ of the student population (Sugai et al., 2000). These primary level interventions were used school-wide and were designed to decrease the risk for negative student behaviors.

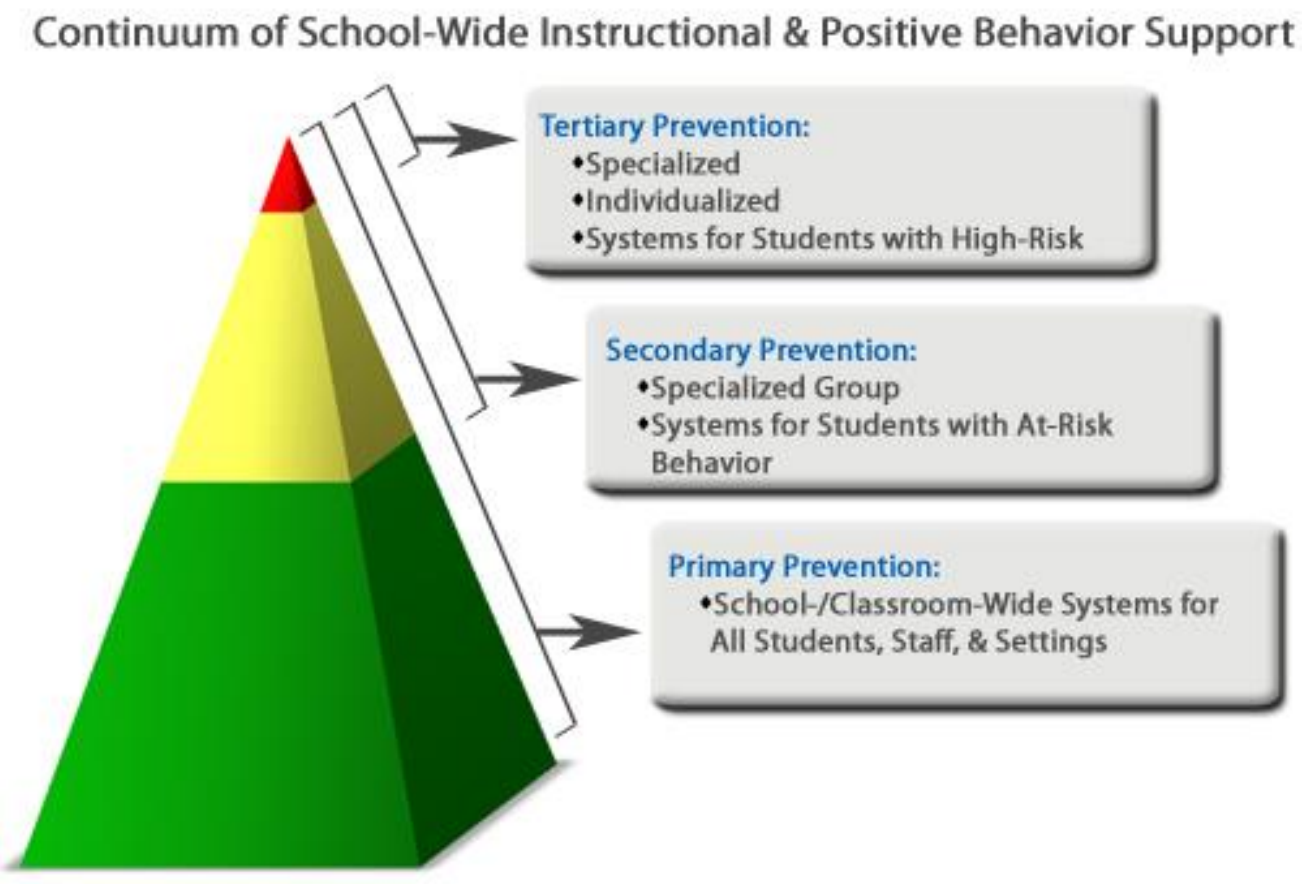

\section{Figure 1.}

(Permission to use this diagram granted by OSEP 12/5/11)

The second level of the triangle, the middle portion, represented approximately $5 \%$ to $10 \%$ of the student population that were not successful at the primary intervention level. These students typically had academic and/or behavioral problems. They often had two office discipline referrals and required more intense interventions. The third level of 
the triangle, the top portion, was representative of the most intensive level and required tertiary interventions. It was estimated $1 \%$ to $5 \%$ of the students required interventions at this level. These students were determined as unsuccessful at the primary and secondary levels as exhibited by their continued resistance to positive reinforcers and interventions. They displayed chronic behavioral and/or academic problems that interfered with their success in school.

According to Sugai et al. (2000) this small group of students was responsible for approximately $40 \%$ to $50 \%$ of the behavior problems at the school. In the SWPBS approach, these students required a more individualized approach that was more intensive. At this level the students also were involved in a functional behavior assessment (FBA) that was described as an evaluation of the antecedent/consequence event of a specific problem behavior. The FBA was utilized as part of the SWPBS approach used at the K-12 alternative school. The importance of the FBA was revealed in a study by Stoiber and Gettinger (2011) that provided empirical support that "functional assessment and positive behavior supports improve classroom environments, decrease challenging behaviors, and strengthen positive behaviors" (p. 704).

According to OSEP (2005), the identified percentages of Tier I in the three-tiered model were exemplified in the national report for the 2003-04 school year. The identified standards of $80 \%$ to $90 \%$ elementary students and $70 \%$ to $80 \%$ middle/high school students were met. This was more specifically represented by $87 \%$ of the elementary schools, $75 \%$ of the middle schools, and $73 \%$ of the high schools in Tier I. This information was necessary as a frame of reference for how the K-12 alternative public school fits into this three-tiered model. 
The second SWPBS key component included the four elements necessary to sustain a PBS program. These elements shown in Figure 2 were: (a) outcomes, (b) practices, (c) data, and (d) systems. The outcomes were the behavioral and academic targets, the practices represented the strategies and interventions, the data involved identification of what needed to be changed and the effects of the interventions, and the systems were the supports necessary to carry out PBIS practices. Figure 2 represented what was followed by the K-12 alternative public school through this process.

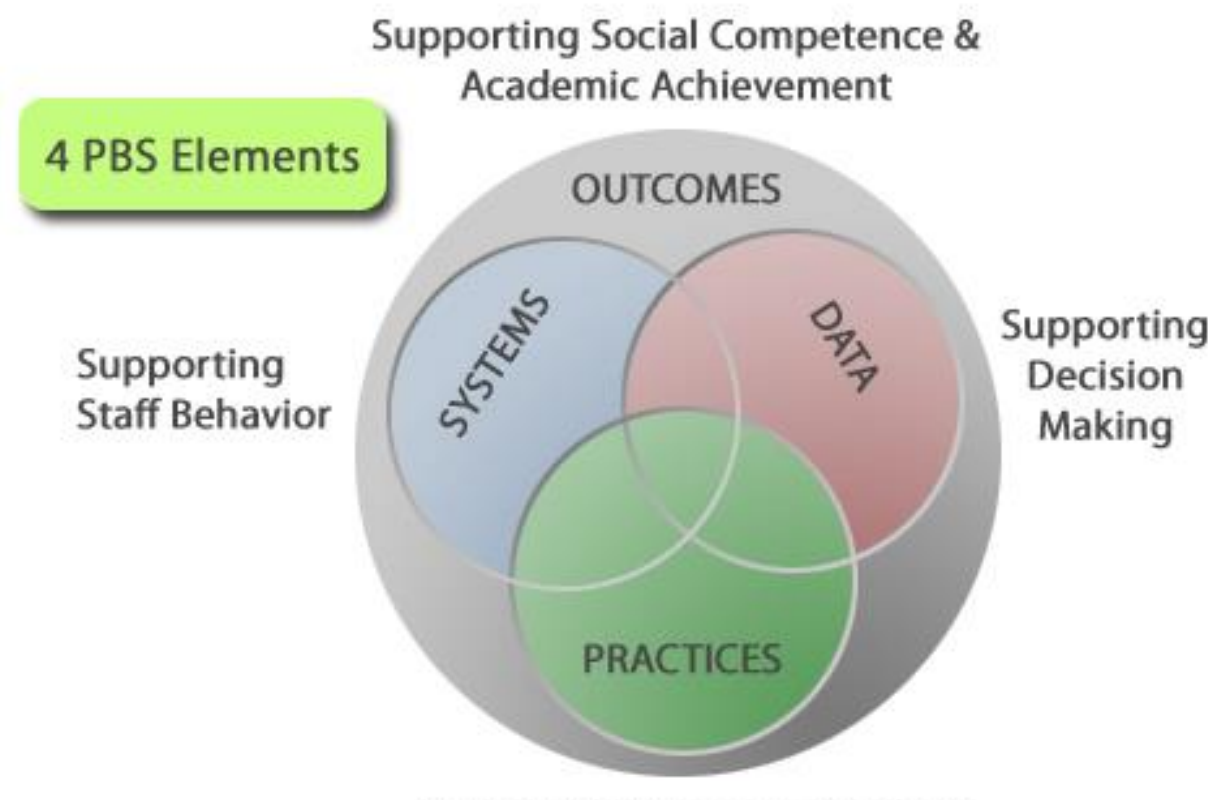

Supporting Student Behavior

(Permission to use this diagram granted from OSEP 12/5/11)

Figure 2.

In the 1980's, better programming was needed in the schools to address discipline, safety, and academic success. Sugai and Horner (2002) reported PBIS originated as a response to this need. SWPBS then evolved to address improvement in student behavior, school climate, and improved graduation rates. SWPBS included all 
students and staff, and provided system change through various levels of interventions. PBIS involved two specific characteristics. The first characteristic involved positive student behavior leading to appropriate skills development. The ultimate goal was achieved success at school, at home, and in the community. The second characteristic involved support through ongoing strategies to best meet the student's needs. "Positive behavior support incorporates a broad range of systemic and individualized strategies for achieving important social and learning outcomes while preventing problem behavior" (Scott et al., 2002, p. 535). This was accomplished through the establishment of three elements: (a) collected data used by staff to make important decisions, (b) organized PBS teams to support the staff in implementing the PBS strategies, and (c) continued effective practices that supported positive student behavior.

Numerous steps were followed by the K-12 alternative public school when putting these elements into practice. Specifically, there were seven steps described by Bradshaw, Mitchell, and Leaf (2010) that included: (a) forming a building-level leadership that included an administrator and staff members who established the action plan and guided others in the SWPBS implementation; (b) there was an external behavior support coach who provided technical assistance and consultation; (c) the school team identified several expectations such as "be respectful, responsible, honest, and in control" that were known to all students and staff and posted in classrooms and non-classroom areas; (d) teachers developed lesson plans that incorporated behavioral expectations and were taught to students at least once a month; (e) a tangible reward was used to reinforce positive behaviors known as "Notable Knights" and were given to students when they made appropriate choices and displayed positive behavior; (f) a pre-determined protocol 
for classroom-managed behavior versus office-managed behavior was in place as well as consequences for violating rules and the corresponding disciplinary action; and (g) team members received training on documenting discipline problems and a formal system was developed to analyze the disciplinary data through the SWIS reporting system to make decisions regarding SWPBS implementation and the need for possible use of Tier II or Tier III interventions.

Three-Tiered Level System: Traditional Public School vs. K-12 Alternative Public School

In the traditional public school setting, Tier I consisted of approximately $80 \%$ of the student population, Tier II consisted of approximately $15 \%$ of the student population, and Tier III consisted of approximately $5 \%$ of the population. The Tier II and Tier III students were typically those who were presenting the most behavior problems, were failing in school, had problems with authority, were behind in earning credits, etc. These factors typically resulted in these students being referred to the K-12 public alternative school.

The students at the K-12 alternative public school in this case study were considered to be "at-risk". Although these students were considered to be the "at-risk" students in Tier II or Tier III at their original traditional public school, once these students attended the K-12 public alternative school, they started at Tier I. The SWPBS framework allowed for creating a three-tiered system to meet the unique needs of the K12 alternative public school students. The at-risk behaviors/problems presented previously at their sending school then became the new norm for Tier I at the K-12 alternative public school. This multi-tiered system at the K-12 alternative public school is shown in Figure 3. 
Multi-Tiered Levels for K-12 Alternative Public School

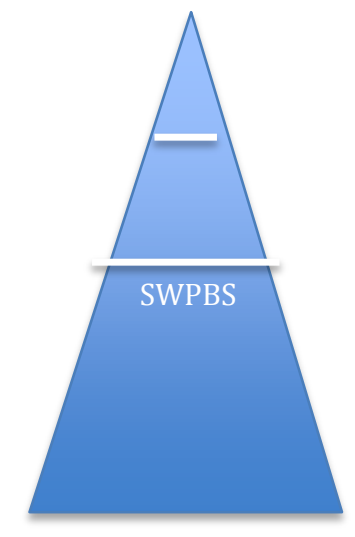

Tier III - Involved high-risk students with severe behaviors (individual intervention and support)

Tier II - Involved at-risk students with increased behaviors (group intervention and support)

Tier I - Involved all staff and all at-risk students in every setting (All students were considered at-risk at the K-12 alternative public school)

Figure 3.

The difference between the Tier I, Tier II, and Tier III system of the traditional public school and this K-12 alternative public school was the "at-risk" students at the traditional public schools were in levels II and III. At the K-12 alternative public school, the "at-risk" students were in all three levels. Tier II and Tier III were then perceived as varying degrees of "at-risk" at the K-12 alternative public school. As time progressed, some of these students conformed to the SWPBS expectations at the K-12 alternative public school. However, other students continued to have difficulty with following Tier I expectations and then they were identified accordingly for Tier II and Tier III interventions.

The continuum of school-wide instructional and positive behavior support as seen previously in Figure 1 was the same for both the traditional public school and the K-12 alternative public school. The only difference was the K-12 alternative public school indicated Tier I students as also being "at-risk". Otherwise, it was expected the percentage of students in each Tier was the same for both public and alternative schools; Tier I at $80 \%$, Tier II at $15 \%$, and Tier III at 5\%. 


\section{Primary Intervention}

The primary intervention was also known as the universa/ level and was a schoolwide approach that involved all students and school staff. The universal interventions were designed to prevent the onset of problem behaviors. It was anticipated in schoolwide implementation that these primary interventions were effective with the majority of students. Approximately $12 \%$ of all children and teenagers in the United States were diagnosed with some form of emotional or behavioral disorder that significantly affected their ability to function (Nelson et al., 2009). At the K-12 alternative public school a large majority of students were diagnosed with emotional or behavioral disorders.

\section{Secondary Intervention}

The secondary intervention was also known as the selective level and involved students who were identified to be at-risk. Within the K-12 alternative public school the students were considered to be at-risk, however they did not automatically enter at the Tier II level. They were considered to be Tier II at their previous traditional public school however, once they arrived at the K-12 alternative public school they started at Tier I.

Once the students participated in the Tier I intervention and were unsuccessful at that level, they were then considered for Tier II. These students were identified through the analysis of office discipline referrals (ODR) data. Teachers and staff referred students for Tier II interventions as not all students were found through ODR data. These students were at risk for developing more serious problems, but did not meet the criteria for Tier III interventions. Through the use of ODR data, specific information was gathered to show the types of misbehavior as well as when and where the behaviors occurred.

As a result of these findings the school PBIS team was able to specify appropriate 
Tier II interventions. Part of the criteria for receiving Tier II interventions occurred when the student was unsuccessful at Tier I interventions and displayed chronic behavior problems. Some examples of Tier II interventions included increased academic support and classroom management support, instruction in social skills, increased supervision in non-classroom settings, and check-in/check-out procedures (Dunlap, Goodman, McEvoy, \& Paris, 2010).

The check-in/check-out procedure used in Tier II was a dropout prevention intervention designed for at-risk students with increased academic and behavioral issues. The check-in/check-out format was used in the K-12 alternative public school as an intervention. Crone, Horner, and Hawken (2003) developed the Behavior Education Program (BEP) that used the Check-In/Check-Out system (CICO). The student was assigned a school mentor who monitored the student's academic progress, attendance, behavior and other school related issues. The mentor was a paraprofessional, or classified or certified personnel. This person made a connection with the student on a regular basis and not only checked on progress, but also provided encouragement and support. The goal was to develop positive interpersonal relationships between the students and adults as another way of encouraging student's motivation to learn as well as decrease problem behaviors (McIntosh, Filter, Bennett, Ryan, \& Sugai, 2010). This mentoring system was used in the SWPBS approach at the K-12 alternative public school as a means of developing and maintaining appropriate interpersonal relationships.

One of the most critical features of Tier II interventions involved the completion of a functional behavioral assessment (FBA). According to Horner, Sugai, and Anderson (2010) the FBA constituted various levels of intensity from using the most common 
methods of interviews and observations to conducting experimental analyses. The FBA was devised through collaboration with other team members at the K-12 alternative public school. The first step in completing the FBA was to identify the variables that triggered the inappropriate behaviors. These were also known as antecedent variables that continued to reinforce the inappropriate behaviors. The second step was an investigation of where and when the behaviors occurred. The third step of the assessment was student skill deficits as well as strengths. Finally, the PBS team developed a behavioral support plan to assist the student in achieving both academically and behaviorally. Once the plan was followed, data collection continued as a method of evaluating the SWPBS intervention success (Martin, Tobin, \& Sugai, 2002). The data collection was a critical piece of the research pie and was collected from the Student Information Systems of SASI, Power School, and SWIS at the K-12 alternative public school.

Not only was the data collection important, but even more critical was the implementation and evaluation of the Tier II interventions at the K-12 alternative public school. Hoyle, Marshall, and Yell (2011) reviewed the literature and found there was a limited amount of research in the area of implementation and evaluation of Tier II interventions. Therefore, the authors conducted a survey to determine the Tier II interventions used by middle schools. They received responses from $92 \%$ of the states and found most of them used the BEP or CICO as the quantitative data tool to evaluate the interventions. However, due to some inconsistencies found within the data, there was some concern as to whether the interventions were implemented with fidelity. Also as a result of their study, these authors determined future research was needed regarding the quantitative methods used to monitor Tier II interventions. 


\section{Tertiary Intervention}

The tertiary intervention was also known as the indicated level for those students who were considered an increased level of severe at-risk behavior and required more intensive interventions at the K-12 alternative public school. The at-risk behaviors impeded learning, were dangerous, very disruptive, or frequent and chronic. Since the students at the K-12 alternative public school were considered to be at-risk students, the three tiers were redefined. Tier III became redefined as a higher level of risk than what was found at the traditional public school. These at-risk behaviors were reflective of the types of behaviors exhibited by students at the K-12 alternative public school. There were young children from primary grades and older who displayed behaviors beyond the control of school personnel. At times this behavior resulted in students being placed in handcuffs by the police and taken to juvenile detention.

Universal interventions were addressed frequently in the literature. However, both at the secondary and tertiary levels there were limited examples. Scott et al., (2010) pointed out these limited examples focused mostly on various strategies and processes. These authors believed a better focus offered "clear descriptions of a conceptual foundation or the development of systemic approaches in line with the multi-tiered logic of PBS" (p. 514). At both the secondary and tertiary levels, "supports should be based on the principles and procedures of applied behavior analysis to define behavioral challenges, complete functional behavioral assessments, and design effective and efficient procedures for correcting patterns of problem behavior in conjunction with student-centered and family-centered planning approaches" (Osher, 2010, p. 50). 
Table 6 showed a range of strategies that expressed a more meaningful representation of practices and procedures at the secondary and tertiary levels. This table represented the continuum that was followed at both the secondary and tertiary levels at the traditional education settings and was also followed by the K-12 alternative public school. However, it was important to remember that although the continuum was the same, the K-12 alternative public school students were a higher at-risk population at the secondary and tertiary levels.

Table 6

Summary Table of Interventions Continuum at the Secondary and Tertiary Levels of PBS

Primary/Secondary Level

\begin{tabular}{|c|c|}
\hline Focus & Key Features \\
\hline \multicolumn{2}{|c|}{ Secondary Interventions } \\
\hline Positive Relationships & $\begin{array}{l}\text { Cultural and communication issues are } \\
\text { considered to create positive relationships } \\
\text { between teachers and students as they interact } \\
\text { across school settings. }\end{array}$ \\
\hline Effective Instruction & $\begin{array}{l}\text { Problem contexts include effective instructional } \\
\text { practices such as explicit directions, modeling. } \\
\text { prompting, guided practice, opportunities to } \\
\text { respond and feedback. }\end{array}$ \\
\hline Effective Management & $\begin{array}{l}\text { Problem contexts include effective management } \\
\text { practices such as consistency, encouragement, } \\
\text { proximity/movement and contingent } \\
\text { consequences. }\end{array}$ \\
\hline \multicolumn{2}{|c|}{ Tertiary Interventions } \\
\hline $\begin{array}{l}\text { Consultation-Based } \\
\text { Functional Thinking }\end{array}$ & $\begin{array}{l}\text { Teachers meet with school consultant and } \\
\text { discuss student behavior to identify possible } \\
\text { functions. Simple intervention plans are } \\
\text { implemented with focus on antecedent } \\
\text { manipulations. }\end{array}$ \\
\hline Team-based FBA & All teachers familiar with student meet and \\
\hline
\end{tabular}


discuss student using both direct and indirect FBA measures to identify possible function. Behavior plans are implemented across all settings.

Wraparound-Based

Team of relevant school, community, and family FBA persons uses a wide range of assessments to identify functions across settings and develop behavior plans that are implemented across life domains.

Tertiary Level

Permission granted on 12/16/11 from Terrance Scott, Ph.D. to use this Table.

Within the tertiary level, the wraparound-based interventions were the most comprehensive levels of support (Epstein et al., 2005). The wraparound process involved the student, family, school, and community agencies. Within the K-12 alternative public school, the wraparound process included not only the school and the student, but also families and community agencies. The stakeholders within the community have determined the need for their involvement with the local school district. A group was organized in partnership together with the K-12 alternative public school and involved approximately fifteen different organizations that included the local medical hospital, mental health facility, youth substance abuse organization, etc. Once the team completed a functional behavior assessment, academic strategies and behavior supports were designed and implemented. As part of the SWPBS approach this was called a wraparound process and was a Tier III intervention.

The wraparound process was described by Eber, Breen, Rose, Unizycki, and London (2008) as a comprehensive intervention used in Tier III for students with the greatest emotional and behavioral needs. Wraparound services were the most complex and were designed to work with the student, his/her family, and teachers as a proactive team. This team investigated the student's strengths and needs, designed interventions, 
and enlisted interagency services. A facilitator led the team that (a) engaged students, families, and teachers who experienced frustration from failed interventions; (b) assisted with the design of the interventions; (c) coordinated others such as the student, family, teacher, and agencies to form a team; (d) ensured all were involved in implementation; and (e) regularly used data to develop interventions and monitor the progress (Eber et al., 2008).

\section{Traditional Public School SWPBS vs. Alternative Public School SWPBS}

Every year there were thousands of students who were suspended or expelled in public schools across the United States. Oftentimes, suspensions were the result of minor infractions, mostly disruptions in the classroom. Of the students suspended, some were sent home repeatedly. This was true in the traditional public school as well as this K-12 alternative public school being studied. Critics complained that suspended or expelled students got into more trouble in the community when sent home. They also missed out on learning when they were not in school and got behind in their work. Instead of suspending students, it was recommended they be taught more appropriate behavior. "Punishing acts of disrespect or minor disruption doesn't help them manage that. And the nature of adolescence is to rebel. It's the job of the parents and also the schools to guide them in how to do that appropriately" (Billitteri, 2008, p. 2). In response to this dilemma, the K-12 alternative public school in this case study implemented a SWPBS approach.

Alternative schools were not always associated directly with the public school system. For example, Foley and Pang (2010) looked at various types of alternative settings in Illinois. They learned alternative settings were separate facilities and not associated with the public schools. If this was true in other states, this may be a possible 
explanation as to why there was no literature regarding SWPBS research in alternative public schools. The K-12 alternative public school however, was a part of the local public school district in Missouri.

\section{Student Behavioral Data and Discipline}

To best understand the possible SWPBS impact at the K-12 alternative public school it was necessary to look at the past history of student behavioral data and discipline. Historically, misbehavior resulted in the use of negative approaches to reprimand students. The most common forms of punishment were suspensions and expulsions. It was believed school suspension would help a student learn from their behavior and also be a deterrent for others. However, this notion was not supported in the research (Sugai \& Horner, 2000). Until the implementation of SWPBS, time outs, ISS, and OSS were the only consequences for major behavioral problems in the K-12 public alternative school.

Zero tolerance policies emerged in the 1990's as a response to deadly school shootings. As a result, the number of students suspended or expelled rose dramatically. For example, Billitteri (2008) reported the Milwaukee schools had thousands of students suspended for minor infractions. The data showed almost 40 percent of the 9,000 students were suspended one to three days at least once a year, some more often. The Michigan Student Advocacy Center founder, Ruth Zweifler said, "On various levels, children who have concerns either about something they have done or about other kids will hesitate to go to an adult because the response is punishment, rather than help. It reinforces for staff that these kids are dangerous. It just doesn't build a healthy, trusting, learning community" (Billitteri, 2008, p. 7). These findings by the Milwaukee schools were 
relevant to the current research regarding the K-12 alternative public school. The research specifically revealed the impact SWPBS had on student behavioral data and discipline.

Additional past research also indicated the consequences of ISS, OSS, and expulsion that was used at the K-12 alternative public school. Skiba (2000), Indiana State University professor of counseling and educational psychology, studied school violence and discipline codes. He was also a national expert on school discipline policies. He reported the research indicated those schools with zero tolerance policies that used suspension and expulsion as consequences for student misbehavior seemed to have lower achievement rates, poor school climate, and increased behavior problems. In addition, classroom conditions also increased a student's risk for school problems and subsequently affected their being successful at learning (Downer, Rimm-Kauffman, \& Pinata, 2007). Skiba recommended a graduated discipline due to the evidence that zero tolerance policies inadvertently rewarded negative behaviors. There was no empirical evidence showing suspension and expulsion deterred problem behaviors.

Sprick (2009) corroborated this finding and reported "reactive and exclusionary approaches to discipline are common in secondary schools, but do not improve behavior or ensure safety. A tiered strategy that combines responses to intervention with positive behavior support is more effective" (p. 19). Historically, the education system failed to manage poor student behavior. The research revealed both reactive responses such as detentions and corporal punishment as well as exclusionary practices such as expulsions and timeouts showed that these practices were ineffective.

Research studies over the past 30 years showed school climate significantly effected both academic achievement and student behavior. Specifically in relation to 
disciplinary practices, Osher et al. (2010) investigated school discipline through the development of self-discipline, targeted interventions, and broad interventions. These interventions correlated to the individual student, classroom, and school-wide needs. SWPBS was addressed specifically as a response to discipline. Instead of using punishment, a positive school climate and a set of interventions were employed to best meet student needs. School-wide interventions "create cognitive and behavioral ecologies that promote situational order and student learning and development" (Osher et al., p. 48). School discipline involved more than punishment.

Further exploration of school discipline occurred when Netzel and Eber (2003) investigated PBIS in an urban elementary school of 600 students. This pilot study was conducted to determine whether a PBIS approach would help decrease the 117 out-ofschool suspensions (OSS) in one school year. The current discipline philosophy of the school staff and administration needed to be changed before PBIS could be put into practice. The staff and administration believed a consequence for misbehavior was determined at the time of the incident. There were no consistent procedures for managing disruptive behavior and no effective disciplinary measures.

A gradual shift occurred from a reactive discipline plan to a proactive discipline plan through PBIS interventions. The first step involved helping the staff and administration understand how the procedures used were not successful. If detention and OSS were successful then expected decreases in inappropriate behaviors would occur. However, within their school it was shown that detentions and OSS did not decrease disruptive behaviors. The research literature also supported this finding (Cregor, 2008).

The second step in setting up a more proactive approach involved educating the 
staff and administrators about the rationale for time management. Using a proactive approach required planning student success in advance rather than dealing with a problem after the situation occurred. This approach allowed for better time management and efficiency as well as it gave the staff and administrators the opportunity to use a continuum of consequences instead of OSS. "The continuum of consequences included administrator warning, student meeting, debriefing log, behavior contract, correspondence with the parent, parent and teacher meeting, indoor recess, and out-ofschool suspension" (Netzel \& Eber, 2003, p. 74). As a practical consideration, Handler et al., (2007) identified the need for both administrative support and team action planning through SWPBS practices. The authors found an increased likelihood that these practices resulted in a 10\% decrease in OSS during initial SWPBS implementation. OSS was a part of the attendance variable being investigated in this case study at the K-12 alternative public school.

\section{Attendance}

One of the variables addressed in this case study at the K-12 alternative public school was attendance. Townsend (2011) conducted a study of 458 at-risk students from 16 elementary schools and eight secondary schools using SWPBS. Tier I or Tier II interventions were used to determine the effects of SWPBS on attendance. The study found that $44 \%$ of the participants decreased their days of absences as a result of SWPBS participation.

Cregor (2009) investigated the use of SWPBS in two different elementary schools. One school had 70\% African-American students and 30\% Caucasian students. In addition, $80 \%$ of the student population qualified for free or reduced lunch. The other 
school investigated had $81 \%$ Caucasian students and 19\% African-American students. The students that qualified for free and reduced lunch was $15 \%$ of the population. Although both of these schools were very different from each other regarding ethnicity and poverty levels, Cregor (2009) found SWPBS implementation made a significant impact on improved attendance rates at both schools.

A study conducted by Ross (2012) had a different outcome than other studies regarding SWPBS impact on attendance. The researcher studied the SWPBS effects on attendance at one elementary school in Kentucky. The study evaluated the attendance percentages from the 2006-07 to the 2011-12 school year. The results revealed there were no significant SWPBS effects on attendance during the six-year period. This finding was in sharp contrast to the previous studies that reported an increase in attendance rates with SWPBS implementation (Cregor, 2009; Townsend, 2011).

\section{Academic Achievement}

An important aspect of positive behavioral change was establishing and maintaining a positive school climate. Cohen and Pickeral (2007) indicated, "Positive school climate is associated with and/or predictive of academic achievement, effective risk prevention efforts, and healthy youth development" (p.29). However, in a review of the literature, Nelson et al. (2009) found SWPBS effects did not show an increase in academic performance. Sanders (2009) also conducted a study of SWPBS effects on academic achievement and office discipline referrals at an elementary school (K-5) of 396 students during the 2007-08 school year. The results indicated there were no increases in academic achievement and no decreases in office discipline referrals. These results were inconsistent with findings in the literature review that showed a positive 
SWPBS impact on academic performance (Cooper, 2011; Simonsen et al., 2012). In looking at the Sanders (2009) study, the limitations may have explained the findings. For example, this study only investigated SWPBS for two years. The first year 2008-09 of SWPBS implementation was compared to the previous year 2007-08 prior to the implementation of SWPBS. The K-12 alternative public school case study investigated the SWPBS implementation for a period of four years.

A three year study was conducted by Luiselli, Putnam, Handler, and Feinberg (2005) involving elementary students (K-5) in an urban city in the mid-west. This particular school had a history of academic underachievement. The three-year study revealed SWPBS implementation significantly increased academic achievement. This was measured by significant improvement in scores on nationally norm-referenced standardized tests. Specifically, scores were higher in the two areas tested, reading comprehension and math. These results were similar to other findings related to SWPBS impact on academic achievement. This was also an area addressed regarding the case study at the K-12 alternative public school.

Several SWPBS studies showed an increase in academic achievement. Muscott, Mann, and LeBrun (2008) conducted a study involving 28 schools (K-12) and early childhood education programs in New Hampshire that implemented SWPBS for two years. The study results indicated an academic increase in math gains. Lassen, Steele, and Sailor (2006) conducted a study of the relationship between SWPBS and academic achievement. The unit of analysis was an inner city middle school in the Midwest. The results indicated a correlation between SWPBS and academic achievement. There were decreased problem behaviors as well as increased standardized scores in math and 
reading. McEvoy and Welker (2000) looked at antisocial behavior, academic failure, and school climate. They found a high correlation between suspensions and academic failure. The majority of research indicated SWPBS improved academic achievement in the areas of grade point average (GPA) and course credits earned (Guest, 2011).

\section{Office Discipline Referral}

The office discipline referral (ODR) was one of the most commonly used outcome measures for evaluating SWPBS impact. Reviewing ODR's was most effective when completed frequently and systematically. McKevitt and Braaksma (2008) described this process as an "efficient, effective, and naturally occurring way to monitor the impact of a universal PBIS system on student performance" (p. 736). Research showed office discipline referrals were indicators of student problem behaviors. However, there were limited studies that examined the validity of using ODR's. As a result, Pas, Bradshaw, and Mitchell (2011) conducted a study to determine the efficacy of ODR's as a valid source for data based decision-making. The researchers examined the ODR's in 21 elementary schools involving over 8,000 students and found that ODR's were valid and reliable measures of student problem behaviors.

Several research studies showed positive SWPBS effects on ODR's. Sprague et al. (2001) conducted a study using a control-group design. They compared the outcomes of nine SWPBS schools to six control schools. The results indicated the SWPBS schools had a significant decrease in ODR's as compared to the other schools. The ODR's decreased $51 \%$ at the SWPBS elementary schools and decreased $8 \%$ at the control elementary schools. At the middle schools there was a decrease of $36 \%$ of ODR's at the SWPBS middle schools and an increase of $82 \%$ at the control middle school. This study 
represented the magnitude of the SWPBS impact on ODR's.

Luiselli, Putnam, Handler, and Feinberg (2005) conducted a study of 590 elementary school students (K-5) in an urban mid-western city. This particular school had a history of academic underachievement. The three-year study revealed when SWPBS was put into practice ODR's and suspensions were decreased. Sherrod, Getch, and Ziomek-Daigle (2009) conducted a study using a two-level approach using a targeted intervention group approach and a school-wide approach at a suburban elementary school during the 2007-08 school year. The school-wide approach involved SWPBS with the entire student population of 468 students. Results indicated a 26\% ODR reduction. The number of ODR's went from 219 in 2006-07 before SWPBS was used, to 162 ODR's following SWPBS implementation in 2007-08.

In addition to the school-wide initiative, a small group was also formed and included those students who were described by Sugai and Horner (2006) as at-risk students who required targeted approaches at the SWPBS Tier III level. The authors reported $8 \%$ to $10 \%$ of the student population required this level of intensity. The school counselor conducted a group of five at-risk students for eight weeks. Each week had a lesson with a specific theme as follows: purpose/expectations of the group, rules, problem-solving, anger/anger management, distractions from learning, positive communication skills, negative labels, what was learned in the previous seven sessions. As a result, $60 \%$ of the support group students had zero discipline referrals. This outcome was consistent with the findings of previous research that showed the effects of SWPBS implementation on ODR reduction and suspensions (Coleman, 2008; Guest, 2011; Lassen, Steele, \& Sailor, 2006; Netzel \& Eber, 2003; Warren et al., 2006). 
Spaulding et al. (2010) reported that most ODR studies used relatively small samples of students or schools that affected the generalizability of results. The authors indicated there were not any published large-scale studies that had common methods of collecting and reporting school-wide data. As a result, these authors conducted a study of ODR patterns and corresponding administrative decisions. They used 1,510 schools across the United States that started SWPBS during the 2005-06 school year. Through data collected from SWIS, they found most elementary school ODR's originated from peer problems in the classroom. The middle school ODR's resulted from student/adult interactions and the high school ODR's were a result of being tardy and skipping school. Those students who had zero to one ODR's for the academic school year was $88 \%$ at the elementary schools, $72 \%$ at the middle schools, and $67 \%$ at the high schools. These were traditional public schools. The current case study investigated the SWPBS impact on ODR's at a K-12 alternative public school.

Since the use of SWPBS has only been in recent years it was difficult to find any long-term studies. However, a five-year longitudinal study was conducted in 37 Maryland elementary public schools to determine SWPBS effectiveness. The data revealed when SWPBS was implemented with fidelity, suspensions and ODR's significantly decreased (Bradshaw, Mitchell, \& Leaf, 2010). The current case study at the K-12 public alternative school was conducted over a four-year period and investigated four separate school years 2007-08, 2008-09, 2009-10, and 2010-11.

\section{Dropout Rate}

The National Center for Education Statistics (n.d.) reported the national dropout rate during the 2008-09 school year involved approximately 607,000 public high school 
students who dropped out of school between the $9^{\text {th }}$ and $12^{\text {th }}$ grades. This constituted a 4.1\% national dropout rate. The Missouri dropout rate was further explained by the Annie E. Casey Foundation (2011), that indicated 6\% of 16 to 19 year old Missouri students dropped out of school in 2010. In addition, 9\% or 30,000 Missouri students aged 16 to 19 years old dropped out in 2011. These dropouts were also shown to be unemployed.

The dropout rate was a great concern as those students who did not graduate oftentimes suffered consequences that were costly for both the student and society. Dropouts were limited in the type of jobs for which they were qualified. The high unemployment rates made it even more difficult for dropouts to find jobs. When they did find a job, they most likely were low-paying jobs and had little job security. These individuals were possibly unable to afford housing or utilities and basic living necessities, and may become dependent on welfare programs and other government assistance programs. This was costly for society as the taxpayers fund these agencies.

The National Center for Education Statistics (n.d.) reported the negative outcomes for high school dropouts. For example, in 2009 the median income for a student between the ages of 18 and 67 who dropped out of high school was $\$ 25,000$ as compared to the same age group who completed high school where $\$ 43,000$ was the median income. The dropouts lost income was approximately $\$ 630,000$ over a lifetime. This represented an individual loss, but there was also a society loss as well of about $\$ 240,000$ over the lifetime of each high school dropout. This calculation included welfare costs, Medicaid costs, criminal activity rates, and lower tax contributions (Levin \& Belfield, 2007).

Just knowing the percentage of dropouts in the country was not enough. There needed to be a closer inspection of the reasons for these dropout rates as a means to 
finding solutions to correct the problem. Rumberger and Palardy (2005) noted there was no single reason why students dropped out of school. There were many reasons that were complex and involved a multitude of factors not just involving the student, but also the student's family, school, and community. The Oregon Department of Education (2002) determined the top ten reasons for why students dropped out of their schools. The ten reasons were (a) not enough credits to graduate, (b) lack of parental support for education, (c) dysfunctional home life, (d) worked more than 15 hours per week, (e) substance abuse, (f) frequent discipline referrals, (g) pregnant or student parent, (h) felt peer pressure to not achieve, and (i) had a history of attending three or more high schools. These were similar reasons for why students dropped out of the K-12 alternative public school studied.

Gleason and Dynarski (2002) further investigated the literature in economics, sociology, and education and found that researchers identified relationships between dropping out and five kinds of variables. The variables were: (a) demographic characteristics and family background, (b) past school performance, (c) personal and/or psychological characteristics, (d) adult responsibilities such as working or caring for a family member, and (e) the school or neighborhood characteristics. The authors found that researchers agreed on these factors even though different data sources were used or the time frames studied were different. They also found other risk factors may have affected dropout rates such as student's educational expectations, feelings about how much control they had in their educational success, and self-esteem issues. Overall, the research findings determined a need for improving interpersonal relationships at home and at school, a need for mutual respect between teachers/staff and students, and a need 
for individualized positive interventions for students with attendance and behavior problems. Although this information was gathered in 2002, it was very relevant for students in 2011, particularly the students at the K-12 alternative school. Another study revealed similar dropout reasons. Jenson (2010) reported an unusually high percentage of dropouts involving drug use, crime, and poverty in communities across the United States.

Rumberger and Larson (1998) found that if any students were held back between $8^{\text {th }}$ grade and $12^{\text {th }}$ grade, these students were two times more likely to drop out of school or attend an alternative school. Neild and Balfanz (2006) also found that eighth grade students who failed Math or English or who missed five weeks of school had a 75\% chance of dropping out of high school. More recently, Ruglis and Freudenberg (2010) found most students dropped out of high school in the $9^{\text {th }}$ or $10^{\text {th }}$ grade.

Several studies found if a school had a high suspension rate, there was also a high dropout rate. For example, Suh and Suh (2007) used the National Longitudinal Survey of Youth (NLSY) and investigated the risk factors that led to students dropping out of school. Results of their data analysis revealed 16 significant predictors of dropout. One of the predictors was a previous history of suspensions. In addition, the probability of a student dropping out of school increased by $78 \%$ if that student had a history of suspensions. Similar research by Christle, Jolivette, and Nelson (2007), who studied the Kentucky Department of Education dropout rates for two years, found schools with higher dropout rates had significantly higher suspension rates than schools with low dropout rates. And finally, researchers Lee, Cornell, Gregory and Fan (2011) conducted a study using 289 Virginia public high schools and hypothesized there would be a correlation between school suspensions and dropout rates. The findings indicated an 
accurate hypothesis: when suspensions were used as discipline, the suspensions were accurate dropout rate predictors. This information was quite alarming when applied to the 3.3 million students who were suspended each year from school (U.S. Department of Education, 2008).

White and Kelly (2010) searched counseling journals written from 1985 to 2008 to find any articles about dropout or truancy. They then critically reviewed articles that specifically focused on dropout prevention. There were 20 articles and of those articles, only six focused on school-based interventions. There appeared to be a critical need for interventions to address the dropout rate in the United States, and SWPBS was a possible answer.

In reviewing the Connecticut schools, the State Education Resource Center (2009) found a significant reduction in dropout rates among schools using SWPBS. In other research, Muscott, Mann, and LeBrun (2008) conducted a study involving $28 \mathrm{New}$ Hampshire (K-12) schools and early childhood education programs that had been implementing SWPBS for two years. The results indicated a decrease of 6,010 ODR's and a reduction of 1,032 suspensions in the middle and high schools. The researchers determined this recovered 571 leadership days, 864 teaching days, and 1,701 learning days.

\section{Persistence to Graduation}

Ruglis and Freudenberg (2010) reported some of the lowest graduation rates occurred at the largest urban schools in the United States. They indicated research showed that in 13 out of 50 of the nation's largest schools, one-half of these students left school in the $9^{\text {th }}$ grade. Heilig (2011) conducted a study in which over 45,000 high school 
students in the Houston Independent School District (HISD) were tracked to determine the graduation rate. This study found the majority of the students did not graduate.

It was imperative that if students were to stay on the path for graduation there needed to be early identification and effective interventions that prevented student disengagement. Balfanz, Herzog, and MacIver (2007) conducted a longitudinal study from 1996 to 2004. They followed approximately 13,000 students during this time period and identified four indicators to predict $60 \%$ of the students in the sixth grade who would not persist to graduation. The four indicators were: (a) academic performance, (b) misbehavior, (c) poor attendance, and (d) status variables such as special education or ESL (English as a Second Language) status. As a result of this study, it was found that most students who failed either a Math or English course in the sixth grade did not graduate. Results also indicated only $20 \%$ of the students graduated within one year of their cohort graduation time if a student received an unsatisfactory grade in any subject during the sixth grade. The odds of graduating on time, or at all, decreased even more when the students had two or more suspensions in the sixth grade.

Another predictor of a student most likely to not graduate was in regard to attendance. If a student attended less than $80 \%$ of the time during their sixth grade year, they were most likely to not persist to graduation. The authors suggested that since there were early warning systems in the sixth grade that it would be beneficial for schools to adopt effective whole school reforms and to employ targeted interventions regarding attendance, behavior, and the individual. They stated graduation rates could be increased substantially.

Balfanz (2011) reported approximately $25 \%$ of sixth grade students in high 
poverty areas who had difficulty with behavior, attendance, and course failure most likely did not persist to graduation. He described SWPBS as a model to address these three areas as a means of increasing the graduation rate. He further stated the model was only effective using three integral components. They were: (a) the teachers, staff, and administrators needed to have a shared mission and purpose, (b) the structure of the school needed to be scheduled so teachers can work with a core set of students for a period of time, and (c) teachers needed schedules that allowed them to work as core teachers (such as all Math teachers) and also as an interdisciplinary team. It was predicted that if these three areas were successful the likelihood of the students staying on the path to graduation would increase.

When the No Child Left Behind Act of 2001 (NCLB, 2006) was enacted high schools and states were required to report their graduation rates. Stakeholders observed there was inconsistency among the states as to how the graduation rate was calculated. In 2008, in an effort to achieve higher accountability, the U.S. Department of Education mandated all of the states to follow a four-year adjusted cohort rate beginning in the 2011-12 school year. This uniform rate estimated the percentage of students who started high school in the $9^{\text {th }}$ grade and graduated four years later. Prior to the 2011-12 mandated requirement for a four-year cohort graduation rate, it was not required schools measure the graduation rate or report how long it took for students to graduate.

In the city where the current case study was conducted an article appeared in the local newspaper on November 23, 2011 that explained the state of Missouri started using a new formula to calculate graduation rates. This was due to the new mandate by the U.S. Department of Education that required all states to use a specific formula. This allowed 
the graduation rates to be compared uniformly across the U.S. This new method was called the four year adjusted cohort graduation rate. A cohort group included all of the students who first enter high school together as freshmen. The graduation rate was to be determined by identifying those students who started together as a cohort and graduated at the end of the four years. However, the way graduation rates were computed varied between the states. For example, in Missouri, students who took longer than four years to graduate were included in the graduation rate whereas this was not the situation in other states. The graduation rate increased in Missouri over the past ten years from 82.4 percent in 2002 to 86.4 percent in 2011 . The K-12 alternative public school was in a small community in Missouri. The local school district graduation rate in 2011 was 89.6 percent under the old formula. However, under the new four-year formula the 2011 graduation rate was 82.4 percent.

Many students, particularly those with disabilities did not graduate within the four-year time frame. However, under the Individuals with Disabilities Education Act (IDEA, 2006) students with disabilities were allowed to attend public high school until the age of 21 years old. They met certain requirements and had at least one of the 12 diagnoses that required special education services. The student was then involved with a special education team to design and put into practice an individualized education plan (IEP). This plan identified specific educational goals as well as a time frame for coursework completion and other graduation eligibility requirements. NCLB gave IEP students the opportunity to complete high school one year after the four-year cohort date. Since IDEA allowed the IEP student to graduate up to the age of 21 , this represented a discrepancy between the NCLB and IDEA requirements. 
It was difficult to remedy this situation as stakeholders and policy makers did not have the information they needed from the high schools, districts, states, and the U.S. Department of Education. This was due to the fact these entities used different methods for calculating high school graduation rates (Mishel \& Roy, 2006). According to the National Dropout Prevention Center for Students with Disabilities (2008) there were three different methods used to calculate graduation rates. These methods included the leaver rate, the event rate, and the cohort rate. The leaver rate was used by 21 states and the U.S. Department of Education. The event rate was used by 15 states and the cohort rate was used in 19 states.

The leaver rate estimated the percentage of students that left school with a diploma compared to those students who left as a result of dropping out, aging out, or dying. The event rate estimated the percentage of students with disabilities that graduated with a diploma compared to the total enrollment of special education students for that class in that year. The cohort rate estimated the percentage of students who started school in the $9^{\text {th }}$ grade and graduated four years later. There was also a five-year cohort rate that accommodated students with disabilities. Many of the students at the K-12 alternative public school fell into this category.

Schifter (2011) conducted a study of students with disabilities to determine the length of time it took for them to graduate from high school. In using data from the 2010 National Longitudinal Transition Study-2, she found that many students graduated after four, five, or six years after entering high school. However, results of the study also indicated $72.4 \%$ of the students with disabilities graduated eight years after they entered high school. These findings needed to be scrutinized as the study used self-reported data 
in which the students themselves reported whether or not they graduated with a high school diploma. The validity of these results was questionable. Reliable data retrieval methods would be more accurate using academic records.

According to the American School Counselor Association (ASCA, 2005), one of the most identifiable factors of the profession of school counseling was the focus on primary prevention. This focus was what distinguished the school counseling profession from other helping professions. White and Kelly (2010) reviewed the role of the school counselor in dropout prevention. They described the role of the counselor as "a significant and critical element in the school success formula" (p. 11). By implementing empirically supported interventions, the counselor played an important part in helping the students remain in school and persist to graduation.

Literature Review Summary

As evidenced by this comprehensive literature review there was a lack of research investigating the impact of SWPBS implementation at a K-12 alternative public school setting. Historical progression of SWPBS at the traditional public schools was evident, however, there were no empirical studies found in the literature showing SWPBS at K-12 alternative public schools. Specifically, the literature review revealed the SWPBS approach at the traditional schools had a positive outcome for all five categorical variables being explored in this case study: academic achievement, attendance, office discipline referrals, dropouts, and persistence to graduation. The findings revealed that schools with SWPBS were more likely to have an increase in academic achievement and attendance. It was also determined that office discipline referrals were the most used indicators to assess school discipline and monitor SWPBS effectiveness. Regarding 
office discipline referrals, the results also showed that SWPBS impacted school discipline as evidenced by a decrease in the total number of ODR's. The literature further revealed the number of dropouts decreased and the number of graduates increased at the traditional schools that implemented SWPBS. Consequently, according to the literature, SWPBS had a positive impact on several factors at the traditional public schools. There were no studies conducted at K-12 alternative public schools related to academic achievement, attendance, office discipline referrals, dropout rates, or persistence to graduation. 


\section{CHAPTER THREE}

\section{RESEARCH DESIGN AND METHODOLOGY}

To explore the research questions, a quantitative, non-experimental, case study methodology was selected based on the works of Bradshaw, Mitchell, and Leaf (2010); Curtis, Van Horne, Robertson, and Karvonen (2010); Horner, Sugai, and Anderson, (2010); and Luiselli, Putnam, Handler, and Feinberg (2005). As defined by Creswell (2009) a case study involves only one entity. The current case study was a K-12 alternative public school in full implementation of SWPBS. Building on the work of Sugai and Horner (2002) as described in the literature review, this case study was designed to add to the SWPBS literature. The three major objectives included: (a) reporting a trend analysis of SWPBS outcomes at a K-12 alternative public school over a four-year period using archival data from four separate years (2007-08, 2008-09, 200910, and 2010-11), (b) examining the relationship between SWPBS and academic achievement, attendance, office discipline referrals, dropout rate, and persistence to graduation, and (c) investigating the adherence to SWPBS and other indicators on the overall outcome. There were five dependent variables and performance outcomes.

This case study was chosen due to a need for educational leaders to be able to identify the specific student performance factors that were positively affected by the implementation of SWPBS interventions. Administrators and other school personnel benefitted from studies that examined the correlation between the five categorical variables identified as academic achievement, attendance, office discipline referrals, dropout rates and persistence to graduation to make the best informed decisions regarding program implementation. Currently, the correlation between these variables and SWPBS 
cannot be found in any previous studies specifically used at a K-12 alternative public school setting.

According to the research, SWPBS strategies were very successful at reducing office discipline referrals, improving academic achievement, decreasing the dropout rate, and increasing the graduation rate (Dunlap, Carr, Horner, Zarcone, \& Schwartz, 2009; Sugai \& Horner, 2008; Townsend, 2011; Balfanz, 2011). These research studies were conducted at traditional elementary, middle, or high school environments. The studies did not include any alternative public schools and also did not include any K-12 alternative public schools.

This chapter presented a discussion of the problem statement, research questions and hypotheses, and research method and design. A description of the setting and participants, the data collection, and methods of analysis were also included. The validity and reliability of the measures were addressed. Finally, ethical considerations and limitations of the case study were addressed.

\section{Statement of the Problem}

What was not known were the overall SWPBS effects on academic achievement, attendance, office discipline referrals, dropout rate, and persistence to graduation at a K-12 alternative public school. A literature review revealed there was a positive impact of SWPBS on these same variables at traditional public schools. However, there were no published empirical studies conducted that focused on SWPBS impact and these same variables at a K-12 alternative public school. Simonsen, Britton, and Young (2010) stated, "Although there is considerable research on intervention approaches (e.g., function based support) to support individual students with challenging behaviors, there 
is a lack of research on school-wide intervention approaches to support all students in alternative school settings" (p. 180). With the enactment of the No Child Left Behind (NCLB) Act of 2001, schools were charged with finding ways to provide positive school climates and increase positive student success both academically and behaviorally. According to McNeil (2011) six areas were addressed in NCLB expectations and were identified as annual testing, academic progress, report cards, teacher qualifications, reading programs, and funding changes. Understanding the importance of NCLB expectations assisted in gaining a perspective of SWPBS usage.

First, in regard to annual testing, schools were required to participate in testing to meet the set state academic standings. Students in $3^{\text {rd }}$ through $8^{\text {th }}$ grades were expected to be tested in math and reading once a year. The students at elementary, middle, and high schools were required to test in Science at least one time. Then, by the 2013-14 school year, students were expected to reach a proficient level regarding the identified adequate yearly progress (AYP) standards. Second, NCLB required all students to be proficient on state exams by the 2013-14 school year. Both the student population and various student subgroups were required to meet state AYP targets. The Title I schools that failed this requirement two consecutive years would be given additional technical assistance, and the students would be given the opportunity to attend other area schools. Schools that did not achieve AYP for three years consecutively would be given additional assistance. Continued AYP failure would result in the school being subject to specific corrective measures.

Third, starting the 2002-03 school year, districts were required to submit annual report cards showing student achievement data. Fourth, the high school teacher's 
expectations were highly qualified in their core subject areas. The teachers considered "highly qualified" possessed the appropriate subject area certification and subject matter proficiency. Also, by the end of the 2005-06 school year, all paraprofessionals hired with Title I monies were required to complete two years of college, complete a minimum Associate degree, or pass an evaluation showing teaching proficiency and subject knowledge. Fifth, NCLB created a program called Reading First for students from Kindergarten through $3^{\text {rd }}$ grades. A priority was made for students in high poverty areas. And finally, funding changes identified by NCLB directed money to those schools that had a majority of poverty level students. Provisions were also designed to give schools the flexibility to determine how they wanted the monies spent as allotted by the federal government (McNeil, 2011). According to McNeil, approximately 38\% of the schools were failing to meet 2010 AYP. By 2011, there was concern expressed by the U.S. Secretary of Education that $82 \%$ of the schools would fail AYP standards. The overall failure rate was not that high, however there were states that had $50 \%$ failure rates, McNeil reported. It appeared the NCLB mandates were difficult to achieve. Therefore, compliance with federal mandates required school administrators to employ cost effective programs that produced positive student behavior and successful academic achievement. A literature review revealed SWPBS interventions improved the quality of the student behavior and academic learning.

The current case study investigated the impact of SWPBS strategies on five student performance factors at a Midwest K-12 alternative public school. No previous research was conducted on the relationship between SWPBS interventions and academic achievement, attendance, office discipline referrals, dropout rates, and persistence to 
graduation at a K-12 alternative public school setting. This lack of information indicated a gap in the literature.

\section{Research Methods}

This case study used a quantitative research approach. This method of research is widely used and well known in the scientific community. According to Skarbek, Henry, and Parish (2006), "research is an activity that tests a hypothesis, draws conclusions, and contributes to generalizable knowledge" (p.19). There were three kinds of research: qualitative, quantitative, and mixed methods. According to Mertens (2005), quantitative research was used to "discover causal (correlational) relationships" (p.116). The author further explained the rigor involved in conducting quantitative research included internal and external validity as well as reliability. Hunter and Leahey (2008) reviewed articles written between 1935 and 2008 in two scholarly journals, the American Journal of Sociology and the American Sociological Review. They found approximately two-thirds of over one thousand articles used quantitative methods.

The quantitative research design was the most appropriate method to best study the correlation between the independent variable of SWPBS and the dependent variables of academic achievement, attendance, office discipline referrals, dropout rate, and persistence to graduation. The current case study started with a quantitative analysis of data from various sources. The ODR data was collected from the SWIS computer program. Academic achievement, attendance, office discipline referrals, dropout rates, and graduation rates were collected from the school data systems known as Power School and SASI.

Finally, the data from these sources were analyzed by using various quantitative 
methods to determine whether SWPBS had an effect on any of the five categorical variables. This current case study used data from various sources to learn how SWPBS affected the student performance factors at the K-12 alternative public school.

\section{Research Design}

The research design was a quantitative, non-experimental case study. A descriptive summary statistics analysis and an analysis using the Chi-square "goodness of fit" test as described by Field (2009) were used to examine data collected from the K-12 alternative public school archival databases for a four year period. The Chi-square test accommodated two or more outcome categories, and in this current case study five variables were researched. Therefore, the Chi-square test was the most appropriate statistical analysis as evidenced by the flexibility of comparing several categories. Specifically, this allowed statistical analyses using frequencies and percentages of the

five categories (a) academic achievement, (b) attendance, (c) office discipline referrals, (d) dropout rate, and (e) persistence to graduation. The Statistical Package for Social Sciences version 20 (SPSS IBM, 2011) and VassarStats (Lowry, 2012) were used to calculate and analyze the data.

\section{Research Questions}

The research questions guiding this case study are listed below:

RQ1 - What are the summary statistics for academic achievement by grade level, by course, and by each study year as measured by the number of passing grades?

RQ2 - What are the summary statistics for attendance by grade level and by study year? RQ3 - Is there a difference in the number and percent of office discipline referrals by grade level for the school years 2007-08, 2008-09, 2009-10, and 2010-11? 
RQ4 - Is there a difference in the number and percent of dropouts by grade level for the school years 2007-08, 2008-09, 2009-10, and 2010-11?

RQ5 - Is there a difference in the number and percent of graduates for the school years 2007-08, 2008-09, 2009-10, and 2010-11?

The impact of SWPBS on each of the five research questions is depicted in Figure 4.
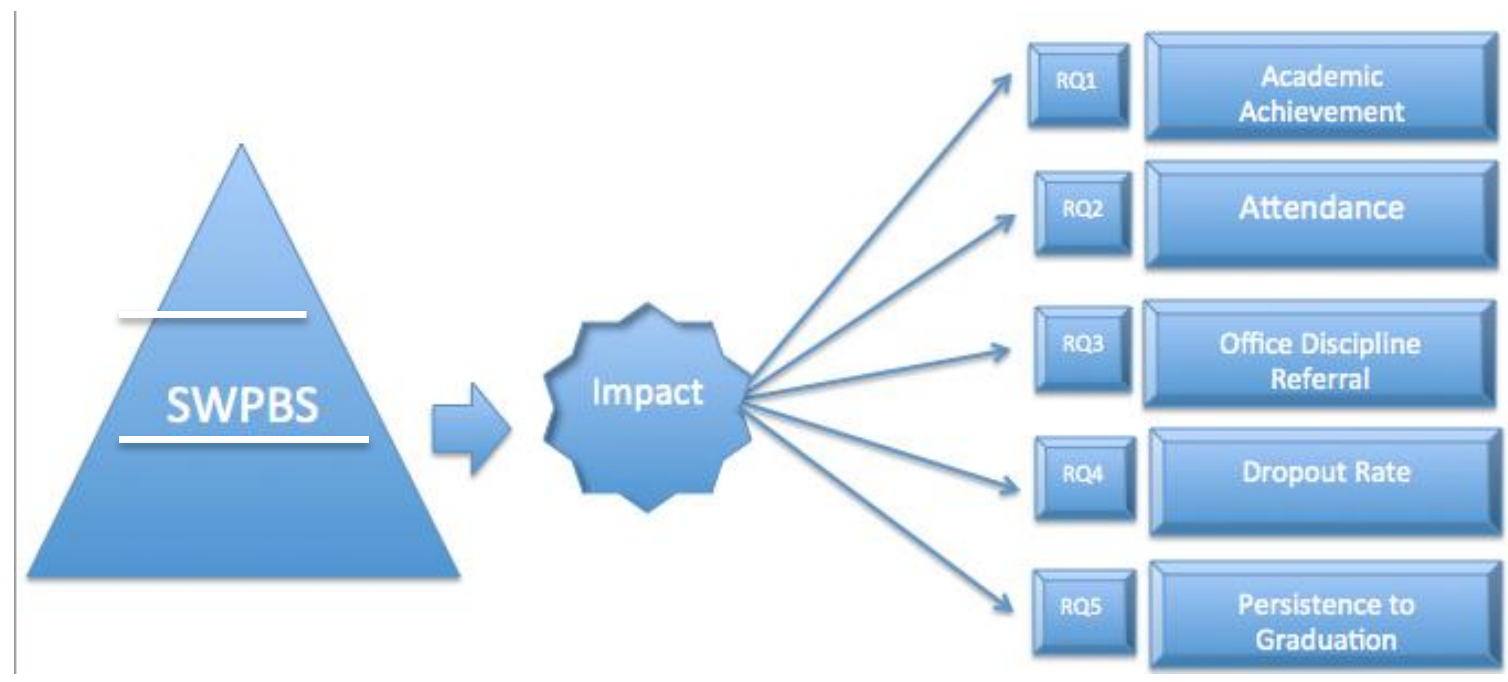

Figure 4.

\section{Population to Be Studied}

The case study population included 1,164 students at a Midwest K-12 alternative public school. The students were Kindergarten through $12^{\text {th }}$ grade, ages five to 18 years old. These students were referred to the K-12 public alternative school by their sending schools located within the boundaries of the local public school district. The sending schools included three high schools, four middle schools, and sixteen elementary schools.

Some students attending the K-12 public alternative school had Individual Education Plans (IEP's) and therefore had a diagnosis of a mental, emotional, and/or 
learning disability. The IEP established an educational plan regarding their disability to meet each student's unique needs to be successful in school. Interval data were collected using the scores between one independent variable and five categorical grouping variables. The independent variable was the SWPBS approach and the dependent variables were academic achievement, attendance, office discipline referrals, dropout rate, and persistence to graduation. The case study population included Kindergarten through $12^{\text {th }}$ grade students, enrolled each year $(2007-08,2008-09,2009-10$, and 201011) at the K-12 alternative public school.

\section{Data Collection and Analysis}

The School-Wide Information System (SWIS) (May et al., 2000) was used to track ODR's per student, per case study year. The ODR's per student, per case study year were extrapolated from The School-Wide Information System (SWIS) (May et al., 2000). The attendance including the types of absences (excused or unexcused) were gathered from the Power School technology and the School Administration Student Information System (SASI). Power School and SASI were the electronic computer technology systems used district-wide for collecting and storing student data. Graduation data were also determined through Power School and SASI technology. Persistence to graduation was the number of students who remained in school, who successfully completed all graduation requirements, and who graduated. A descriptive summary statistics analysis and Chi-square "goodness of fit" test was used as described by Field (2009). The data from these analyses were imported to IBM SPSS (2011) for further examination.

Tables and graphs were used to present the data regarding academic achievement, attendance, discipline referrals, dropout rate, and persistence to graduation. The year 
2007-08, before SWPBS implementation, were presented in graph form. Additional graphs displayed these same dependent variables for the first year SWPBS was first implemented in the 2008-09 school year and also for 2010-11 as a representative year when SWPBS was in full implementation. The graphs with accompanying descriptive information revealed trends over four years.

Specifically, statistical analyses were conducted using five performance factors: academic achievement, attendance, office discipline referrals, dropout rate, and persistence to graduation. Both the independent variable and the dependent variables were nominal. The Chi-square test was used to answer the five research questions. This test of significance method was used when the groups were grouped by characteristics and there was no treatment.

Summary statistics were computed to describe the demographics of gender and ethnicity of the student population at the K-12 alternative public school. In addition, summary statistics were also used for academic achievement to determine the frequency and percentage of passing grades by grade level, by core course, and by each case study year (RQ1). Summary statistics were also used to determine the frequency and percentage of absences by grade level and by case study year (RQ2). Archival data were further analyzed to investigate the frequency and percentage of office discipline referrals by grade level and by case study year (RQ3). In addition, the data were analyzed to determine the frequency and percentage of dropouts by grade level and by case study year (RQ4). And finally, the data were analyzed to find out whether or not there was a difference in the frequency and percentage of graduates for the case study years (RQ5). 


\section{Measurements}

The outcome measurements for this case study were academic achievement, attendance, dropout rate, office discipline referrals, and graduation rates. These five measures were obtained from Power School, SASI, and SWIS retrieved from archival data at the K-12 alternative public school from 2007-08, 2008-09, 2009-10, and 2010-11.

\section{Academic Achievement}

For Kindergarten through $8^{\text {th }}$ grade students, achievement was determined by a passing grade of "C" or higher earned in the core subjects Math and Communication Arts. The data for grades $9^{\text {th }}$ through $12^{\text {th }}$ grades were determined by a "P" for passing grades in the core subjects Math and Communication Arts.

\section{Attendance}

For the purpose of this trend analysis case study the number of absences was calculated for each student, by grade level, and per case study years. Those students who had 10 or more absences in a year were totaled.

\section{Office Discipline Referrals}

At the K-12 alternative public school, ODR's were generated initially from the classroom teacher in response to student behavior. The behavior displayed by the student was determined to be a major or minor infraction, an ODR form was completed that specifically identified the disruptive or inappropriate behavior, and the student was then sent to the office. The administrator determined the appropriate consequence that included a conference with the student, consultation with the parent, and possibly ISS or OSS. A trained, authorized staff member entered the information in SWIS. Overall, ODR's were important data points as they were the validity indicators of problem 
behaviors.

\section{Dropout Rates}

The dropout rate was determined by the number of students who stopped attending this K-12 alternative public school and did not enroll in another school. Once they missed 10 days of school at the K-12 alternative public school they were dropped and were no longer enrolled.

\section{Graduation Rates}

To assess the graduation rates for each academic year 2007-08, 2008-09, 2009-10, and 2010-11, data was gathered from Power School and SASI by the school district data technician. The data indicated the graduates at the end of each spring semester from the four identified school years.

\section{Reliability and Validity}

It was important to ensure the reliability and validity of the measures used in this case study. A strategy addressed in regard to issues of these factors was trustworthiness. Trustworthiness was the standard by which quantitative research was judged. Quantitative research was evaluated by both validity and reliability. Issues of validity, reliability, and generalizability were addressed in accordance with the statistical analyses and subsequent results. Reliability was the consistency of the measurement. Reliability estimated the degree to which an instrument measured the same way each time it was used with the same subjects under the same conditions. According to Mertens (2005) generalizability occurred after the analysis and some conclusions were made about the correlation, and then generalized to another real-life population.

Validity was when a test measured what it set out to measure. Mertens described 
four types of validity in research: conclusion, internal, construct, and external. The following were examples of how validity related to this case study: (a) Conclusion validity asked if there was a relationship between the program and the observed outcome. In this case study, the question was asked: Was there a connection between SWPBS implementation and the five outcome variables? (b) Internal validity asked if there was a relationship between the program and the outcome and if there was a causal relationship. For example, did the implementation of SWBPS cause office discipline referrals to decrease? (c) Construct validity asked if there was a relationship between how the concepts in this case study were operationalized to the actual causal relationship being studied. In other words, did the treatment (SWPBS) reflect the construct of office discipline referrals? Also, did the measured outcome (decrease in ODR's) reflect the construct of student behavior? (d) External validity referred to the ability to generalize the results of this case study to other settings. For example, could the results of this case study regarding ODR's be generalized to other K-12 alternative public schools?

\section{Ethical Considerations}

To maintain compliance with the Family Educational Rights and Privacy Act (FERPA) regulations a memorandum of understanding was submitted to MU IRB by both the researcher and the school district where the K-12 alternative public school was

located. The memorandum related directly to confidentiality. This memo contained three stipulations: (a) the school district blinded the student names prior to giving the data to the doctoral student researcher, (b) the purpose for the data was for use in the doctoral student's dissertation research, and (c) the data was destroyed once the dissertation was completed. 


\section{Limitations}

There were several limitations that were anticipated in this case study. The ability to draw inferential conclusions from the data to a larger group was a limitation, since the case study only involved 1,164 students. Another limitation was generalizability of the data results to another alternative school. This was due not only to the number of students, but also the four-year time frame the K-12 alternative public school used SWPBS. A longitudinal case study was possibly needed.

Finally, a limitation of this study involved researcher bias as described by Creswell (2009). The researcher is employed as the guidance counselor at the K-12 alternative public school being studied and has assigned duties related to SWPBS at the school. As a means to guarantee the researcher was not directly involved in the collection of the SWPBS data, a data technician was assigned by the school district Data Assessment Coordinator with approval from the Superintendent to collect the data. The school district data technician accessed the School Information Computer Systems. Then prior to giving the data to the researcher, the technician removed the student names to safeguard student anonymity. In addition, this process also addressed the issue of researcher bias by not having the researcher collect the data. This ensured researcher bias did not affect the results.

\section{Summary}

A literature review revealed there were no published SWPBS research studies conducted at K-12 alternative public schools. Therefore, one goal of this research was to add to the literature in an area that is lacking. This was achieved through investigating the SWPBS impact and examining its effects, if any, on academic achievement, attendance, 
office discipline referrals, dropout rates, and persistence to graduation at a K-12 alternative public school environment. Using SPSS as a statistical tool, the data was analyzed through Chi-square tests to make these determinations. The remaining Chapters Four and Five, were constructed in such a way that inferences and conclusions were drawn from these analyses. In addition, recommendations and implications were also identified. 


\section{CHAPTER FOUR}

\section{RESULTS AND FINDINGS}

This case study investigated the impact of School-Wide Positive Behavior Support (SWPBS) on five selected student performance factors (academic achievement, attendance, office discipline referrals, dropout rate, and persistence to graduation). The unit of analysis for this case study involved a Missouri K-12 alternative public school. Carr (2002) describes SWPBS as “... an intervention based on social, behavioral,

educational, and biomedical science that combines evidence-based practices with formal systems-change strategies focused on both improving the valued lifestyle options available and reducing problem behaviors" (p. 4). At the K-12 alternative public school a SWPBS three-tiered approach involving all students was designed to improve behavior and academic performance. A SWPBS literature review revealed many research studies regarding traditional public schools, however there were no empirical studies involving SWPBS at K-12 alternative public schools.

Therefore, the purpose of this case study was two-fold: (a) respond to an information gap in the literature, and (b) evaluate whether or not SWPBS strategies decreased the dropout rate and discipline referrals, as well as increased academic performance, attendance, and persistence to graduation at a K-12 alternative public school setting during 2007-08, 2008-09, 2009-10, and 2010-11. This four-year case study involved the entire school population. There was no random sampling.

\section{Case Study Data Organization}

This case study examined how SWPBS impacted five categorical variables at a K-12 alternative public school. The data collection processes, statistical test calculations, 
and statistical analyses were addressed as previously outlined in Chapter Three.

Subsequently, Chapter Four presents the case study data by examining five research questions. The case study data and findings were organized by the sequential order of these questions.

\section{Research Questions}

Within this trend analysis case study, the following research questions were explored:

RQ1 - What were the summary statistics for academic achievement by grade level, by course, and by each study year as measured by the number of passing grades?

RQ2 - What were the summary statistics for attendance by grade level and by study year?

RQ3 - Was there a difference in the number and percent of office discipline referrals by grade level and school years 2007-08, 2008-09, 2009-10, and 2010-11?

RQ4 - Was there a difference in the number and percent of dropouts by grade level for the school years 2007-08, 2008-09, 2009-10, and 2010-11?

RQ5 - Was there a difference in the number and percent of graduates for the school years 2007-08, 2008-09, 2009-10, and 2010-11?

\section{Case Study Population}

Case study population included Kindergarten through $12^{\text {th }}$ grade at-risk students at a Missouri K-12 alternative public school. Some of these students included those who had special needs. These students had diagnoses including mental, emotional, and/or learning disabilities requiring Individual Education Plans (IEP's). The IEP was established as an educational plan for each student regarding these disabilities and 
behavioral/academic needs. In addition, another student group attending the K-12 alternative public school included $7^{\text {th }}$ through $12^{\text {th }}$ graders who had been adjudicated by the juvenile court. These students were court ordered to complete a six-month program at the local county juvenile residential facility and attend the K-12 alternative public school.

The total school population at the K-12 alternative public school enrolled during 2007-08, 2008-09, 2009-10, and 2010-11 was studied. There was no random sampling. There was a total 1,164 students during the four-year case study period. The students included 870 males and 294 females ages five through 19 years old. The ethnicities represented were 942 Caucasian students, 147 African-American students, 70 Hispanic students, and five Indian students. This case study identified both gender and ethnicity as demographic information. Table 7 reveals the levels of ethnic diversity per study year. Table 7

Demographics

\begin{tabular}{lllll}
\hline Ethnic Groups & $2007-08$ & $2008-09$ & $2009-10$ & $2010-11$ \\
\hline African-American & 24 & 33 & 42 & 48 \\
Caucasian & 236 & 271 & 219 & 216 \\
Hispanic & 15 & 16 & 17 & 17 \\
Indian & 2 & 1 & 1 & 1 \\
\hline
\end{tabular}

Analysis of Data

This non-experimental case study examined assertions made by traditional school SWPBS proponents who had shown through various studies that SWPBS positively impacted student academics and behavior. The current case study investigated whether or not these findings were true at one Missouri K-12 alternative public school. Specifically, this case study investigated the categorical variables identified as academic achievement, attendance, office discipline referrals, dropout rates, and persistence to graduation. There 
have not been any published empirical studies regarding the SWPBS impact at K-12 alternative public schools. Consequently, this case study explored the paucity of research literature by analyzing the data using five research questions. These research questions guided the data analyses organizational structure. The data were analyzed using SPSS 20 (SPSS IBM, 2011) as the investigative tool determining the SWPBS impact at the Missouri K-12 alternative public school during a period of four years.

\section{Hypothesis 1 A (Communication Arts)}

Regarding RQ1, the null hypothesis stated there would be no significant difference regarding the number of passing grades by the end of the school years 200708, 2008-09, 2009-10, and 2010-11. In response to RQ1, a Chi-square test was used and the level of statistical significance $p<0.05$ was identified. The results showed that during all four study years $p>0.05$ indicating no relationship was found between SWPBS and the frequency of the Communication Arts passing grades, $X^{2}(4)=5.39, p=0.7991$. Since $0.7991>0.05$ no significance was found.

The Communication Arts (CA) Chi-Square statistics were used to make a determination regarding the null hypothesis. These statistics included the number and percentage of students who received a passing grade ( $\mathrm{C}$ or higher) during the four-year study period 2007-08 through 2010-11 school years. There were 149 (53.79\%) students who received CA passing grades at the K-12 alternative public school during 2007-08. The 2008-09 school year revealed there were 193 (60.12\%) students who received CA passing grades. The 2009-10 CA students who received passing grades were 155 (57.40\%). The CA 2010-11 students who received passing grades were 139 (48.83\%). Table 8 shows the average percentage of students in Communication Arts who received a 
passing grade of $\mathrm{C}$ or higher. The data are presented as between grouped grade levels.

Table 8

Summary Statistics for Communication Arts (CA) Passing Grades (C or Higher) Between Years

\begin{tabular}{lllll}
\hline CA Grades & $\begin{array}{l}2007-08 \\
\text { No SWPBS } \\
(\mathrm{N}=149)\end{array}$ & $\begin{array}{l}2008-09 \\
\text { Emerging } \\
(\mathrm{N}=193)\end{array}$ & $\begin{array}{l}2009-10 \\
\text { Established } \\
(\mathrm{N}=155)\end{array}$ & $\begin{array}{l}2010-11 \\
\text { Fully Implemented } \\
(\mathrm{N}=139)\end{array}$ \\
\hline N Valid & 13 & 13 & 13 & 13 \\
Chi-Square & 2.923 & 3.077 & 6.231 & 13.462 \\
$d f$ & 8 & 10 & 9 & 7 \\
$p$ & 0.93909631 & 0.97955343 & 0.71659470 & 0.6162056 \\
\hline
\end{tabular}

Summary statistics were used to determine the results found in Table 9. First, the numbers of students achieving a CA grade of $\mathrm{C}$ or higher was determined. Then these numbers were changed to percentages. The percentages were split into two groupings where the first group was Kindergarten through $6^{\text {th }}$ grade and second group was $7^{\text {th }}$ through $12^{\text {th }}$ grade. The average percentage of each group is displayed in Table 9.

Table 9

Average Percentages of Students Who Achieved "Passing Grades" (C or Higher)

\begin{tabular}{lllll}
\hline CA Grades & $\begin{array}{l}2007-08 \\
\text { No SWPBS } \\
(\mathrm{N}=149)\end{array}$ & $\begin{array}{l}2008-09 \\
\text { Emerging } \\
(\mathrm{N}=193)\end{array}$ & $\begin{array}{l}2009-10 \\
\text { Established } \\
(\mathrm{N}=155)\end{array}$ & $\begin{array}{l}2010-11 \\
\text { Fully Implemented } \\
(\mathrm{N}=139)\end{array}$ \\
\hline $\mathrm{K}^{\text {th }}{ }^{\text {th }}$ & 4.53 & 3.95 & 2.22 & 2.08 \\
$7^{\text {th }}-8^{\text {th }}$ & 11.36 & 12.04 & 14.07 & 14.22 \\
\hline
\end{tabular}

Elementary Grades $\left(K-6^{\text {th }}\right):$ SWPBS and Communication Arts Average Percentages

Figure 5 below presents a clearer picture of the average percentages shown in Table 9. The graph shows the Elementary Grades $\left(\mathrm{K}-6^{\text {th }}\right)$ and High School $\left(7^{\text {th }}-12^{\text {th }}\right)$ during the four-year case study period. The Elementary Grades revealed there was a 
$0.58 \%$ decrease in the number and percentage of CA students who achieved a passing grade (C or higher) when there was no SWPBS as compared to the second year when SWPBS was emerging. The average percentage of CA students who achieved a passing grade (C or higher) declined another $1.73 \%$ from the second to the third year. An additional $0.14 \%$ decrease occurred the third year to the fourth year when SWPBS was implemented. The Elementary Grade $\left(\mathrm{K}-6^{\text {th }}\right)$ students had a $2.53 \%$ decrease in CA students earning passing grades ( $\mathrm{C}$ or higher) from the first year with no SWPBS to the fourth year when SWPBS was fully implemented. SWPBS did not have a positive impact on the Elementary Grade $\left(\mathrm{K}-6^{\text {th }}\right)$ students in achieving CA passing grades of $\mathrm{C}$ or higher. High School $\left(7^{\text {th }}-12^{\text {th }}\right):$ SWPBS and Communication Arts Percentages

The High School $\left(7^{\text {th }}-12^{\text {th }}\right)$ students achieved a $0.68 \%$ increase in CA passing grades (C or higher) when there was no SWPBS as compared to the second year when SWPBS was emerging. Another increase occurred during the SWPBS established third year when an additional $2.03 \%$ of the $\mathrm{CA}$ students achieved a passing grade $(\mathrm{C}$ or higher). From the third to the fourth year when SWPBS was fully implemented there was a $0.15 \%$ increase in the number and percentage of CA students who achieved passing grades (C or higher). The High School $\left(7^{\text {th }}-12^{\text {th }}\right)$ students had a $2.86 \%$ increase in CA students earning passing grades ( $\mathrm{C}$ or higher) from the first year with no SWPBS to the fourth year when SWPBS was fully implemented. 


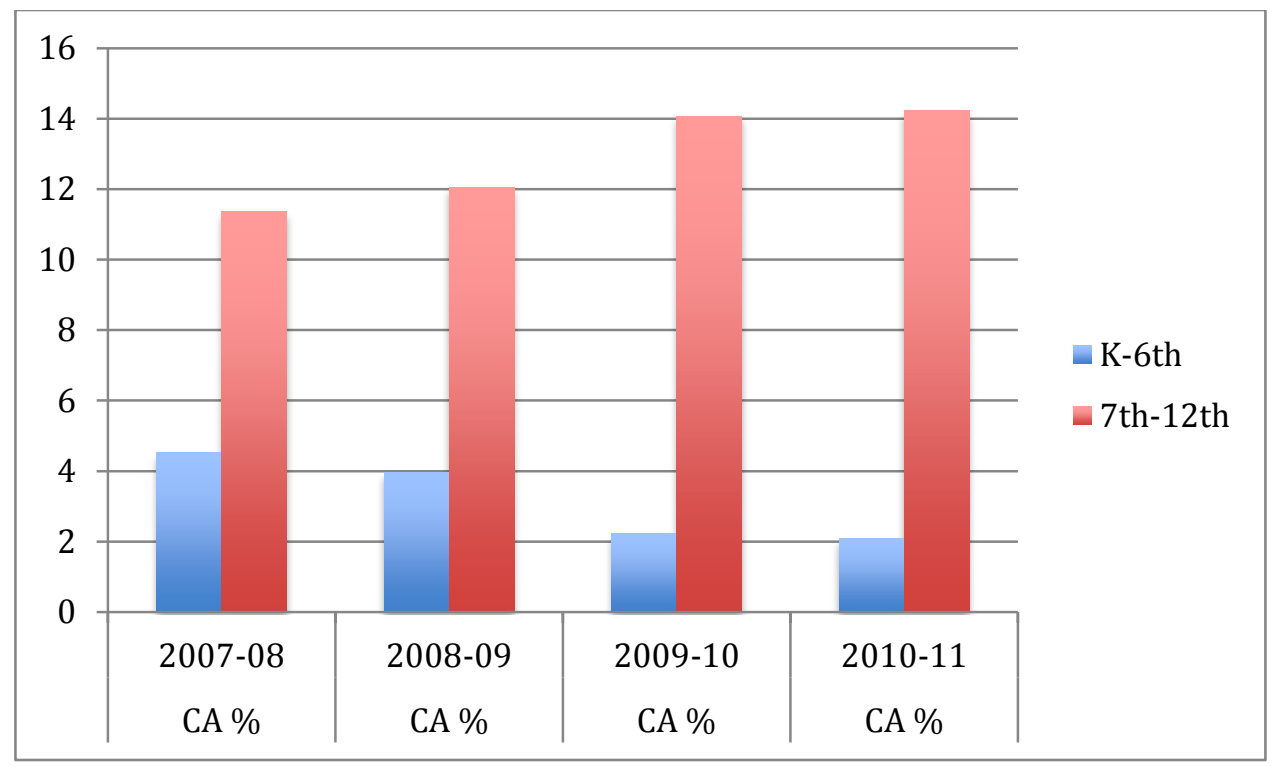

Figure 5.

\section{Hypothesis $1 B$ (Math)}

Regarding RQ1, the null hypothesis stated there would be no significant

difference regarding the number of passing grades by the end of the school years 200708, 2008-09, 2009-10, and 2010-11. In addition to the student's Communication Arts passing grades, Math grades were also investigated at the K-12 alternative public school to examine the null hypothesis. In response to RQ1, a Chi-square test was used and the level of statistical significance $p<0.05$ was identified. The results showed that during all four case study years $p>0.05$ indicating no relationship was found between SWPBS and the frequency of Math passing grades, $X^{2}(4)=5.39, p=0.7991$. Since $0.7991>0.05$ there was no statistical significance.

In addition to the student's Communication Arts passing grades, Math grades were also investigated at the K-12 alternative public school. Table 10 shows the summary statistics regarding the four case study years involving Math passing grades. The 2007-08 
students who received passing MA grades were 113 (40.79\%). The 2008-09 students who received passing MA grades were 162 (50.46\%). The 2009-10 students who received passing MA grades were 137 (50.74\%). The 2010-11 students who received passing MA grades were $145(50.52 \%)$. Table 10 reveals the summary statistics for Math grades $\mathrm{C}$ or higher. During all four case study years $p>0.05$ indicating there was no significance.

Table 10

Summary Statistics for Math "Passing Grades” (C or Higher) Between Years

\begin{tabular}{lllll}
\hline Math Grades & $\begin{array}{l}2007-08 \\
\text { No SWPBS } \\
(\mathrm{N}=113)\end{array}$ & $\begin{array}{l}2008-09 \\
\text { Emerging } \\
(\mathrm{N}=162)\end{array}$ & $\begin{array}{l}2009-10 \\
\text { Established } \\
(\mathrm{N}=137)\end{array}$ & $\begin{array}{l}\text { 2010-11 } \\
\text { Fully Implemented } \\
(\mathrm{N}=145)\end{array}$ \\
\hline N Valid & 13 & 13 & 13 & 13 \\
N Missing & 0 & 0 & 0 & 0 \\
Chi-square & 2.923 & .846 & 3.154 & 4.308 \\
$d f$ & 8 & 11 & 9 & 8 \\
$p$ & 0.93909631 & 0.99997858 & 0.95787488 & 0.82832060 \\
\hline
\end{tabular}

Summary statistics were used to determine the results found in Table 11. First, the numbers of students achieving a Math grade of $\mathrm{C}$ or higher was determined. Then these numbers were changed to percentages. The percentages were split into two groupings where the first group was Kindergarten through $6^{\text {th }}$ grade and second group was $7^{\text {th }}$ through $12^{\text {th }}$ grade. Table 11 shows the average percentage of each group. Table 11

Average Percentages for Math "Passing Grades" (C or Higher) by Grouped Grade Levels

\begin{tabular}{lllll}
\hline Grade Level & $\begin{array}{l}2007-08 \\
\text { No SWPBS } \\
(\mathrm{N}=113)\end{array}$ & $\begin{array}{l}2008-09 \\
\text { Emerging } \\
(\mathrm{N}=162)\end{array}$ & $\begin{array}{l}2009-10 \\
\text { Established } \\
(\mathrm{N}=137)\end{array}$ & $\begin{array}{l}2010-11 \\
\text { Fully Implemented } \\
(\mathrm{N}=145)\end{array}$ \\
\hline${\mathrm{K}-6^{\text {th }}}^{\text {th }}-12^{\text {th }}$ & 2.88 & 2.17 & 1.74 & 1.39 \\
\hline
\end{tabular}


Elementary Grades $\left(K-\sigma^{\text {th }}\right)$ : SWPBS and Average Math Percentages

Figure 6 presents a clearer picture of the average Math percentages shown in Table 11. The graph shows the Elementary Grades $\left(\mathrm{K}-6^{\text {th }}\right)$ and High School Grades $\left(7^{\text {th }}-\right.$ $12^{\text {th }}$ ) during the four-year case study period. The Elementary Grades revealed there was an average $0.71 \%$ decrease in the number and percentage of Math students who achieved a passing grade (C or higher) when there was no SWPBS as compared to the second year when SWPBS was emerging. The average percentage of Math students who achieved a passing grade ( $\mathrm{C}$ or higher) declined each year to the fourth year when SWPBS was implemented. The Elementary Grades $\left(\mathrm{K}-6^{\text {th }}\right)$ had a $1.49 \%$ decrease in Math students earning passing grades (C or higher) from the first year with no SWPBS to the fourth year when SWPBS was fully implemented. SWPBS did not have a positive impact on the Elementary $\left(\mathrm{K}-6^{\text {th }}\right)$ students to achieve a Math passing grade of $\mathrm{C}$ or higher.

High School $\left(7^{\text {th }}-12^{\text {th }}\right)$ : SWPBS and Average Math Percentages

The High School $\left(7^{\text {th }}-12^{\text {th }}\right)$ students achieved an increase of $1.70 \%$ Math students who achieved a passing grade (C or higher) when there was no SWPBS as compared to the second year when SWPBS was emerging. Another increase occurred during the SWPBS established third year when an average percentage of $1.44 \%$ of the Math students achieved a passing grade (C or higher). From the third to the fourth year when SWPBS was fully implemented there was a $0.50 \%$ decrease in the number and percentage of Math students who achieved passing grades ( $\mathrm{C}$ or higher). The High School $\left(7^{\text {th }}-12^{\text {th }}\right)$ Math students had a $2.34 \%$ average increase earning passing grades ( $\mathrm{C}$ or higher) from the first year with no SWPBS to the fourth year when SWPBS was fully implemented. 


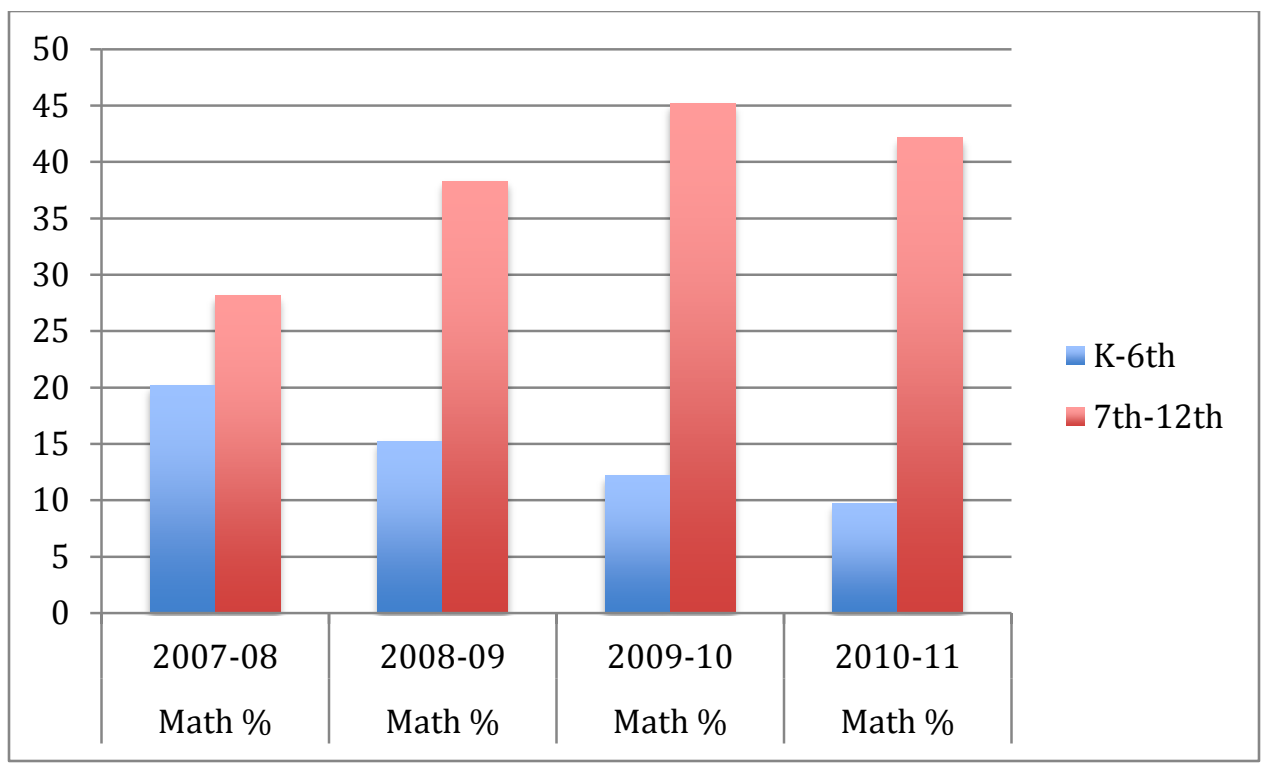

Figure 6 .

\section{Hypothesis 2 (Attendance)}

Regarding RQ2, the null hypothesis stated there would be no significant differences regarding attendance at the K-12 alternative public school during the case study years 2007-08, 2008-09, 2009-10, and 2010-11. In response to RQ2, absences were investigated per grade level and per study year at the K-12 alternative public school. Table 12 shows the summary statistics regarding the four study years involving absences. The 2007-08 students who had 10 or more absences were 102 (36\%). The 2008-09 students who had 10 or more absences were 113 (35\%). The 2009-10 students who received 10 or more absences were 85 (31\%). The 2010-11 students who received 10 or more absences were 112 (39\%). Table 12 revealed the summary statistics for absences. The results showed that during all four case study years $p>0.05$ indicating the results were not significant. 
Table 12

Students with 10 or More Absences Between Years

\begin{tabular}{lllll}
\hline Students Absent & $\begin{array}{l}2007-08 \\
\text { No SWPBS } \\
\mathrm{N}=102\end{array}$ & $\begin{array}{l}2008-09 \\
\text { Emerging } \\
\mathrm{N}=113\end{array}$ & $\begin{array}{l}2009-10 \\
\text { Established } \\
\mathrm{N}=85\end{array}$ & $\begin{array}{l}2010-11 \\
\text { Fully Implemented } \\
\mathrm{N}=112\end{array}$ \\
\hline Student \% & $36 \%$ & $35 \%$ & $31 \%$ & $39 \%$ \\
Chi-square & 3.077 & 3.077 & 3.154 & 3.077 \\
$d f$ & 10 & 10 & 9 & 10 \\
$p$ & 0.9795 & 0.9795 & 0.9578 & 0.9795 \\
\hline
\end{tabular}

In addition to summary statistics for absences as shown in Table 12, more specific information regarding absences was shown in Table 13. Percentages of students who had 10 or more absences by grade level and per year are presented. Summary statistics were used to determine the results found in Table 13. First, the numbers of students achieving 10 or more absences per year was determined. Then these numbers were changed to percentages. The percentages were split into two groupings where the first group was Kindergarten through $6^{\text {th }}$ grade and second group was $7^{\text {th }}$ through $12^{\text {th }}$ grade. The average percentage of each group is displayed in Table 13.

Table 13

Average Percentages for Students with 10 or More Absences By Grouped Grade Levels

\begin{tabular}{lllll}
\hline Grade Level & $\begin{array}{l}2007-08 \\
\text { No SWPBS } \\
(\mathrm{N}=102)\end{array}$ & $\begin{array}{l}2008-09 \\
\text { Emerging } \\
(\mathrm{N}=113)\end{array}$ & $\begin{array}{l}2009-10 \\
\text { Established } \\
(\mathrm{N}=85)\end{array}$ & $\begin{array}{l}2010-11 \\
\text { Fully Implemented } \\
(\mathrm{N}=112)\end{array}$ \\
\hline $\mathrm{K}^{\text {th }}{ }^{\text {th }}$ & 5.04 & 5.55 & 2.71 & 2.46 \\
$7^{\text {th }}-12^{\text {th }}$ & 10.78 & 10.17 & 13.48 & 13.83 \\
\hline
\end{tabular}

Elementary Grades $\left(K-\sigma^{\text {th }}\right):$ SWPBS and Average Percentages of Absences

Student numbers per grade level and per case study year that had 10 or more absences are summarized in Figure 7. There were 102 students during 2007-08 who had 
10 or more absences, 2008-09 had 113 students, 2009-10 had 85 students, and 2010-11 had 112 students. Figure 7 presents a clearer picture of the average percentage of absences shown in Table 13. The graph shows the Elementary Grades $\left(\mathrm{K}-6^{\text {th }}\right)$ and High School $\left(7^{\text {th }}-12^{\text {th }}\right)$ grades during the four-year case study period. The Elementary Grades revealed there was a $0.51 \%$ increase in the average percentage of student absences when there was no SWPBS as compared to the second year when SWPBS was emerging. The average percentage of students who achieved 10 or more absences decreased $2.84 \%$ from the second year to the third year. During the fourth year when SWPBS was implemented there was an additional $0.25 \%$ average decrease in absences. The Elementary Grade (K$6^{\text {th }}$ ) students had a $2.58 \%$ decrease in absences ( 10 or more) from the first year with no SWPBS to the fourth year when SWPBS was fully implemented. SWPBS did not have a positive impact on the Elementary Grade $\left(\mathrm{K}-6^{\text {th }}\right)$ students to achieve less than 10 or more absences in a year.

High School $\left(7^{\text {th }}-12^{\text {th }}\right)$ : SWPBS and Average Percentages of Absences

The High School $\left(7^{\text {th }}-12^{\text {th }}\right)$ students had an average decrease of $0.61 \%$ students (10 or more absences) when there was no SWPBS as compared to the second year when SWPBS was emerging. An average 3.31\% increase in absences occurred among the high school students during the SWPBS established third year. From the third to the fourth year when SWPBS was fully implemented there was an average $0.85 \%$ increase in the number and percentage of students who had 10 or more absences. The High School $\left(7^{\text {th }}-12^{\text {th }}\right)$ students had an average $3.05 \%$ increase in absences ( 10 or more) during the first year with no SWPBS as compared to the fourth year when SWPBS was fully implemented. Overall, SWPBS did not have a positive impact on absences regarding the 
High School $\left(7^{\text {th }}-12^{\text {th }}\right)$ students during the four case study years. This is further revealed in Figure 7.

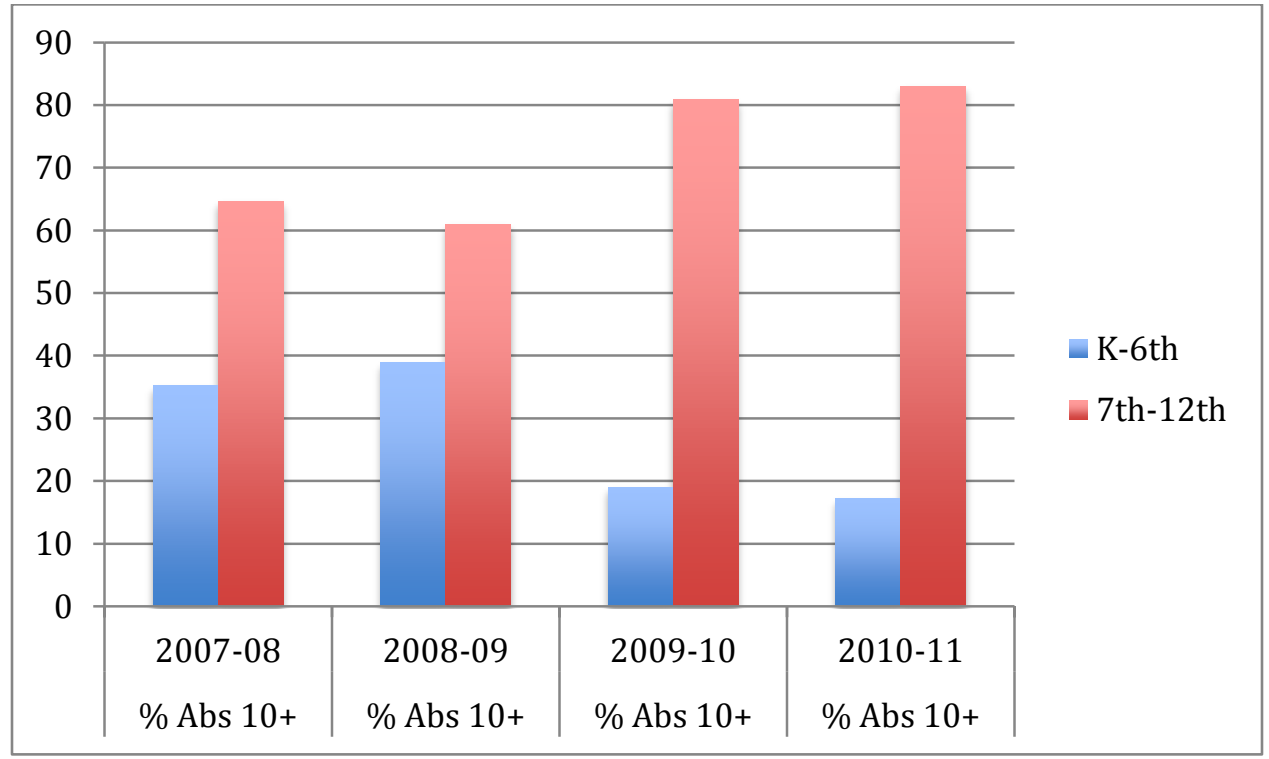

Figure 7.

\section{Hypothesis 3 (Office Discipline Referrals)}

Regarding RQ 3, the null hypothesis stated there would be no significant differences involving the number of office discipline referrals by the end of the identified school years 2007-08, 2008-09, 2009-10, and 2010-11. The office discipline referrals (ODR's) summary statistics included the number and percentage of ODR's during the four-year case study period 2007-08 through 2010-11 school years. A Chi-square test was used as the statistical analysis and the level of significance $p<0.05$ was identified. Table 14 revealed the office discipline referrals summary statistics. The results showed that during all four case study years $p>0.05$ indicating no significance.

There were 620 (42.93\%) office discipline referrals at the K-12 alternative public school during 2007-08. The 2008-09 school year revealed there were 727 (52.34\%) office 
discipline referrals. The 2009-10 school year revealed 797 (75.84\%) office discipline referrals. During the 2010-11 school year there were 561 (61.69\%) office discipline referrals.

Table 14

Summary Statistics for Office Discipline Referrals Between Years

\begin{tabular}{|c|c|c|c|c|}
\hline ODR's & $\begin{array}{l}2007-08 \\
\text { No SWPBS } \\
(\mathrm{N}=620)\end{array}$ & $\begin{array}{l}2008-09 \\
\text { Emerging } \\
(\mathrm{N}=727)\end{array}$ & $\begin{array}{l}2009-10 \\
\text { Established } \\
(\mathrm{N}=797)\end{array}$ & $\begin{array}{l}2010-11 \\
\text { Fully Implemented } \\
(\mathrm{N}=561)\end{array}$ \\
\hline $\mathrm{N}$ Valid & 13 & 13 & 13 & 13 \\
\hline N Missing & 0 & 0 & 0 & 0 \\
\hline Chi-square & .000 & .000 & .846 & .000 \\
\hline$d f$ & 12 & 12 & 11 & 12 \\
\hline$p$ & 1 & 1 & 0.9999 & 1 \\
\hline
\end{tabular}

In addition to summary statistics for office discipline referrals as shown in Table 14, more specific information regarding ODR's are shown in Table 15. Percentages of office discipline referrals by grade level and per case study year are presented. Summary statistics were used to determine the results found in Table 15. First, the numbers of office discipline referrals (ODR's) received per grade per year were determined. Then these numbers were changed to percentages. The percentages were split into two groupings where the first group was Kindergarten through $6^{\text {th }}$ grade and second group was $7^{\text {th }}$ through $12^{\text {th }}$ grade. Table 15 shows the average percentage of each group. 
Table 15

Average Percentage of Office Discipline Referrals Between Grouped Grade Levels

\begin{tabular}{lllll}
\hline Grade Level & $\begin{array}{l}2007-08 \\
\text { No SWPBS } \\
(\mathrm{N}=620)\end{array}$ & $\begin{array}{l}2008-09 \\
\text { Emerging } \\
(\mathrm{N}=727)\end{array}$ & $\begin{array}{l}2009-10 \\
\text { Established } \\
(\mathrm{N}=797)\end{array}$ & $\begin{array}{l}2010-11 \\
\text { Fully Implemented } \\
(\mathrm{N}=561)\end{array}$ \\
\hline $\mathrm{K}-6^{\text {th }}$ & 3.72 & 5.32 & 7.95 & 7.17 \\
$7^{\text {th }}-12^{\text {th }}$ & 2.80 & 2.51 & 3.36 & 1.90 \\
\hline
\end{tabular}

Elementary Grades $\left(K-6^{\text {th }}\right)$ : SWPBS and Average Percentages of Office Discipline Referrals (ODR's)

Additional detail about results in Table 15 are reflected in Figure 8. Student numbers per grade level and per case study year that had 10 or more absences per year were indicated. There were 620 ODR's during 2007-08, 727 ODR's during 2008-09, 797 ODR's during 2009-10, and 561 ODR's during 2010-11. Figure 8 shows the Elementary Grades $\left(\mathrm{K}-6^{\text {th }}\right)$ and High School $\left(7^{\text {th }}-12^{\text {th }}\right)$ grades during the four-year case study period. The Elementary Grades results revealed there was an average $1.60 \%$ increase in the number and percentage of ODR's when there was no SWPBS as compared to the second year when SWPBS was emerging. The average percentage of ODR's increased $2.63 \%$ during the SWPBS emerging year. The third year there was an average $0.78 \%$ decrease during the fourth year when SWPBS was implemented. The Elementary Grades $\left(K-6^{\text {th }}\right)$ had an average $3.45 \%$ increase in ODR's from the first year with no SWPBS to the fourth year when SWPBS was fully implemented. SWPBS did not have a positive impact regarding the number of ODR's received in the Elementary Grades $\left(\mathrm{K}-6^{\text {th }}\right)$.

High School ( $\left.7^{\text {th }}-12^{\text {th }}\right)$ : SWPBS and Office Discipline Referrals

Regarding the High School $\left(7^{\text {th }}-12^{\text {th }}\right)$ students there was an average $0.29 \%$ decrease in ODR's when there was no SWPBS as compared to the second year when 
SWPBS was emerging. The second year to the third year there was an average $0.85 \%$ increase in ODR's. An average 1.46\% decrease in ODR's occurred among the high school students from the third to the fourth year when SWPBS was fully implemented. The High School $\left(7^{\text {th }}-12^{\text {th }}\right)$ students had a $0.9 \%$ increase in ODR's during the first year with no SWPBS as compared to the fourth year when SWPBS was fully implemented. Overall, SWPBS did not have a positive impact on ODR's regarding the High School $\left(7^{\text {th }}-12^{\text {th }}\right)$ students during the four case study years. This is further revealed in Figure 8.

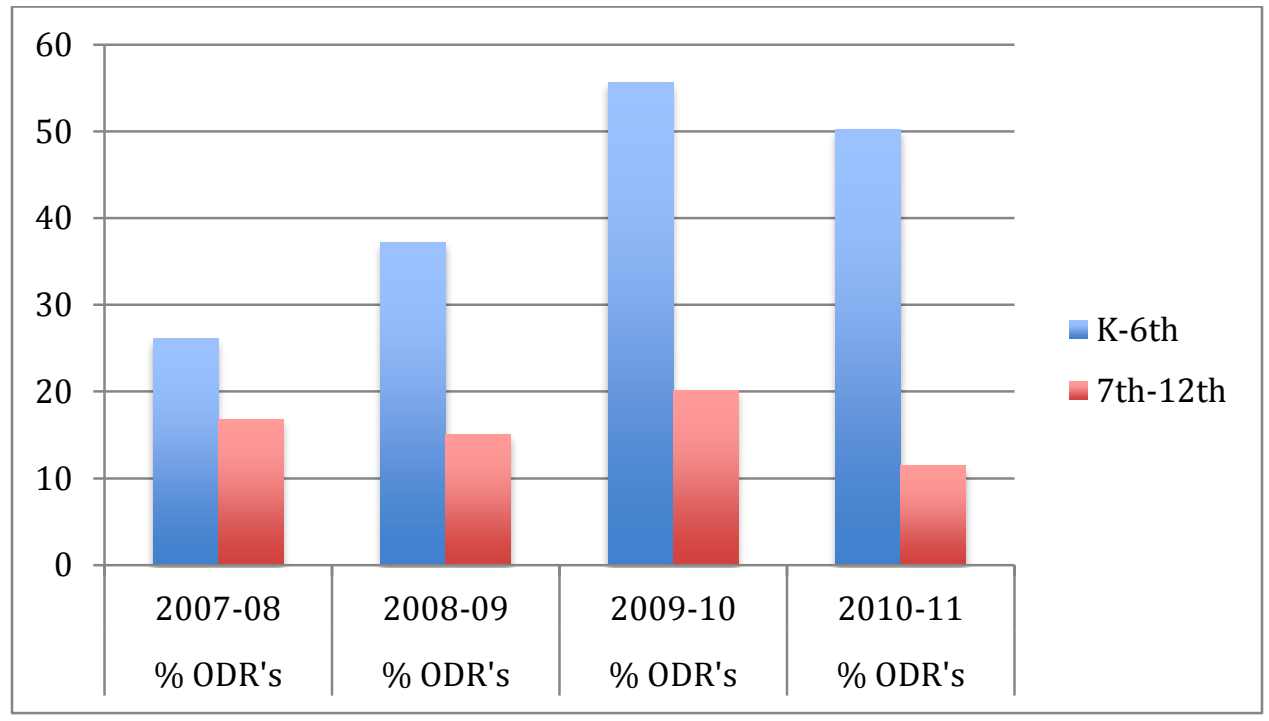

\section{Figure 8.}

\section{Hypothesis 4 (Dropouts)}

Regarding RQ4, the null hypothesis stated there would be no significant difference involving the number and percent of dropouts by grade level regarding the school years 2007-08, 2008-09, 2009-10, and 2010-11. A Chi-square test was conducted regarding the dropout rate involving the four study years. Since $p>0.05$ there was no statistical significance found regarding SWPBS and the dropout rate.

Table 16 shows the dropouts by number, by grade levels $9^{\text {th }}$ through $12^{\text {th }}$ grades, 
and by the identified case study years. The 2007-08 school year revealed there were 277 total students and 102 (36.82\%) dropouts. The 2008-09 school year revealed there were 321 total students and 49 dropouts indicating a $15.26 \%$ dropout rate. The $2009-10$ school year revealed there were 270 students and no dropouts due to administrative decisions. As a result, the zero dropout percentage during 2009-10 skewed the data. Finally, the 2010-11 school year revealed there were 287 total students and 69 dropouts indicating a $24.04 \%$ dropout rate.

Table 16

Summary Statistics for Students Who Dropped Out $\left(9^{\text {th }}-12^{\text {th }}\right)$ Between Years

\begin{tabular}{lllll}
\hline Dropouts & $2007-08$ & $2008-09$ & $2009-10$ & $2010-11$ \\
& No SWPBS & Emerging & Established & Fully Implemented \\
& $(\mathrm{N}=102)$ & $(\mathrm{N}=49)$ & $(\mathrm{N}=0)$ & $(\mathrm{N}=69)$ \\
N Valid & 4 & 4 & - & 4 \\
Chi-square & .000 & .000 & - & .000 \\
Dropout $\%$ & $36.82 \%$ & $15.26 \%$ & - & $24.04 \%$ \\
$d f$ & 3 & 3 & - & 3 \\
$p$ & 1 & 1 & - & 1 \\
\hline
\end{tabular}

In addition to summary statistics for dropouts as shown in Table 16, more specific information regarding dropouts are shown in Table 17. Percentages of the number of students who dropped out by grade level and per case study year are presented. Summary statistics were used to determine the results found in Table 17. First, the numbers of dropouts received per grade level and per year was determined. Then these numbers were changed to percentages. The average percentage of each group is displayed in Table 17. 
Table 17

Percentage of Dropouts Between Grade Levels $\left(9^{\text {th }}-12^{\text {th }}\right)$

\begin{tabular}{lllll}
\hline Grade Level & $\begin{array}{l}2007-08 \\
\text { No SWPBS } \\
(\mathrm{N}=102)\end{array}$ & $\begin{array}{l}2008-09 \\
\text { Emerging } \\
(\mathrm{N}=49)\end{array}$ & $\begin{array}{l}2009-10 \\
\text { Established } \\
(\mathrm{N}=0)\end{array}$ & $\begin{array}{l}2010-11 \\
\text { Fully Implemented } \\
(\mathrm{N}=69)\end{array}$ \\
\hline $9^{\text {th }}$ & 3.61 & 1.86 & 0 & 1.74 \\
$10^{\text {th }}$ & 7.58 & 2.80 & 0 & 2.96 \\
$11^{\text {th }}$ & 10.10 & 4.98 & 0 & 7.03 \\
$12^{\text {th }}$ & 15.52 & 5.60 & 0 & 13.33 \\
\hline
\end{tabular}

High School $\left(9^{\text {th }}-12^{\text {th }}\right)$ : SWPBS and Average Percentage of Dropouts

In addition to the results in Table 17, these same results are shown in Figure 9. Student numbers and percentages of dropouts per grade level and per case study year were indicated. There were 102 (36.81\%) dropouts during 2007-08, 49 (15.24\%) during 2008-09, there were zero dropouts during 2009-10, and 69 (25.06\%) during 2010-11.

Figure 9 presents additional details about the percentage of dropouts shown in Table 17. The graph shows the High School $\left(9^{\text {th }}-12^{\text {th }}\right)$ dropouts during the four-year case study period. The High School dropout results revealed there was an average 5.39\% decrease in the number and percentage of dropouts when there was no SWPBS as compared to the second year when SWPBS was emerging. There were no dropouts during the third year when SWPBS was established. The percentage of dropouts decreased $3.47 \%$ during the fourth year when SWPBS was implemented. The High School $\left(9^{\text {th }}-12^{\text {th }}\right)$ students had an average $1.92 \%$ decrease in dropouts from the first year with no SWPBS to the fourth year when SWPBS was fully implemented. SWPBS did not have a positive impact on the number of dropouts received at the High School $\left(7^{\text {th }}-12^{\text {th }}\right)$ level. This is further revealed in Figure 9. 


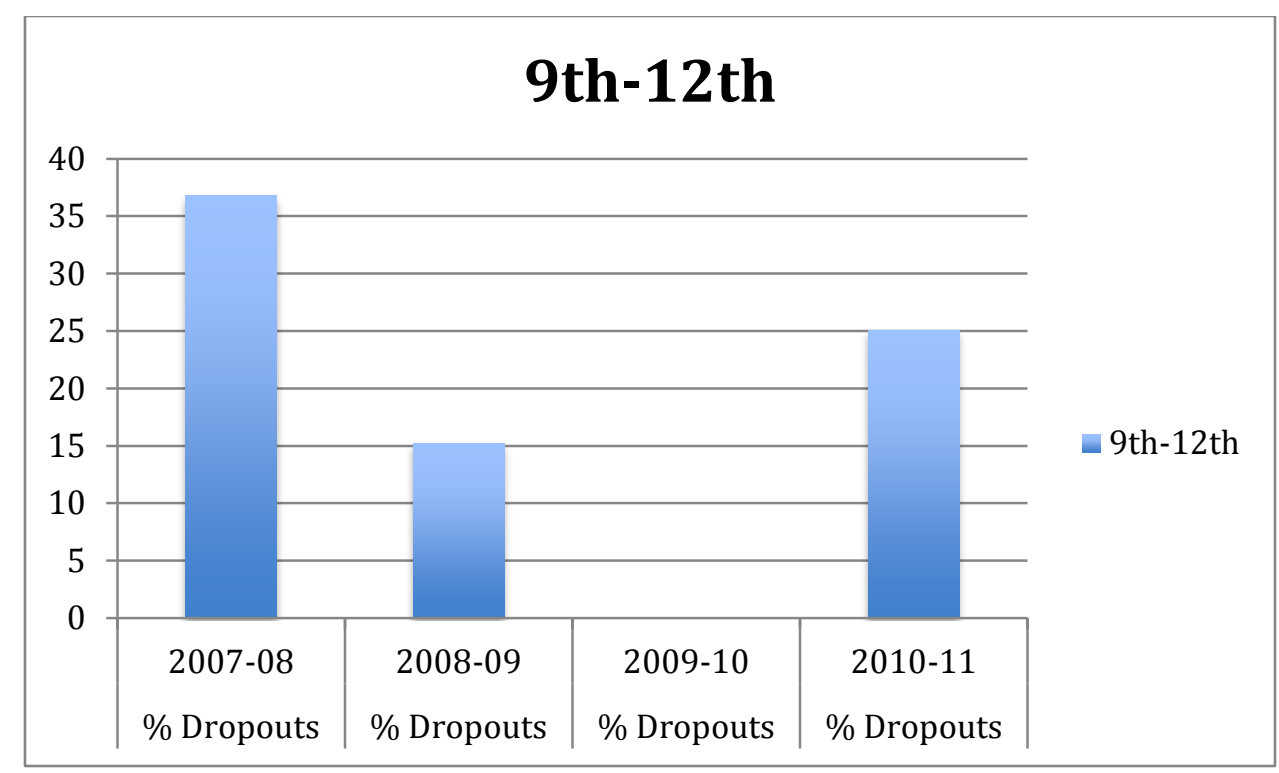

Figure 9.

\section{Hypothesis 5 (Graduates)}

Regarding RQ5, the null hypothesis stated there would be no significant

difference in the number and percent of graduates during the identified study years 200708, 2008-09, 2009-10, and 2010-11. Table 18 shows the graduates by number and percent, the total seniors each year, and the identified four case study years. A Chi-square test was used and the results indicated the Chi-square value was 12.00 based upon 9 degrees of freedom and was not significant since $p=0.2133$. There was not a significant association between the number of graduates receiving SWPBS strategies and those who did not receive SWPBS strategies $X^{2}(4)=12.00, p>.05$. The 2007-08 school year revealed (Table 18) there were 100 total $12^{\text {th }}$ grade students and 42 graduates. This represents a $42.00 \%$ graduation rate. During the 2008-09 school year there were 73 students total and 25 who graduated representing a $34.24 \%$ graduation rate. The $2009-10$ school year revealed there were 64 total $12^{\text {th }}$ grade students and 27 graduates indicating a 
$42.18 \%$ graduation rate. Finally, the $2010-11$ school year revealed there were 133 graduating students and 53 graduates indicating a $39.84 \%$ graduation rate. The percentage rates per year were calculated by dividing the number of students graduating by the number of students in the graduating class. Table 18 shows the summary statistics for students who graduated each case study year.

Table 18

Summary Statistics for Students Who Graduated $\left(12^{\text {th }}\right.$ Grade) Per Year

\begin{tabular}{lllll}
\hline Graduates & $2007-08$ & $2008-09$ & $2009-10$ & $2010-11$ \\
& No SWPBS & Emerging & Established & Fully Implemented \\
Seniors & $(\mathrm{N}=100)$ & $(\mathrm{N}=73)$ & $(\mathrm{N}=64)$ & $(\mathrm{N}=133)$ \\
\% Grads & $42.00 \%$ & $34.24 \%$ & $42.18 \%$ & $39.84 \%$ \\
\hline
\end{tabular}

High School $\left(12^{\text {th }}\right)$ : SWPBS and Percentage of Graduates

In addition to Table 18 , the $12^{\text {th }}$ grade total student numbers and the graduate numbers during the four case study years are presented in Figure 10. Student numbers and percentages of graduates per grade level and per case study year were indicated. There were 42 (42\%) graduates during 2007-08, 25 (34.24\%) graduates during 2008-09, 27 (42.18\%) graduates during 2009-10, and 53 (39.84\%) graduates during 2010-11. The graph (Figure 9) presents a clearer picture of the percentage of graduates shown in Table 18. The graph shows the High School graduates during the four-year case study period. The High School results revealed there was a 7.76\% decrease in the number and percentage of graduates when there was no SWPBS as compared to the second year when SWPBS was emerging. A 7.94\% graduate increase occurred when comparing the second year SWPBS emerging to the third year when SWPBS was established. The percentage of graduates decreased $2.34 \%$ the fourth year when SWPBS was implemented. The High School had a $2.16 \%$ decrease in graduates from the first year with no SWPBS to the 
fourth year when SWPBS was fully implemented. SWPBS did not have a positive impact on the number of graduates at the High School level. This is further revealed in Figure 10 that shows the number of graduates and the total number of $12^{\text {th }}$ grade students.

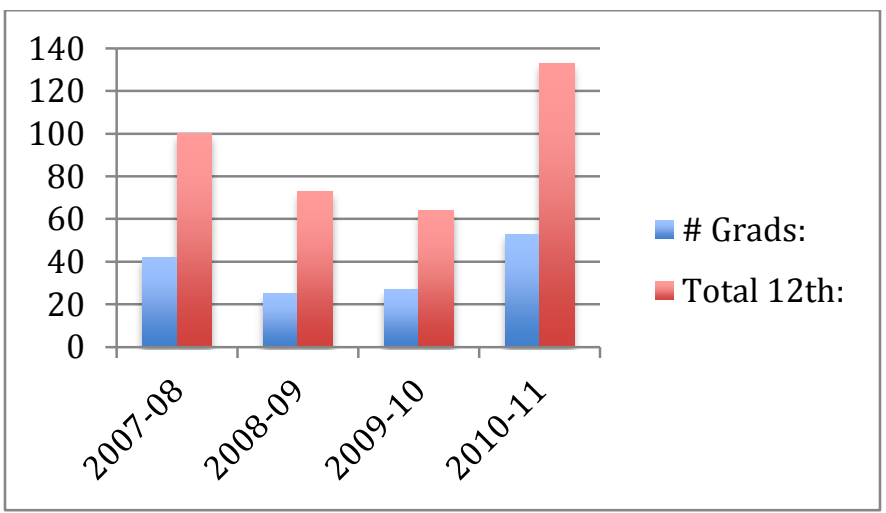

Figure 10.

A more specific graph as shown in Figure 11 reveals the percentage of students who graduated per year. This graph reveals the percentage of students who graduated in each of the case study years. During 2007-08 the graduates were 42\%, 2008-09 there were $34.24 \%$ graduates, $2009-10$ there were $42.18 \%$ graduates and $2010-11$ there were $39.84 \%$ graduates.

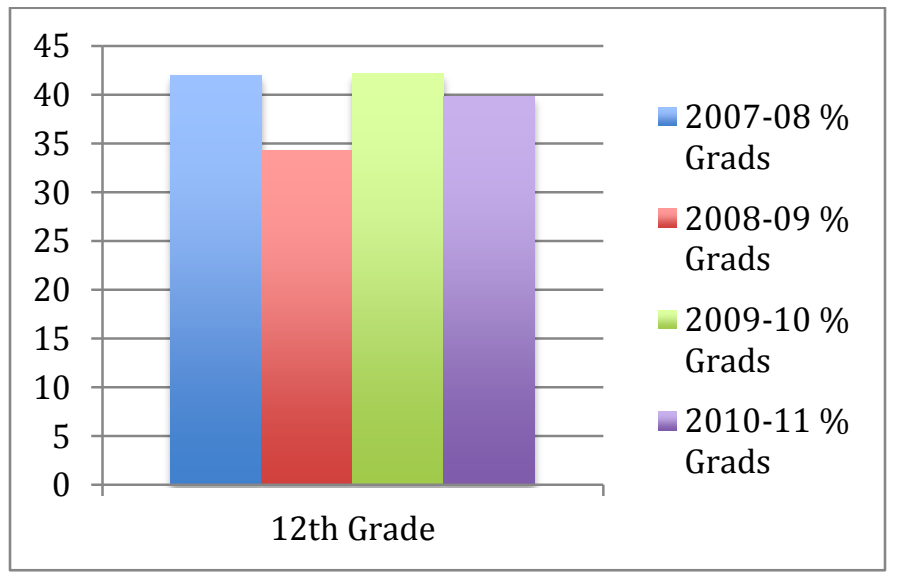

Figure 11 . 


\section{Summary and Conclusion of Data Analysis}

This case study examined the five categorical variables academic achievement, attendance, office discipline referrals, dropout rate, and persistence to graduation. The statistical analyses presented involved the five null hypotheses posed at the beginning of this case study. The data analyses followed the order of the research questions. A Chisquare test was run on each of the five variables and results yielded a $p$ value greater than the identified 0.05 level. In response to each of the five research questions the statistical results revealed no significant differences were found regarding the five categorical variables and SWPBS.

\section{Summary}

Chapter Four provided the data analyses for this case study. The findings were the result of a case study using School-Wide Positive Behavior Supports (SWPBS) at a Missouri K-12 alternative public school. Historical data were retrieved from the school district data archives. The SWPBS impact on academic achievement, attendance, office discipline referrals, dropout rates, and persistence to graduation were investigated. Quantitative data were collected from three School Information Systems (SIS) including SASI, Power School, and SWIS regarding the school years 2007-08, 2008-09, 2009-10, and 2010-11. Summary statistics were provided for each research question and included the number and percentages for the five variables per grade level per case study year. The research questions were answered using the Chi-square statistical results to accept or reject the null hypotheses regarding the categorical variables academic achievement, attendance, office discipline referrals, dropout rate, and persistence to graduation. There were no statistically significant differences found regarding the five variables when 
SWPBS was used as compared to when SWPBS was not used. Chapter Five will provide conclusions, discussion, and implications for future research and practices. 


\section{CHAPTER FIVE}

\section{DISCUSSION}

\section{Introduction}

The purpose of this case study was to determine the progressive SWPBS impact on five selected student performance factors at a Missouri K-12 alternative public school. As the school counselor at the K-12 alternative public school I observed other methods used to positively affect student academic achievement and behavior, however these approaches were not maintained for various reasons. When SWPBS was selected for use at the K-12 alternative public school the staff and administrators participated in professional development regarding SWPBS. An important concept learned was SWPBS was not a program started all at once. Instead, SWPBS was a very methodical process completed over time from the emerging stage to full implementation.

This case study was needed to determine the effectiveness of SWPBS at the K-12 alternative public school. By investigating SWPBS impact on academic achievement, attendance, office discipline referrals, dropouts, and persistence to graduation, the case study findings add to the current gap in the literature. The results of this case study will assist administrators and other stakeholders in assessing SWPBS success and to what extent behavioral and academic achievement occurred at the K-12 alternative public school. This knowledge will help determine the future of SWPBS at the K-12 alternative public school as well as inform school personnel of any policy or SWPBS implementation changes.

The remainder of Chapter Five will focus on the SWPBS results. Chapter Five will present a case study overview and also include a discussion of the findings, 
conclusions, and implications. The chapter concludes with recommendations regarding future research/practice, and a summary.

\section{Overview of the Case Study}

Maintaining students in school with the expectation they will succeed academically, attend regularly with minimal or no behavioral incidents, and also persist to graduation is a daunting task for K-12 educators and administrators. As the professional school counselor at the K-12 alternative public school the difficulty with achieving these expectations has been directly observed. With the enactment of the No Child Left Behind (NCLB) Act of 2001, schools were charged with finding ways to provide positive school climates and increase positive student success both academically and behaviorally (McNeil, 2011). One approach that has been chosen by many school administrators is School-Wide Positive Behavior Support (SWPBS). This current case study has focused specifically on one Missouri K-12 alternative public school that chose to implement SWPBS to increase student academic and behavioral success. SWPBS has been investigated in traditional public schools, however there have not been any empirical studies investigating SWPBS at K-12 alternative public schools. This gap in the literature is revealed further in the next section regarding the SWPBS literature review.

\section{Review of Literature}

A literature review revealed SWPBS at traditional public schools has positively impacted academic achievement (Cooper, 2011); attendance (Townsend, 2011); office discipline referrals (Dunlap, Carr, Horner, Zarcone, \& Schwartz, 2009); dropout rates (Townsend, 2011); and persistence to graduation, (Balfanz, 2011). However, the literature review revealed there have not been any published empirical studies regarding 
SWPBS impact at alternative public schools (Simonsen, Britton, \& Young, 2010). This case study addressed this gap in the literature by investigating SWPBS impact regarding five selected performance factors at an alternative public school. The next section explains the statistical analysis process used to investigate the SWPBS impact on the five selected performance factors.

\section{Review of Methods}

This case study involved a Missouri K-12 alternative public school during the years 2007-08, 2008-09, 2009-10, and 2010-11. Archival data were retrieved from the public school district where the K-12 alternative public school is located. A school district data technician exported the archival data that included every student (K-12) encompassing the identified case study years. The student names were removed by the data technician thereby ensuring confidentiality and student anonymity. The data were then scrubbed and transferred to Excel worksheets by the researcher. The research methodology included descriptive statistics, and student frequencies and percentages were by grade level and per case study year.

Five research questions were answered by using quantitative data that were run through SPSS 20 (SPSS IBM, 2011) using a Chi-square "goodness of fit" statistical analysis (Field, 2009). The test results revealed no significant differences among groups regarding the five categorical variables. Although there were no significant statistical differences, this does not mean the SWPBS impact on the categorical variables had no meaning. The Chi-square finding of no significance only means a relationship did not exist statistically (Faherty, 2008). As a result, the meaning of this relationship, even though it was not statistically significant, has relevance to the outcomes of this case study 
and is explained in the discussion of findings.

\section{Discussion of Findings}

The findings of the statistical analyses illustrated there were no significant differences related to each of the five performance factors. None of the five hypotheses were supported such as the relationship between attendance rates when SWPBS was implemented versus attendance rates when SWPBS was not used. This finding remained consistent among the other four stated performance factors, academic achievement, office discipline referrals, dropout rate, and persistence to graduation. Specifically, the relationship between a performance factor "with" SWPBS and "without" SWPBS, there were no significant differences. Each performance factor was hypothesized to be positive indicating SWPBS implementation would make a significant impact on academic achievement, attendance, office discipline referrals, dropout rate, and persistence to graduation. The assumption of these hypotheses was SWPBS implementation would increase the academic achievement, attendance, and the graduation rates and in addition would decrease the number of office discipline referrals and dropouts. However, this was not found in this case study. Instead, the findings suggested SWPBS implementation did not have a significant impact on the five variables using this dataset. It is this researcher's opinion, based upon observations at the K-12 alternative public school, these findings could be explained by a lack of staff "buy-in", staff turnover, and the transient nature of the student population. These factors could directly affect SWPBS implementation, however would require another study to further investigate these explanations.

The K-12 alternative public school implemented SWPBS as a proactive approach to school safety by developing comprehensive strategies that promoted positive behavior. 
Examination of the findings were based upon the overarching question: Does SWPBS implementation increase academic achievement, attendance and graduation rate as well as decrease the number of office discipline referrals and dropouts? The five research questions guiding this case study are restated and the discussion of findings are based upon the SWPBS literature review found previously in Chapter Two and also the statistical analyses results identified in Chapter Four.

\section{Academic Achievement: SWPBS and Statistical Findings}

RQ1 - What are the summary statistics for academic achievement by grade level, by course, and by each study year as measured by the number of passing grades? Regarding RQ1, the null hypothesis stated there would be no significant difference regarding the number of passing grades by the end of the school years 2007-08, 2008-09, 2009-10, and 2010-11. In response to RQ1, a Chi-square test was used as the statistical analysis. The findings showed no relationship between SWPBS and the average percentage of the Communication Arts and Math passing grades ( $\mathrm{C}$ or higher) during the four-year case study.

Although the results were not statistically significant, there were additional important findings when looking specifically at the differences between the Elementary Grade $\left(\mathrm{K}-6^{\text {th }}\right)$ student's passing grades and the High School $\left(7^{\text {th }}-12^{\text {th }}\right)$ student's passing grades. The results revealed that during the four-year case study, the CA and Math passing grades steadily declined for the Elementary Grade $\left(\mathrm{K}-6^{\text {th }}\right)$ students and gradually increased regarding the High School $\left(7^{\text {th }}-12^{\text {th }}\right)$ students. In addition, a comparison of the first year without SWPBS as compared to the fourth year SWPBS full implementation, the findings revealed the Elementary Grade $\left(\mathrm{K}-\mathrm{t}^{\text {th }}\right)$ students had an average $2.53 \%$ 
decrease in CA passing grades and an average $1.49 \%$ decrease in Math passing grades. SWPBS did not have a positive impact on the Elementary Grade $\left(\mathrm{K}-6^{\text {th }}\right)$ students in achieving CA passing grades of $\mathrm{C}$ or higher.

In looking at the High School $\left(7^{\text {th }}-12^{\text {th }}\right)$ students, a further comparison of the first year without SWPBS as compared to the fourth year SWPBS full implementation, the findings revealed these students had an average $2.86 \%$ increase in CA passing grades and an average $2.34 \%$ increase in Math passing grades. Although not statistically significant, the average percentages revealed SWPBS was more successful with the High School $\left(7^{\text {th }}-\right.$ $\left.12^{\text {th }}\right)$ students than the Elementary Grade $\left(\mathrm{K}-6^{\text {th }}\right)$ students at achieving passing CA and Math grades of $\mathrm{C}$ or higher.

The statistical analysis findings of this case study have been presented in regard to academic achievement. In addition to the statistical analysis findings, it is also important to discuss the findings in conjunction with the SWPBS literature. This discussion will further explore the relevance of SWPBS findings in this case study with those found in the current literature regarding academic achievement.

\section{Academic Achievement: SWPBS and Findings in the Literature}

A literature review revealed increased attendance occurred following SWPBS implementation (Cregor, 2009; Townsend, 2011). However, the current case study results revealed there was no significant difference found during the four case study years in regard to academic achievement at the K-12 alternative public school studied. Research literature revealed SWPBS implementation increased academic achievement (Algozzine, Wang, \& Violette, 2011). These same results were also found to be true throughout this four-year case study involving the Math students. During the first year (2007-08) when 
there was no SWPBS implementation, the Math students achieved the most passing grades during the fourth year (2010-11) when SWPBS was fully implemented. The lowest number of achieved Math grades occurred during the year when there was no SWPBS.

This same outcome was not found to be true throughout the four years at the K-12 alternative public school regarding the Communication Arts (CA) students. Instead, the frequency and percentage of CA students achieved more passing grades during the first year (2007-08) when there was no SWPBS than when SWPBS was fully implemented the fourth year (2010-11). Consequently, these findings were not corroborated by current literature.

\section{Attendance: SWPBS and Statistical Findings}

RQ2 - What are the summary statistics for attendance by grade level and by study year? Regarding RQ2, the null hypothesis stated there would be no significant differences regarding attendance at the K-12 alternative public school during the case study years 2007-08, 2008-09, 2009-10, and 2010-11. In response to RQ2, absences were investigated per grade level and per study year at the K-12 alternative public school. Absences were calculated for each student that acquired 10 or more absences per year. A Chi-square test was used as the statistical analysis and the findings revealed that during the four case study years no relationship was found between SWPBS and the average percentage of absences.

Although the results were not statistically significant, there were additional important findings when looking specifically at the differences between the Elementary Grade $\left(\mathrm{K}-6^{\text {th }}\right)$ student's absences and the High School $\left(7^{\text {th }}-12^{\text {th }}\right)$ student's absences. The 
results revealed during the four-year case study, the students with 10 or more absences per year decreased for the Elementary Grade $\left(\mathrm{K}-6^{\text {th }}\right)$ students and increased regarding the High School $\left(7^{\text {th }}-12^{\text {th }}\right)$ students. In addition, a comparison of the first year without SWPBS as compared to the fourth year SWPBS full implementation, the findings revealed the Elementary Grade $\left(\mathrm{K}-6^{\text {th }}\right)$ students had an average $2.58 \%$ decrease in absences (10 or more) and the High School $\left(7^{\text {th }}-12^{\text {th }}\right)$ students had an average $3.05 \%$ increase in absences (10 or more). Even though the Elementary Grade $\left(\mathrm{K}-6^{\text {th }}\right)$ students had a minimal decline in absences, the findings revealed there was no statistical significance and did not support SWPBS as being a primary contributing factor.

\section{Attendance: SWPBS and Findings in the Literature}

The literature review revealed increased attendance occurred following SWPBS implementation (Cregor, 2009; Townsend, 2011). However, the current case study results revealed there was no significant differences found during the four case study years regarding academic achievement. Students with 10 or more absences had the highest number of occurrences during 2010-11. This occurred during the year when SWPBS was fully implemented. The least number of students with 10 or more absences occurred during the initial case study year 2007-08 when there was no SWPBS. This finding was supported by a study that revealed similar results. Ross (2012) studied elementary school absences during a six-year period and found no significant differences when SWPBS was implemented. The lowest rate of $10+$ absences occurred in the current study when there was no SWPBS and the highest when SWPBS was fully implemented. Over the four-year period the absentee rate increased once SWPBS was implemented. The use of SWPBS was not successful regarding its impact on attendance. As a result, teachers and 
administrators need to examine why absences increased when SWPBS was implemented.

\section{Office Discipline Referrals: SWPBS and Statistical Findings}

RQ3 - Is there a difference in the number and percent of office discipline referrals by grade level for the school years 2007-08, 2008-09, 2009-10, and 2010-11? Regarding RQ 3, the null hypothesis stated there would be no significant differences involving the number of office discipline referrals by the end of the identified school years 2007-08, 2008-09, 2009-10, and 2010-11. The office discipline referrals (ODR's) summary statistics included the number and percentage of ODR's during the four-year case study period 2007-08 through 2010-11 school years. A Chi-square test was used as the statistical analysis and the findings revealed during the four case study years no relationship was found between SWPBS and the average percentage of ODR's.

Although the results were not statistically significant, there were additional important findings when looking specifically at the differences between the Elementary Grade $\left(\mathrm{K}-6^{\text {th }}\right)$ ODR's and the High School $\left(7^{\text {th }}-12^{\text {th }}\right)$ ODR's. The results revealed that during the four-year case study, Elementary Grade $\left(\mathrm{K}-6^{\text {th }}\right)$ ODR's increased and High School $\left(7^{\text {th }}-12^{\text {th }}\right)$ ODR's decreased. In addition, a comparison of the first year without SWPBS as compared to the fourth year SWPBS full implementation, the findings revealed the Elementary Grade $\left(\mathrm{K}-6^{\text {th }}\right)$ students had an average 3.45\% increase in ODR's and the High School $\left(7^{\text {th }}-12^{\text {th }}\right)$ grade students had an average $0.9 \%$ decrease in ODR's. Overall, there was only a slight decrease in the High School $\left(7^{\text {th }}-12^{\text {th }}\right)$ grade students ODR's and a minimal increase as compared to the Elementary Grade $\left(\mathrm{K}-6^{\text {th }}\right)$ ODR increase. These outcomes revealed there was no significant finding regarding (K-12) ODR's, and therefore SWPBS did not positively impact ODR's. 


\section{Office Discipline Referrals: SWPBS and Findings in the Literature}

Literature research reveals SWPBS has a positive impact regarding the number of office discipline referrals received (Sherrod, Getch, \& Ziomek-Daigle, 2009; Coleman, 2008; Guest, 2011; Lassen, Steele, \& Sailor, 2006). These studies all showed a significant ODR decrease when SWPBS was implemented. This decrease would also be expected to be true at the K-12 alternative public school. However, this was not found to be true when looking at the number and percentage of ODR's during the four-year case study period. Rather, the results indicated an increase of ODR's during the time SWPBS was implemented. The first year of the case study (2007-08) revealed the lowest number of ODR's whereas the third and fourth years (2009-10 and 2010-11) had the highest number of ODR's when SWPBS was implemented. Again the results revealed the lowest number of ODR's occurred when there was no SWPBS. This study needs to be replicated and the time frame extended to determine if the ODR's decrease after more than one year of full SWPBS implementation.

\section{Dropout Rate: SWPBS and Statistical Findings}

RQ4 - Is there a difference in the number and percent of dropouts by grade level for the school years 2007-08, 2008-09, 2009-10, and 2010-11? Regarding RQ4, the null hypothesis stated there would be no significant difference involving the number and percent of dropouts by grade level regarding the school years 2007-08, 2008-09, 2009-10, and 2010-11. A Chi-square test was used as the statistical analysis and the findings revealed during the four case study years no relationship was found between SWPBS and the average percentage of dropouts.

Although the results were not statistically significant, there were additional 
important findings when looking specifically at the High School $\left(9^{\text {th }}-12^{\text {th }}\right)$ dropout rate regarding differences between the case study years. The findings revealed that during the four-year case study, the High School $\left(9^{\text {th }}-12^{\text {th }}\right)$ dropout rate had a $5.39 \%$ average decrease in dropouts from the first to the second year. Due to an administrative decision there were no dropouts in the third year. As a result from the second year to the fourth year, there was an average $3.47 \%$ decrease in dropouts. The High School $\left(9^{\text {th }}-12^{\text {th }}\right)$ students had an average $1.92 \%$ decrease in dropouts from the first year with no SWPBS to the fourth year when SWPBS was fully implemented. SWPBS did not have a positive

impact on the number of dropouts at the High School $\left(9^{\text {th }}-12^{\text {th }}\right)$ level. Although there was a decrease in the number of dropouts over the four-year case study period, it was very minimal and found not to be statistically significant. Consequently, the results did not support SWPBS as being a primary contributing factor.

\section{Dropout Rate: SWPBS and Findings in the Literature}

Research literature revealed SWPBS implementation had a significant impact on decreasing the dropout rate (Muscott, Mann, \& LeBrun, 2008). The decrease at the K-12 alternative public school would also be expected and subsequently was found to be true. The frequency and percentage of dropouts at the K-12 alternative public school revealed a higher dropout rate during 2007-08 when there was no SWPBS. The number and frequency of dropouts decreased during the 2010-11 school year when SWPBS was fully implemented. The dropout rate decreased to the lowest rate in the fourth year when SWPBS was fully implemented. Future research is necessary to see why this occurred.

\section{Graduation Rate: SWPBS and Statistical Findings}

RQ5 - Is there a difference in the number and percent of graduates for the school 
years 2007-08, 2008-09, 2009-10, and 2010-11? Regarding RQ5, the null hypothesis stated there would be no significant difference in the number and percent of graduates during the identified study years 2007-08, 2008-09, 2009-10, and 2010-11. A Chi-square test was used as the statistical analysis and the results indicated there was not a significant association between the number of graduates receiving SWPBS strategies and those who did not receive SWPBS strategies.

Although the results were not statistically significant, there were additional important findings when looking specifically at the High School $\left(12^{\text {th }}\right)$ graduation rate regarding differences between the case study years. The findings revealed that during the four-year case study, the High School had a 7.76\% decrease in the number and percentage of graduates when there was no SWPBS as compared to the second year when SWPBS was emerging. A 7.94\% graduate increase occurred when comparing the second year SWPBS emerging to the third year when SWPBS was established. The percentage of graduates decreased $2.34 \%$ the fourth year when SWPBS was fully implemented. The High School had a $2.16 \%$ decrease in graduates from the first year with no SWPBS to the fourth year when SWPBS was fully implemented. Overall, SWPBS did not yield a statistically significant impact on the number of high school graduates.

\section{Graduation Rate: SWPBS and Findings in the Literature}

Research literature revealed SWPBS implementation had a significant impact on increasing the graduation rate (Balfanz 2011). This increase in the graduation rate would also be expected to be true at the K-12 alternative public school. However, this was found not to be true since the percentage of graduates declined over the four-year case study period. A lower percentage of graduates occurred during the year (2007-08) when there 
was no SWPBS as compared to the fourth year (2010-11) when SWPBS was fully implemented. The declining graduation rate may be due to a multitude of factors all related to the unique issues of the alternative public school student. These students typically have many personal issues such as teen pregnancy, alcohol and drugs, mental health issues, domestic violence, poor anger control, etc. It could also be affected by the changes in the formula by which dropouts are defined. These issues as well as others are ones I have directly observed that help to create barriers to academic success at the K-12 alternative public school.

SWPBS provides the expectations and goals for being successful. This case study investigated some of the areas necessary to determine a student's level of success. They include academic achievement, attendance, office discipline referral, dropout rate, and persistence to graduation. In order to determine success in these areas, implications for practice are suggested in the next section.

Implications for Practice

Information gleaned from this case study indicated the K-12 alternative public school provided SWPBS strategies designed to achieve specific student academic and behavioral outcomes, but the school also experienced problems with SWPBS implementation. Based on these findings, the researcher identified specific implications that are applicable to SWPBS practices used at the K-12 alternative public school.

One implication involves the expectation of staff and administration "buy-in" in order for SWPBS to be successful. Current SWPBS research focuses on the importance of staff and administration buy-in for SWPBS success. The idea of staff and administration "buy-in" was discussed in Chapter Two and the present study 
acknowledged its importance. An implication involving professional development at the K-12 alternative public school would be to provide opportunities for staff to be more directly involved in planning and developing SWPBS programming to strengthen the "buy-in" objective. Staff and administration need to be on board to implement SWPBS with fidelity and sustainability.

Another implication related to program design also involves the need for staff and administration involvement. In order to make a significant difference in outcomes involving performance factors similar to those in this case study there needs to be a plan articulating the tasks for school personnel to follow and the training needed to implement them correctly. Specific to the Missouri K-12 alternative public school, the use of incentives for student academic and behavioral performance may need to be reviewed. Both the type and frequency of incentives have a direct impact on student behavior either negatively or positively, depending upon how they are used. This describes the process directly observed by the researcher at the K-12 alternative public school.

Specifically, incentives are an integral part of the SWPBS protocol and are used as rewards for positive academic achievement and behavior. Although incentives were not directly researched in this study, the lack of significant outcomes of this case study reveal there are implications for additional areas that need to be addressed in order to facilitate appropriate implementation and significant outcomes.

Finally, another implication involves SWPBS implementation. As discussed previously, there are many studies regarding SWPBS in the traditional public schools. From the perspective of the current case study, a key question is: If classroom teachers at the K-12 alternative public school were provided with more support and SWPBS training, 
and students were taught SWPBS expectations, would outcomes be positively impacted? If this is shown to be accurate, then training and support programs will require revision and be redesigned to accommodate the unique needs of the special needs or at-risk students in this setting. It may be the SWPBS design that is effective in the traditional public school is not as effective in the K-12 alternative public school and may need to be restructured. This may require a different adaptation of the SWPBS framework when applied to K-12 alternative public schools. It is this researcher's opinion that the threetiered level system may need to include more intensive strategies at Tier I.

\section{Recommendations}

The following recommendations are related to the scope of this study. SWPBS research has been conducted at traditional public schools, but K-12 alternative public schools have not been studied. It is recommended SWPBS studies be conducted regarding other K-12 alternative public schools to determine SWPBS effectiveness. The current case study did not reveal any significant findings regarding the SWPBS impact at this Missouri K-12 alternative public school.

It is recommended more studies be conducted at alternative public schools to further examine the SWPBS impact on academic achievement, attendance, office discipline referrals, dropouts, and graduation rates. Additional factors should also be considered such as gender, ethnicity, free-reduced lunch, homeless, pregnant and parenting youth, etc. In addition to these variables, a researcher should also use a random sample rather than an entire school population. This would allow for studying a specific group of students who all started and ended classes at the same time. Also, an expanded research study should involve more alternative public schools using SWPBS. Using more 
schools will allow for a larger sample size.

It is also this researcher's recommendation that in addition to a quantitative case study, a qualitative case study at an alternative public school would also provide beneficial research. Specifically, a case study that investigates the alternative public school teachers and administrator's perspective on SWPBS "buy-in" concept would be a necessary component determining successful SWPBS implementation and sustainability. Since the literature review has shown there have not been any empirical studies published regarding SWPBS at K-12 alternative public schools, it is necessary for future research to investigate SWPBS in this environment.

The results of this current study revealed there were no significant findings regarding SWPBS and the five performance factors. These outcomes raised more questions than answers. Some questions are: (a) Do the students at K-12 alternative public schools require a different three-tiered level system as compared to those in the traditional public schools? (b) Does the process of advancing from one level to another take a longer time for these students? (c) Does professional development need to focus more on how to provide SWPBS strategies to at-risk and special needs students at K-12 alternative public schools? (d) Does the plan of gradually working through the SWPBS initial stages to full implementation take more years for the K-12 alternative public schools to achieve? Since there are no empirical studies for K-12 alternative public schools to use as guides, future research is essential to answers these questions.

Future investigation using functional behavior assessments and SWPBS would provide more effective teaching strategies and goal setting to meet the alternative school student's academic needs. Research involving a comparison between alternative schools 
using SWPBS would begin to fill the gap in the literature. In addition a case study investigating the student's perceptions of SWPBS participation as well as teacher's experiences with SWPBS would be beneficial. The study could be a mixed methods approach making it a more robust research study. Adding a qualitative approach would increase the methodologies to gain multiple ways of obtaining data and achieving more accurate findings.

The recommendations stated in this section are directed toward school administrators, other educational leaders, and all stakeholders who have a mission and a vision to develop safe schools where students are successful academically and behaviorally. The literature review has shown data based research has investigated SWPBS effectiveness mostly at the elementary school level. There has been minimal SWPBS research conducted at the high school level. And as this case study literature review revealed, there has not been any SWPBS research conducted at a K-12 alternative public school.

\section{Summary}

Although SWPBS has been recognized as a beneficial approach for academic and behavioral success at traditional schools, there have been no empirical studies investigating the SWPBS impact at a K-12 alternative public school. The goal of this research was to explore the use of SWPBS at a K-12 alternative public school and to fill the gap in the literature. Specifically, this case study provided quantifiable data regarding five selected performance factors: (a) academic achievement involving passing grades of C or higher in Communication Arts and Math; (b) absences of 10 or more per year; (c) office discipline referrals; (d) dropouts; and (e) graduates. In addition, this case study 
empirically assessed the impact of SWPBS on these five performance factors.

Using Chi-square statistical analyses, it was concluded that statistically significant differences did not exist between students who had SWPBS and those who did not have SWPBS regarding the five performance factors over a four-year period. Each of the performance factors were investigated according to groupings of Elementary Grades (K$\left.6^{\text {th }}\right)$ and High School $\left(7^{\text {th }}-12^{\text {th }}\right)$ grades. Regarding all five performance factors, SWPBS did not result in significant findings.

Findings in this case study provided valuable information for informing stakeholder decisions. Teachers and staff at the K-12 alternative public school can use this knowledge to focus on SWPBS implementation and outcomes. Principals can use this knowledge to devise professional development to specifically address SWPBS implementation to increase the student success rates both academically and behaviorally in the classroom. These findings will also bring an awareness to students regarding their successes in decisions they make as participants in SWPBS. Students and parents can use this information to determine whether participation in SWPBS affects student success in school. The school district stakeholders want positive student outcomes as a result of their investment of time and money. Stakeholders such as the school district superintendent and administrators can use this information to determine whether SWPBS benefits are worth the program costs, especially during times of budgetary constraints.

This case study shows that although there was no statistical significance found regarding SWPBS impact on five performance factors, it is this researcher's opinion that SWPBS strategies should be continued at the K-12 alternative public school. Since there are no published empirical studies regarding SWPBS impact at K-12 alternative public 
schools, it is not known if the current study has the same SWPBS outcomes as other K-12 alternative public schools. It is possible that significant results regarding SWPBS impact at a K-12 alternative public school may take longer than the three years in this current case study. While the effectiveness of SWPBS on student performance factors at a K-12 alternative public school was not previously researched, the current case study provides a springboard to future SWPBS research. 


\section{References}

Algozzine, B., Wang, C., \& Violette, A.S. (2011). Re-examining the relationship between academic achievement and social behavior. Journal of Positive Behavior Interventions, 13(1), 3-16.

American Psychiatic Association (2000). Diagnostic and statistical manual of mental disorders ( $4^{\text {th }}$ ed., text rev.). Washington, DC: Author.

American Psychological Association (2001). Publication manual for the American Psychological Association. New York: American Psychological Association.

American School Counselor Association (2005). The ASCA national model: A framework for school counseling programs $\left(2^{\text {nd }}\right.$ ed $)$. Alexandria, VA: Author.

Anderson, C.M., \& Kincaid, D. (2005). Applying behavior analysis to school violence and discipline problems: School-wide positive behavior support. The Behavior Analyst, 28(1), 49-63.

Annie E. Casey Foundation (2011). Kids Count. Retrieved December 15, 2011, from http://www.kidscount.org/datacenter

Appleton, J.J., Christenson, S.L., \& Furlong, M.J. (2008). Student engagement with school: Critical conceptual and methodological issues of the construct. Psychology in the Schools, 45(5), 369-386.

Association for Positive Behavior Support (n.d.). Retrieved April 25, 2011 from Www.pbis.org

Baer, D.M., Wolf, M.M., \& Risley, T.R. (1968). Some current dimensions of applied behavior analysis. Journal of Applied Behavior Analysis, 1(1), 91-97.

Baer, D.M., \& Wolf, M.M. (1987). Some still-current dimensions of applied behavior 
analysis. Journal of Applied Behavior Analysis, 20(4), 313-327.

Balfanz, R. (2011). Back on track to graduate. Educational Leadership, 68(7), 54-58.

Balfanz, R., Herzog, L., \& MacIver, D.J. (2007). Preventing student disengagement and keeping students on the graduation path in urban middle-grades schools: Early identification and effective interventions. Educational Psychologist, 42(4), 223-235.

Batsche, G., Elliott, J., Graden, J.L., Grimes, J., Kovaleski, J.F., Prasse, D., et al. (2005). Response to Intervention: Policy considerations and implementation. Alexandria, VA: National Association of State Directors of Special Education. Retrieved on 10/8/12 from www.pbis.org

Beach Center on Disability (2011). Positive behavior support (PBS) and applied behavior analysis (ABA). Retrieved on September 12, 2011 from www.beachcenter.org

Bernhardt, V. (2005). Using data to improve student learning in high schools. Larchmont, NY: Eye on Education, Inc.

Billitteri, T.J. (2008). Discipline in schools: Are zero-tolerance policies fair? CQ Researcher, 18(7), 1-36.

Bohanon, H., Fenning, P., Carney, K., Minnis-Kim, M. J., Anderson-Harriss, S., Moroz, K., et al. (2006). School-wide application of positive behavior support in an urban high school: A case study. Journal of Positive Behavior Interventions, 8(3), 127140.

Bohanon, H., Fenning, P., Eber, L., \& Flannery, B. (2007). Identifying a roadmap of support for secondary students in school-wide positive behavior support 
applications. International Journal of Special Education, 22(1), 39-52.

Booker, K., \& Mitchell, A. (2011). Patterns in recidivism and discretionary placement in alternative education: The impact of gender, ethnicity, age, and special education status. Education and Treatment of Children, 34(2), 193-208.

Bradshaw, C.P., Koth, C.W., Thornton, L.A., \& Leaf, P.J. (2008). Altering school climate through school-wide positive behavioral interventions and supports: Findings from a group-randomized effectiveness trial. Prevention Science, 10(2), 100-115.

Bradshaw, C.P., Mitchell, M., \& Leaf, P. (2010). Examining the effects of school-wide positive behavioral interventions and supports on student outcomes: Results from a randomized controlled effectiveness trial in elementary schools. Journal of Positive Behavioral Interventions, 12(3), 133-148.

Carr, E.G., Dunlap, G., Horner, R.H., Koegel, R.L., Turbull, A.P., \& Sailor, W. et al (2002). Positive behavior support: Evolution of an applied science. Journal of Positive Behavior Interventions, 4(1), 4-16.

Childs, K.E., Kincaid, D., \& George, H.P. (2010). A model for statewide positive behavior support initiative. Journal of Positive Behavioral Support, 12(4), $198-210$.

Christle, C.A., Jolivette, K., \& Nelson, C.M. (2007). School characteristics related to high school dropout rates. Remedial and Special Education, 28(6), 325-339.

Clonan, S.M., McDougal, J.L., Clark, K., \& Davison, S. (2007). Use of office discipline referrals in school-wide decision making: A practical example. Psychology in the Schools, 44(1), 19-27. 
Cohen, J., \& Pickeral, T. (2007). How measuring school climate can improve your school. Education Week, 26(33), 29-30.

Cohn, A.M. (2001). Positive behavioral supports: Information for educators.

Retrieved November 22, 2010 from NASP Resources at http://www.nasponline.org/resources/factsheets/pbs fs.aspx

Coleman, M.E. (2008). Investigating the construct validity of office discipline referrals as a measure of school-wide positive behavior support. UMI Dissertation Publishing. (UMI No. AAT 3325654) Retrieved September 8, 2011 from, Dissertations and Theses Database.

Cooper, R.C. (2011). A study of the relationship between positive behavior support and student academic achievement. UMI Dissertation Publishing. (UMI No. AAT3467203) Retrieved September 7, 2011 from, Dissertations and Theses Database.

Cornelius-White, J. (2007). Learner-centered teacher-student relationships are effective: A meta-analysis. Review of Educational Research, 77(1), 113-143.

Cregor, M. (2008). The building blocks of positive behavior. Education Digest, 74(4), $1-7$.

Creswell, J.W. (2009). Research design: Qualitative, quantitative, and mixed methods approaches ( $3^{\text {rd }}$ ed.). Thousand Oaks, CA: Sage.

Crone, D.A., \& Horner, R.H. (2003). Building positive behavior support systems in schools: Functional behavior assessment. New York, NY: Guilford Press.

Crone, D.A., Horner, R.H., \& Hawken, L.S. (2003). Responding to problem behavior in school: The behavior education program. New York, NY: Guilford. 
Curtis, R., Van Horne, J.W., Robertson, P., \& Karvonen, M. (2010). Outcomes of a school-wide positive behavioral support program. Professional School Counseling, 13(3), 159-164.

Darity, W.A. (2008). Factor analysis. International Encyclopedia of the Social Sciences, 2(3), 75-76. Gale Virtual Reference Library. Web. April 27, 2012.

Downer, J.T., Rimm-Kauffman, S., \& Pinata, R.S. (2007). How do classroom conditions and children's risk for school problems contribute to children's behavioral engagement in learning? School Psychology, 36(3), 413-432.

Ducharme, J.M., \& Schecter, C. (2011). Bridging the gap between clinical and classroom intervention: Keystone approaches for students with challenging behavior. School Psychology Review, 40(2), 257-274.

Dunlap, G., Carr, E.G., Horner, R.H., Koegel, R.L., Sailor, W., Clarke, S. et al (2010). A descriptive, multiyear examination of positive behavior support. Behavioral Disorders, 35(4), 259-279.

Dunlap, K., Goodman, S., McEvoy, C., \& Paris, F. (2010). Schoo/-wide positive behavioral interventions and supports implementation guide, Michigan Department of Education, 1-52.

Eber, L., Breen, K., Rose, J., Unizycki, R.M., \& London, T. (2008). Wraparound as a tertiary level intervention for students with emotional/behavioral needs. Teaching Exceptional Children, 40(6), 16-22.

Epstein, M., Nordness, P.D., Gallagher, K., Nelson, R., Lewis, L., \& Schrepf, S. (2005). School as the entry point: Assessing adherence to the basic tenets of the wraparound approach. Behavioral Disorders, 30(2), 85-93. 
Ervin, R.A., Schaughency, E., Goodman, S.D., McGlinchey, M.T., \& Matthews, A. (2006). Merging research and practice agendas to address reading and behavior school-wide. School Psychology Review, 35(2), 198-223.

Ervin, R.A., Schaughency, E., Matthews, A., Goodman, S.D., \& McGlinchey, M.T. (2007). Primary and secondary intervention of behavior difficulties:

Developing a data-informed problem-solving model to guide decision making at a school-wide level. Psychology in the Schools, 44(1), 7-18.

Faherty, V.E. (2008). Compassionate statistics: Applied quantitative analysis for social services. Los Angeles, CA: Sage Publications.

Field, A. (2009). Discovering statistics using SPSS (3 ${ }^{\text {nd }}$ Edition). Thousand Oaks, CA: Sage Publications.

Filter, K.J., Tincani, M., \& Fung, D. (2009). Surveying professionals' views of positive behavior support and behavior analysis. Journal of Positive Behavior Interventions, 11(4), 222-234.

Flannery, K.B., Sugai, G., \& Anderson, C.M. (2009). School-wide positive behavior support in high school: Early lessons learned. Journal of Positive Behavior Interventions, 11(3), 177-185.

Foley, R.M. \& Pang, L. (2006). Alternative education programs: Program and student characteristics. The High School Journal, 89(1), 10-21.

Fox, L. \& Duda, M.A. (2011). Positive behavior support. Technical Assistance Center on Social Emotional Intervention for Young Children. Retrieved on November 16, 2011 from www.challengingbehavior.org

Franklin, C., Streeter, C.L., Kim, J.S. \& Tripodi, S.J. (2007). The effectiveness of a 
solution-focused, public alternative school for dropout prevention and retrieval. Children \& Schools, 29(3), 133-144.

Gagnon, J.C., Rockwell, S. B., \& Scott, T.M. (2008). Positive behavior supports in exclusionary schools: A practical approach based on what we know. Focus on Exceptional Children, 41(1), 1-21.

Gleason, P., \& Dynarski, M. (2002). Do we know whom to serve? Issues in using risk factors to identify dropouts. Journal of Education for Students Placed At Risk, $7(1), 25-41$.

Good, C.P., McIntosh, K., \& Gietz, C. (2011). Integrating bullying prevention into school-wide positive behavior support. Teaching Exceptional Children, 44(1), 48-56.

Guest, E.M. (2011). The impact of positive behavioral interventions and supports in secondary school settings. UMI Dissertation Publishing. (AAT 3466431). Retrieved October 10, 2011 from http://proquest.com

Handler, M.W., Rey, J., Connell, J., Thier, K., Feinberg, A., \& Putnam, R. (2007). Practical considerations in creating school-wide positive behavior support in public schools. Psychology in the Schools, 44(1), 29-39.

Heilig, J.V. (2011). As good as advertised? Tracking urban student progress through high school in an environment of accountability. American Secondary Education, 39(3), 17-41.

Hergenhahn, B.R. (1976). An introduction to theories of learning, Englewood Cliffs, NJ: Prentice-Hall, Inc.

Herlihy, C.M., \& Quint, J. (2006). Emerging evidence on improving high school student 
achievement and graduation rates: The effects of four popular improvement programs. American Institute for Research, (November) 1-12. Retrieved on September 4, 2011 from www.betterhighschools.org Individuals With Disabilities Education Act, 20 U.S.C. 1400, et seq (2006).

Hieneman, M., Dunlap, G., \& Kincaid, D. (2005). Positive support strategies for students with behavioral disorders in general education setting. Psychology in the Schools, 42(8), 779-794.

Horner, R.H., Sugai, G., \& Anderson, C.M. (2010). Examining the evidence base for school-wide positive behavior support. Focus on Exceptional Children, 42(8), $1-14$

Hoyle, C.G., Marshall, K.J., \& Yell, M.L. (2011). Positive behavior supports: Tier 2 interventions in middle schools. Preventing School Failure: Alternative Education for Children and Youth, 55(3), 164-170.

Hunter, L, \& Leahey, E. (2008). Collaborative research in sociology: Trends and contributing factors. American Sociologist, 39(4), 290-306.

Irvin, L.K., Tobin, T.J., Sprague, J.R., Sugai, G., \& Vincent, C.G. (2004). Validity of office discipline referral measures as indices of school-wide behavioral status and effects of school-wide behavioral interventions. Journal of Positive Behavior Interventions, 6(3), 131-147.

Janosz, M., Archambault, I., Morizot, J., \& Pagani, L. (2008). School engagement trajectories and their differential predictive relations to dropout. Journal of Social Issues, 64(1), 21-40.

Jenson, J.M. (2010). Advances in preventing childhood and adolescent problem 
behavior. Research on Social Work Practice, 20(6), 701-713.

Johnson, D., Rice, M., Edington, W., \& Williams, P. (2005). For the uninitiated: How to succeed in classroom management. Kappa Delta Pi Record, 42(1), 28-32.

Johnston, J.M., Foxx, R.M., Jacobson, J.W., Green, G, \& Mulick, J.A. (2006). Positive behavior support and applied behavior analysis. The Behavior Analyst, 29(1), 5174.

Kauffman, J.M., Myers, D.R., \& Simpson, R.L. (2007). Problems related to underservice of students with emotional or behavioral disorders. Behavioral Disorders, 33(1), 43-57.

Kern, L., \& Manz, P. (2004). A look at current validity issues of school-wide behavior support. Behavioral Disorders, 30(1), 47-59.

Kilian, J.M., \& Kilian, D.W. (2011). A school intervention to increase pro-social behavior and improve academic performance of at-risk students. Improving Schools, 14(1), 65-83.

Kittle, M.D. (2011, April 15). Dropout rate costs Missouri economy millions a year. Southeast Missourian. Retrieved April 22, 2011, from http://www.semissourian.com/story/1719043.htm1

Knoff, H.M. (2000). Organizational development and strategic planning for the millennium: A toward effective school discipline, school safety, and crisis prevention blueprint. Psychology in the Schoo/s, 37(1), 17-32.

Kretlow, A.G., \& Bartholomew, C.C. (2010). Using coaching to improve the fidelity of evidence-based practices: A review of studies. Teacher Education and Special Education, 33(4), 279-299. 
Landis, R.N., \& Reschly, A.L. (2010). An examination of compulsory attendance ages and high school dropout and completion. Educational Policy, 25(5), 719-761.

Lane, K.L., Little, A., Menzies, H., Lambert, W., \& Wehby, J. (2010). A comparison of students with behavior challenges educated in suburban and rural settings: Academic, social, and behavioral outcomes. Journal of Emotional and Behavioral Disorders, 18(3), 131-148.

Lane, K.L., Wehby, J.H., Robertson, E.J., \& Rogers, L.A. (2007). How do different types of high school students respond to school-wide behavior support programs? Journal of Emotional and Behavioral Disorders, 15(1), 3-20.

Lassen, S.R., Steele, M.M., \& Sailor, W. (2006). The relationship of school-wide positive behavior support to academic achievement in an urban middle school. Psychology in the Schools, 43(6), 701-712.

Lee, T., Cornell, D., Gregory, A., \& Fan. X. (2011). High suspension schools and dropout rates for black and white students. Education and Treatment of Children, 34(2), 167-192.

Lehr, C.A., Hansen, A., Sinclair, M.F., \& Christenson, S.L. (2003). Moving beyond dropout towards school completion: An integrative review of data-based interventions. School Psychology Review, 32(3), 342-364.

Levin, H.M., \& Belfield, C.R. (2007). Educational Interventions to Raise High School Graduation Rates. In C.R. Belfield and H.M. Levin (Eds.), The price we pay: Economic and social consequences of inadequate education (pp. 177-199). Washington, DC: Brookings Institution Press.

Lewis, T.J., Jones, S.E.L., Horner, R.H., \& Sugai, G. (2010). School-wide positive 
behavior support and students with emotional/behavioral disorders:

Implications for prevention, identification and intervention. Exceptionality, 18(2), 82-93.

Liaupsin, C.J., Jolivette, K., \& Scott, T.M. (2004). School-wide systems of support: Maximizing student success in schools. In R.B. Rutherford, M.M. Quinn, \& R. Sathur (Eds.) Handbook of research in emotional and behavioral disorders (pp. 487-501). New York, NY: Guilford Press.

Lowry, R. (2012). VassarStats: Website for Statistical Computation, Retrieved September 22, 2012 from www.vassarstats.net

Luiselli, J.K., Putnam, R.F., Handler, M.W., \& Feinberg, A.B. (2005). Whole-school positive behavior support: Effects on student discipline problems and academic performance. Educational Psychology, 25(2-3), 183-198.

Lynass, L., Tsai, S.F., Richman, T.D., \& Cheney, D. (2012). Social expectations and behavioral indicators in school-wide positive behavior supports: A national study of behavior matrices. Journal of Positive Behavioral Interventions, 14(3), 153161.

Martin, E.J., Tobin, T.J., \& Sugai, G.M. (2002). Current information on dropout prevention: Ideas from practitioners and the literature. Preventing School Failure, $47(1), 10-18$.

May, S., Ard, W., Todd, A.W., Horner, R.H., Glasgow, A., Sugai, G., et al. (2003). School-wide information system. Eugene: Educational and Community Supports, University of Oregon.

McEvoy, A., \& Welker, B. (2000). Antisocial behavior, academic failure, and school 
climate: a critical review. Journal of Emotional and Behavioral Disorders, $8(3), 130-140$.

McIntosh, K., Filter, K.J., Bennett, J.L., Ryan, C., \& Sugai, G. (2010). Principles of sustainable prevention: Designing scale-up of school-wide behavior support to promote durable systems. Psychology in the Schools, 47(1), 5-21.

McIntosh, K., Flannery, K.B., Sugai, G., Braun, D.H., \& Cochrane, K.L. (2008).

Relationships between academics and problem behavior in the transition from middle school to high school. Journal of Positive Behavior Interventions, 19(4), $243-255$.

McKevitt, B. C., \& Braaksma, A. (2008). Best practices in developing a positive behavior support system at the school level. In A. Thomas and J. Grimes (Eds.), Best practices in school psychology (Vol. 3; pp. 735-747). Bethesda, MD: National Association of School Psychologists.

McNeil, M. (2011). Are 82\% of schools 'failing' under NCLB, as Duncan warned? Education Week, Retrieved December 16, 2011 from www.edweek.org Mertens, D.M. (2005). Research and evaluation in education and psychology: Integrating diversity with quantitative, qualitative, and mixed methods $\left(2^{\text {nd }}\right.$ ed.). Thousand Oaks, CA: Sage.

Miramontes, N.Y., Marchant, M., Heath, M.A., \& Fischer, L. (2011). Social validity of a positive behavior interventions and support model. Education and Treatment of Children, 3(4), 445-468.

Mishel, L., \& Roy, J. (2006). Rethinking high school graduation rates and trends. Washington, DC: Economic Policy Institute. Retrieved November 25, 2011 


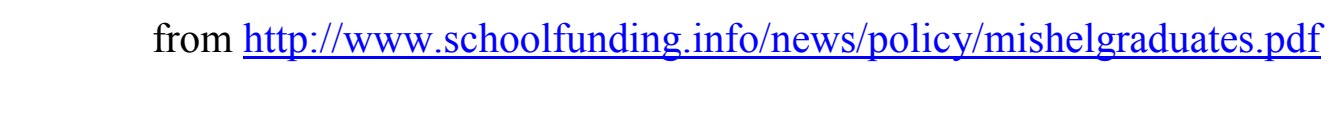

Morris, E.K., Smith, N.G., \& Altus, D.E. (2005). B.F. Skinner's contributions to applied behavior analysis. The Behavior Analyst, 28(2), 99-131.

Morrisey, K.L., Bohanon, H., \& Fenning, P. (2010). Teaching and acknowledging expected behaviors in an urban high school. Teaching Exceptional Children, $42(5), 26-35$.

Muscott, H.S., Mann, E.L., \& LeBrun, M.R. (2008). Positive behavioral interventions and supports in New Hampshire: Effects of large-scale implementation of schoolwide positive behavior support on student discipline and academic achievement. Journal of Positive Behavior Interventions, 10(3), 190-205.

National Center for Educational Statistics (n.d.). Trends in national dropout and completion rates in the United States: 1972 to 2009 Compendium report, 1-108. Retrieved on September 11, 2011 from http//:nces.ed.gov/

National Dropout Prevention Center for Students with Disabilities (2008). An analysis of states' annual performance report data for indicator 1(graduation). A report prepared for the U.S. Department of Education, Office of Special Education Programs. Clemson, SC: Author. Retrieved November 25, 2011 from WWW.ndpc-sd.org

National High School Center, National Center on Response to Intervention, and Center on Instruction (2010). Tiered interventions in high schools: Using preliminary "lessons learned" to guide ongoing discussion. Washington, DC: American Institutes for Research. Retrieved on September 16, 2011 from www.betterhighschools.org 
National School Climate Center (NSCC) for the Comprehensive School Climate Inventory (CSCI), New York, NY; 2007. Retrieved December 4, 2011 from Www.schoolclimate.org,

Neild, R.C., \& Balfanz, R. (2006). Unfulfilled promise: The dimensions and characteristics of Philadelphia's dropout crisis 2000-2005. Philadelphia, PA: Philadelphia Youth Network.

Nelson, J.R. (1996). Designing schools to meet the needs of students who exhibit disruptive behavior. Journal of Emotional and Behavioral Disorders, 4(3), $147-162$.

Nelson, J.R., Hurley, K.D., Synhorst, L., Epstein, M.H., Stage, S., \& Buckley, J. (2009). The child outcomes of a behavioral model. Exceptional Children, 76(1), 7-30.

Netzel, D.M., \& Eber, L. (2003). Shifting from reactive to proactive discipline in an urban school district: A change of focus through PBIS implementation. Journal of Positive Behavior Interventions, 5(2), 71-79.

No Child Left Behind Act of 2001, 20 U.S.C., 6301, es seq. (2006).

No Author. (2013). What's working. Curriculum Review, 52(6), 6-9.

O’Dell, S.M.,Vilardo, B.A., Kern, L., Kokina, A., Ash, A.N., Seymour, K.J., et al (2011). JPBI 10 years later: Trends in research studies. Journal of Positive Behavior Interventions, 13(2), 78-86.

Office of Special Education Programs (OSEP) (2011). Retrieved December 10, 2011

from $\underline{\text { http://www2.ed.gov/about/offices/list/osers/osep/index.html }}$
Olweus, D., Limber, S.P., Flerx, V.C., Mullin, N., Riese, J., \& Snyder, M. (2007).
Olweus bullying prevention program: Schoo/-wide guide. Center City, MN: 
Hazelton.

Oregon Department of Education (2002). Dropout rates in Oregon high schools: 20002001. Retrieved on December 27, 2011 from http://dbi.ode.state.or.us/dropout.htm

OSEP Center on Positive Behavioral Interventions and Supports \& Illinois Positive Behavioral Interventions and Support Network. (2005). ///inois positive behavioral interventions and support network 2004-05 progress report. Lagrangeville: Illinois PBIS Network.

Osher, D., Bear, G.G., Sprague, J.R., \& Doyle, W. (2010). How can we improve school discipline? Educational Researcher, 39(1), 48-58.

Pas, E.T., Bradshaw, C.P., \& Mitchell, M.M. (2011). Examining the effects of office discipline referrals as an indicator of student behavior problems. Psychology in the Schools, 48(6), 541-555.

PBIS (2011). Retrieved on December 22, 2011 from www.pbis.org

Pierce, W.D., \& Cheney, C.D. (2004). Behavior analysis and learning (3 ${ }^{\text {rd }}$ ed.). Mahwah, New Jersey: Lawrence Erlbaum Associates, Publishers.

Positive Behavior and Intervention Supports. (2009). Is school-wide positive behavior support an evidence-based practice? (n.d.) Retrieved October 22, 2009 from www.pbis.org/research.

Prevatt, F.F., \& Kelly, F.D. (2003). Dropping out of school: A review of intervention programs. Journal of School Psychology, 41(5), 377-395.

Raywid, M.A. (1999). History and issues of alternative schools. Education Digest, 64, $47-51$. 
Reinke, W.M., Herman, K.C., \& Stormont, M. (2013). Classroom-level positive behavior supports in schools implementing SW-PBIS: Identifying areas for enhancement. Journal of Positive Behavior Interventions, 15(1), 39-50. Retrieved January 28, 2013 from http://pbi.sagepub.com/content/15/1/39.

Richter, M. (2008). Why it's prudent and practical to implement school-wide positive behavior support (SW-PBS) district-wide. Retrieved November 30, 2010 from Missouri Department of Elementary and Secondary Education Center for PBS/University of Missouri-Columbia at http://pbismissouri.org/starting.html

Ross, G.E. (2012). The effects of positive behavioral interventions and support on student discipline referrals and attendance. Retrieved September 20, 2012 from http://digitalcommons.wku.edu/diss/30

Ruglis, J.R., \& Freudenberg, N. (2010). Toward healthy high schools movement: Strategies for mobilizing public health for educational reform. American Journal of Public Health, 100(9), 1565-1571.

Rumberger, R.W., \& Larson, K.A. (1998). Student mobility and the increased risk of high school dropout. American Journal of Education, 107(1), 1-35.

Rumberger, R.W., \& Palardy, G.J. (2005). Test scores, dropout rates, and transfer rates as alternative indicators of high school performance. American Educational Research Journal, 42(1), 3-42.

Safran, S.P., \& Oswald, K. (2003). Positive behavior supports: Can schools reshape disciplinary practices? Exceptional Children, 69(3), 361-374.

Sanders, N.E. (2009). The effect of participating in school-wide positive behavior support on academic performance and number of office discipline referrals. Proquest 
Dissertation and Theses. (ISBN 9781109243451$)$ Retrieved September 6, 2011, from ERIC Database.

Sasso, G. M. (2004). Measurement issues in EBD research: What we know and how we know it. Behavioral Disorders, 30(1), 60-71.

Schifter, L. (2011). High school graduation of students with disabilities: How long does it take? Exceptional Children, 77(4), 409-422.

School Wide Information System (SWIS) (n.d.). Retrieved June 2, 2011 from WwW.swis.org

Scott, N., Eber, L., Malloy, J., \& Cormier, G. (2005). Intensive comprehensive level of support for high school students. In H. Bohanon-Edmonson, B. Flannery, G. Sugai (Eds.). Positive behavior support in high schools: Monograph from the 2004 Illinois high school forum of positive behavioral interventions and supports. Retrieved December 30, 2011 from http://www.pbis.org/common/pbisresources/ publications/PBSMonograph Complete.pdf

Scott, T. M., Alter, P.J., Rosenberg, M., \& Borgmeier, C. (2010). Decision making in secondary and tertiary interventions of school-wide systems of positive behavior support. Education and Treatment of Children, 33(4), 513-535.

Scott, T.M., Nelson, C.M., Liaupsin, C.J., Jolivette, K, Christle, C.A., \& Riney, M. (2002). Addressing the needs of at-risk and adjudicated youth through positive behavior support: Effective prevention practices. Education and Treatment of Children, 25(4), 532-551.

Shaping Behavior (2011). Applied behavior analysis, Retrieved on December 30, 2011 
from www.shapingbehavior.com/what is aba.html.
Sherrod, M.D., Getch, Y.Q., \& Ziomek-Daigle, J. (2009). The impact of positive behavior support to decrease discipline referrals with elementary students. Professional School Counseling, 12(6). 1-10.

Simonsen, B., Britton, L., \& Young, D. (2010). School-wide positive behavior support in an alternative school setting: A case study. Journal of Positive Behavior Interventions, 12(3), 180-191.

Simonsen, B., Eber, L., Black, A.C., Sugai, G., Lewandowski, H., \& Sims et al (2012). Illinois statewide positive behavioral interventions and supports: Evolution and impact on student outcome across the years. Journal of Positive Behavior Interventions, 14(1), 5-16.

Skarbek, D.M, Harry, P., \& Parish, P.A. (2006). The institutional review board IRB): Another major ingredient of our alphabet soup. Teaching Exceptional Children, 38(4), 26-30.

Skiba, R. J. (2000). Zero tolerance, zero evidence: An analysis of school disciplinary practice. Indiana Education Policy Center. Retrieved November 23, 2011 from www.Indiana.edu/-safeschl/ztze.pdf.

Skinner, B.F. (1974). About behaviorism. New York: Vintage Books.

Spaulding, S.A., Horner, R.H., May, S., \& Vincent, C.G. (2008). Implementation of school-wide PBIS across the United States. Evaluation Briefs, 8(2), 1-6. Retrieved on December 5, 2011 from www.pbis.org/evaluation/ evaluation briefs/now_08_(2).aspx

Spaulding, S.A., Irvin, L.K., Horner, R.H., May, S.L., Emeldi, M., Tobin, T.J., \& Sugai, 
G. (2010). School-wide social-behavioral climate, student problem behavior, and related administrative decisions: Empirical patterns from 1,510 schools nationwide. Journal of Positive Behavior Interventions, 12(2), 69-85.

Sprague, J., Walker, H., Golly, A., White, K., Myers, D.R., \& Shannon, T. (2001). Translating research into an effective practice: The effects of a universal staff and student intervention on indicators off discipline and school safety. Education and Treatment of Children, 24(4), 495-511.

Sprague, J., \& Walker, H.M. (2004). Improving school climate with school-wide positive behavior support. The Utah Special Educator, 25(2) 12-15.

Sprick, R. (2009). Doing discipline differently. Principal Leadership, 9(5), 19-22. State Education Resource Center (2009). Positive behavior support data report and summary: A look at Connecticut. p. 1-64. Retrieved September 14, 2011 from www.ctserc.org

SPSS (2011). IBM SPSS Statistics for Mac OS X, Version 20.0. Armonk, NY: IBM Corp.

State Education Resource Center (2009). Positive behavior support data report and summary: A look at Connecticut, Positive Behavior Support Initiative, 1-64. Retrieved on September 16, 2011 from www.ctserc.org Stillwell, R., \& Hoffman, L. (2009). Public school graduates and dropouts from the common core data: School year 2005-06. Washington, D.C.: U.S. Department of Education. Retrieved November 11, 2011 http://nces.ed.gov/pubs2008/2008 353 rev.pdf. 
Stoiber, K.C., \& Gettinger, M. (2011). Functional assessment and positive support strategies for promoting resilience: Effects on teachers and high-risk children. Psychology in Schools, 48(7), 686-706.

Sugai, Flannery, \& Bohanon-Edmonson (2004). School-wide positive behavior support in high schools: What will it take? Retrieved on 11/16/11 from http://safeschools.dsisd.net/Elem5/HO3-1-24-08.pdf

Sugai, G. \& Horner, R.H. (1999). Discipline and behavioral support: Preferred processes and practices. Effective School Practices, 17(4), 10-22.

Sugai, G., \& Horner, R. (2002). Introduction to the special series on positive behavior support in schools. Journal of Emotional and Behavioral Disorders, 10(3), $130-135$.

Sugai, G., Horner, R.H., Dunlap, G., Hieneman, M., Lewis, T.J., Nelson, C.M., \& Ruef, M. (2000). Applying positive behavior support and functional behavior assessment in school. Journal of Positive Behavior Interventions, 2(3), 131143.

Sugai, G., Horner, R. H., Fixsen, D., \& Blase, K. (2010). Developing systems-level capacity for RtI implementation: Current efforts and future directions. In T.A. Glover \& S. Vaughn (Eds.). Response to intervention: Empowering all students to learn - A critical account of the science and practice (pp. 286-309). New York: Guilford.

Sugai, G., \& Horner, R. (2006). A promising approach for expanding and sustaining school-wide positive behavior support. School Psychology Review, 35(2), 245259. 
Sugai, G., Sprague, J. R., Horner, R. H., \& Walker, H. M. (2000). Preventing school violence: The use of office daily referrals to assess and monitor school-wide discipline interventions. Journal of Emotional and Behavioral Disorders, 8(2) 94-104.

Suh, S., \& Suh, J. (2007). Predictors of categorical at-risk high school dropouts. Journal of Counseling and Development, 85(2), 196-203.

Thornburgh, N. (2006). Dropout nation. Time Magazine, 167(16), 30-40.

Todd, A., Horner, R., \& Tobin, T. (2010). SWIS Documentation Project: Referral form definitions (Version 4.3). Eugene: University of Oregon. Retrieved December 2, 2011 from htpp://www.swis.org/index.php?_facresources;rid_10013

Townsend, C.J. (2011). The impact of education support advisors on the attendance, discipline and achievement of at-risk students. UMI Dissertation Publishing (UMI No. AAT 3428285). Retrieved January 2, 2012 from Dissertations and Theses Database.

Turton, A.M., Umbreit, J., \& Mathur, S.R. (2011). Systematic function-based intervention for adolescents with emotional and behavioral disorders in an alternative setting: Broadening the context. Behavioral Disorders, 36(2), $117-$ 128.

Upreti, G., Liauspin, C., \& Koonce, D. (2010). Stakeholder utility: Perspectives on school-wide data for measurement, feedback, and evaluation. Education and Treatment of Children, 33(4), 497-511.

U.S. Department of Education (2002). Twenty-fourth annual report to congress on the implementation of the Individuals with Disabilities Education Act. Jessup, 
MD: Education Publications Center. Retrieved on December 12, 2011 from www.ed.gov

Vincent, C.G., Swain-Brady, J., Tobin, T.J., \& May, S. (2011). Disciplinary referrals for culturally and linguistically diverse students with and without disabilities: Patterns resulting from school-wide positive behavior support. Exceptionality, 19(3), 175-190.

Wagner, M., Kutash, K., Duchnowski, A.J., Epstein, M.H., \& Sumi, W.C. (2005). The children and youth we serve: A national picture of the characteristics of students with of students with emotional disturbances receiving special education. Journal of Emotional and Behavioral Disorders, 13(2), 79-96.

Walker, B., Cheney, D., \& Stage, S. (2009). The validity and reliability of the selfassessment and program review: Assessing school progress in school-wide positive behavior support. Journal of Positive Behavior Interventions, 11(2), 94-109.

Warren, J.S., Bohannon-Edmondson, H., Turnbull, A.P., Sailor, W., Wickham, D., Griggs, P., et al (2006). School-wide positive behavior support: Address in behavior problems that impede student learning. Educational Psychology Review, 18(2), 187-198.

Warren, J.R., \& Halpern-Manners, A. (2007). Is the glass emptying or filling up? Divergent trends in high school completion and dropout. Educational Researcher, 36(6), 335-343.

Watson, J.B. (1913) In B.R. Hergenhahn (1976). An Introduction to Theories of 
Learning, Englewood Cliffs, NJ: Prentice-Hall, Inc.

White, S.W., \& Kelly, F.D. (2010). The school counselor's role in school dropout prevention. Journal of Counseling and Development, 88(2), 227-236.

Whitted, K.S. (2011). Understanding how social and emotional skill deficits contribute to school failure. Preventing School Failure, 55(1), 10-16.

Wickham, D., Griggs, P., \& Beech, S.E. (2006). School-wide positive behavior support: Addressing behavior problems that impede student learning. Educational Psychology Review, 18(2), 187-198.

Zirkel, P.A., \& Thomas, L.B. (2010). State laws and guidelines for implementing RtI. Teaching Exceptional Children, 43(1), 60-73. Retrieved on 10/8/12 from www.ebscohost.com 
K-12 Alternative Public School

PBIS Expectations Matrix

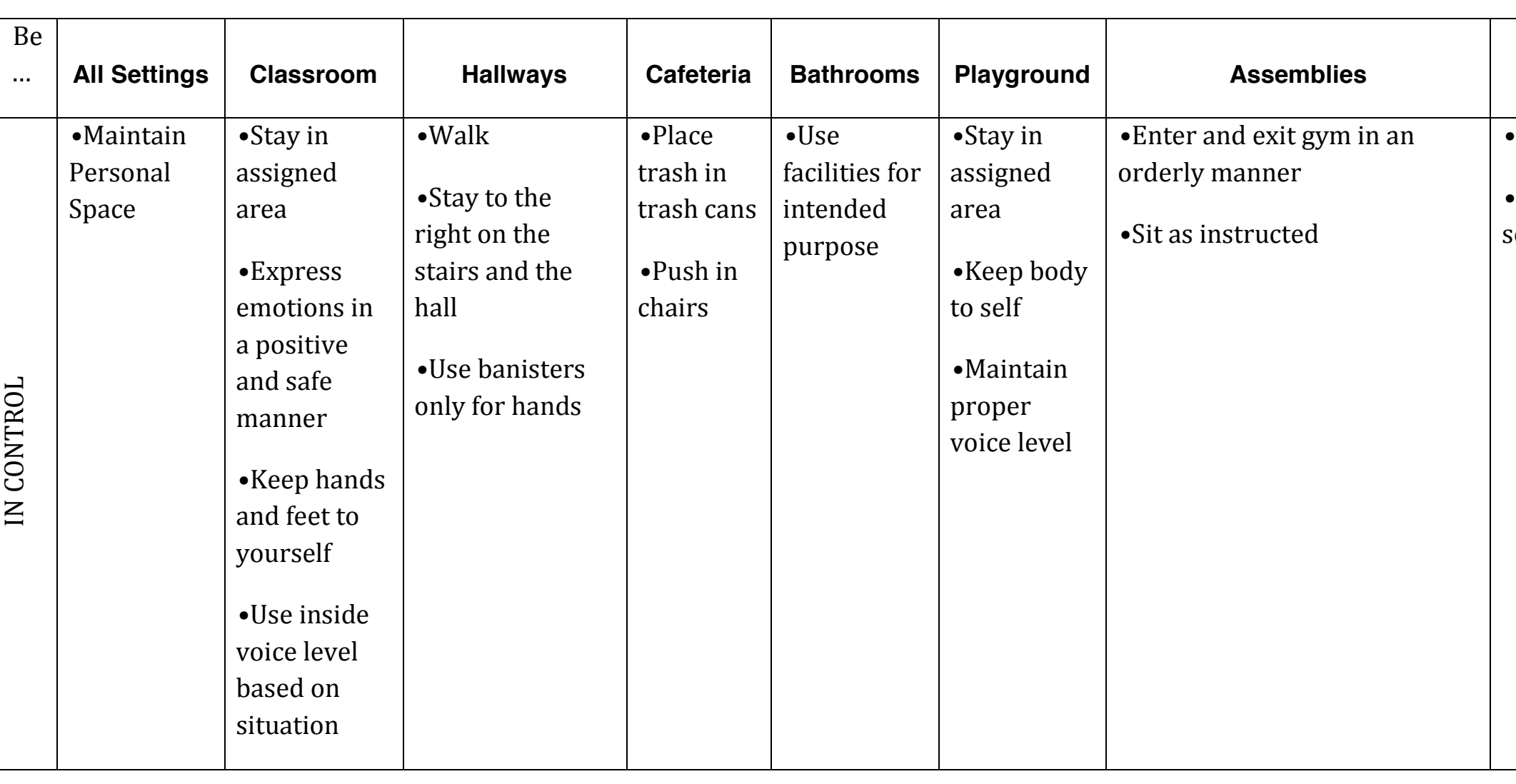




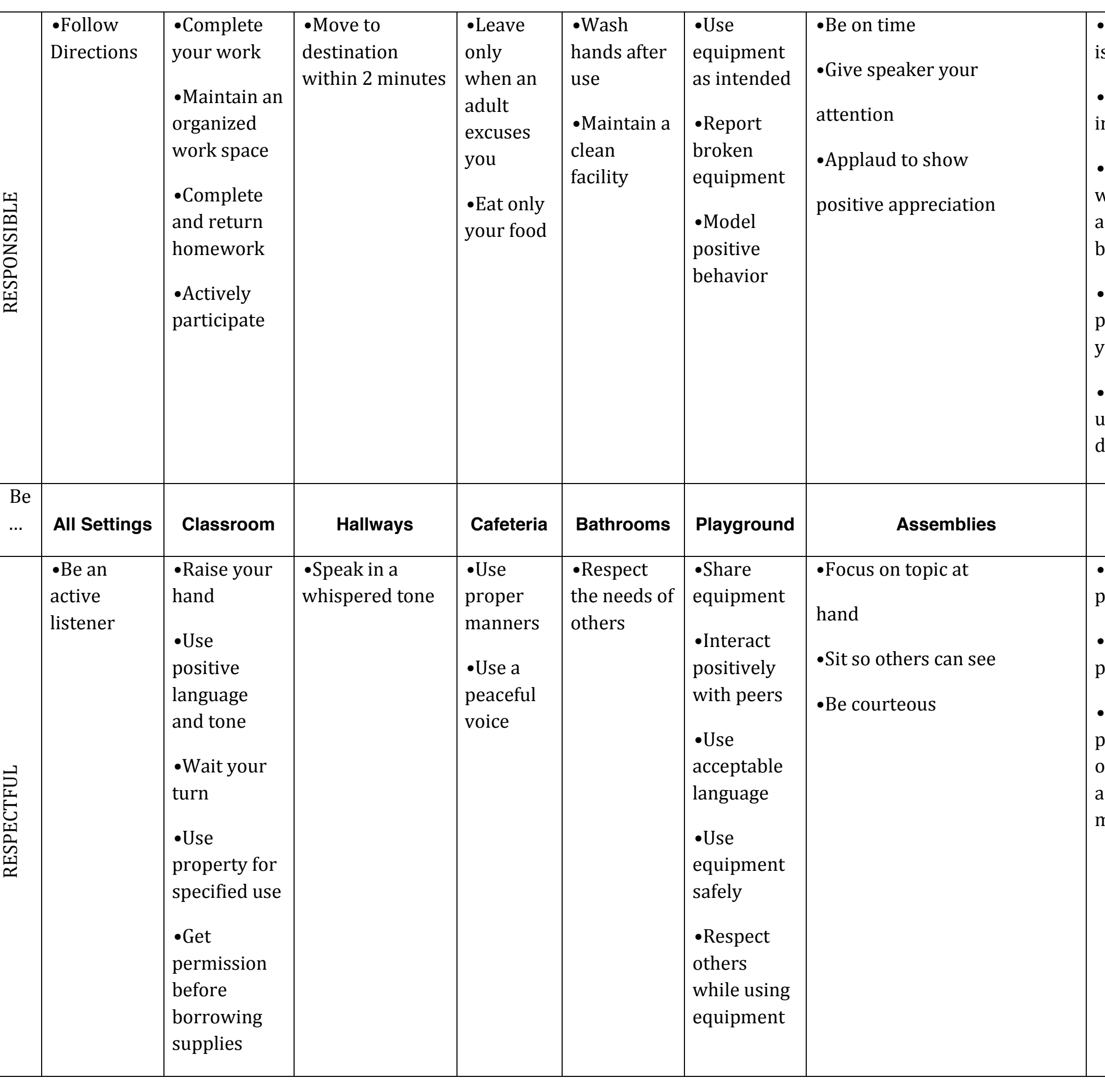




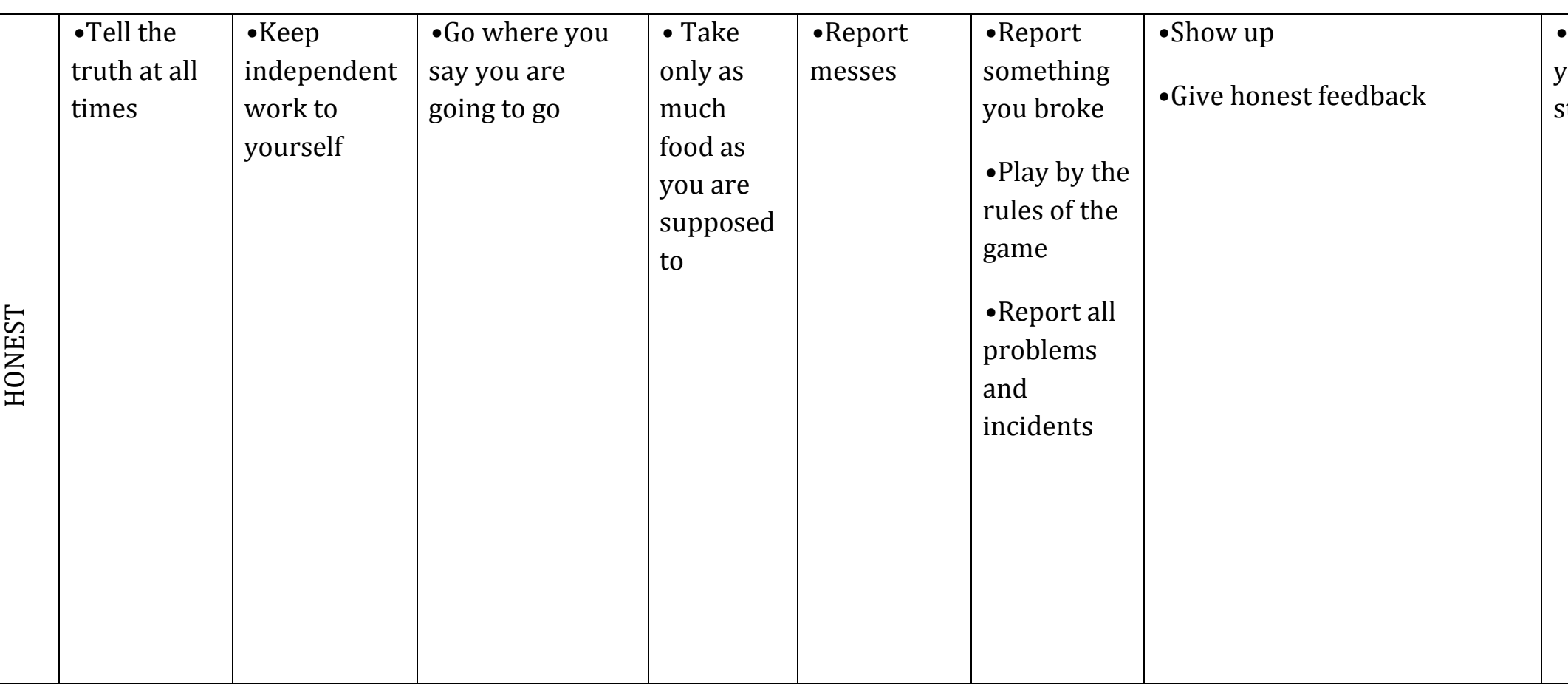




\section{APPENDIX B}

SWISTM Office Referral Definitions

\begin{tabular}{|c|c|}
\hline $\begin{array}{l}\text { Minor Problem } \\
\text { Behavior }\end{array}$ & Definition \\
\hline $\begin{array}{c}\text { Defiance/Disrespect } \\
\text { / Non-compliance } \\
\text { (M-Disrespt) }\end{array}$ & $\begin{array}{l}\text { Student engages in brief or low-intensity failure to } \\
\text { respond to adult requests. }\end{array}$ \\
\hline $\begin{array}{c}\text { Disruption } \\
\text { (M-Disruption) }\end{array}$ & $\begin{array}{l}\text { Student engages in low-intensity, but inappropriate } \\
\text { disruption. }\end{array}$ \\
\hline $\begin{array}{l}\text { Dress Code } \\
\text { Violation } \\
\text { (M-Dress) }\end{array}$ & $\begin{array}{l}\text { Student wears clothing that is near, but not within, the } \\
\text { dress code guidelines defined by the school/district. }\end{array}$ \\
\hline $\begin{array}{l}\text { Inappropriate } \\
\text { Language } \\
\text { (M-Inapp Lan) }\end{array}$ & $\begin{array}{l}\text { Student engages in low-intensity instance of } \\
\text { inappropriate language. }\end{array}$ \\
\hline $\begin{array}{c}\text { Other } \\
\text { (M-Other) }\end{array}$ & $\begin{array}{l}\text { Student engages in any other minor problem behaviors that } \\
\text { do not fall within the above categories. }\end{array}$ \\
\hline $\begin{array}{c}\text { Physical Contact/ } \\
\text { Physical Aggression } \\
\text { (M-Contact) }\end{array}$ & $\begin{array}{l}\text { Student engages in non-serious, but inappropriate } \\
\text { physical contact. }\end{array}$ \\
\hline $\begin{array}{l}\text { Property Misuse } \\
\text { (M-Prpty Misuse) }\end{array}$ & Student engages in low-intensity misuse of property. \\
\hline $\begin{array}{c}\text { Tardy } \\
\text { (M-Tardy) }\end{array}$ & $\begin{array}{l}\text { Student arrives at class after the bell (or signal that class } \\
\text { has started). }\end{array}$ \\
\hline
\end{tabular}




\begin{tabular}{|c|l|}
\hline $\begin{array}{c}\text { Technology } \\
\text { Violation } \\
\text { (M-Tech) }\end{array}$ & $\begin{array}{l}\text { Student engages in non-serious but inappropriate (as } \\
\text { defined by school) use of cell phone, pager, music/video } \\
\text { players, camera, and/or computer. }\end{array}$ \\
\hline
\end{tabular}

\begin{tabular}{|c|l|}
\hline $\begin{array}{c}\text { Major Problem } \\
\text { Behavior }\end{array}$ & \multicolumn{1}{c|}{ Definition } \\
\hline $\begin{array}{c}\text { Abusive Language/ } \\
\text { Inappropriate } \\
\text { Language/ Profanity } \\
\text { (Inapp Lan) }\end{array}$ & $\begin{array}{l}\text { Student delivers verbal messages that include swearing, name } \\
\text { calling or use of words in an inappropriate way. }\end{array}$ \\
\hline Arson & $\begin{array}{l}\text { Student plans and/or participates in malicious burning of } \\
\text { property. }\end{array}$ \\
\hline $\begin{array}{c}\text { Bomb Threat/ } \\
\text { False Alarm } \\
\text { (Bomb) }\end{array}$ & $\begin{array}{l}\text { Student delivers a message of possible explosive materials being } \\
\text { on-campus, near campus, and/or pending explosion. }\end{array}$ \\
\hline $\begin{array}{c}\text { Defiance/Disrespect/ } \\
\text { Insubordination/ }\end{array}$ & $\begin{array}{l}\text { Student engages in refusal to follow directions, talks back } \\
\text { and/or delivers socially rude interactions. }\end{array}$ \\
\hline Non-Compliance \\
(Disrespt)
\end{tabular}




\begin{tabular}{|c|c|}
\hline $\begin{array}{l}\text { Major Problem } \\
\text { Behavior }\end{array}$ & Definition \\
\hline $\begin{array}{l}\text { Fighting/ Physical } \\
\text { Aggression } \\
\text { (Agg/Fight) }\end{array}$ & $\begin{array}{l}\text { Student engages in actions involving serious physical contact } \\
\text { where injury may occur (e.g., hitting, punching, hitting with an } \\
\text { object, kicking, hair pulling, scratching, etc.). }\end{array}$ \\
\hline $\begin{array}{l}\text { Forgery/ Theft } \\
\text { (Forge/Theft) }\end{array}$ & $\begin{array}{l}\text { Student is in possession of, having passed on, or being } \\
\text { responsible for removing someone else's property or has signed } \\
\text { a person's name without that person's permission. }\end{array}$ \\
\hline $\begin{array}{l}\text { Gang Affiliation Display } \\
\text { (Gang Display) }\end{array}$ & $\begin{array}{l}\text { Student uses gesture, dress, and/or speech to display affiliation } \\
\text { with a gang. }\end{array}$ \\
\hline $\begin{array}{l}\text { Harassment/Bullying } \\
\text { (Harass) }\end{array}$ & $\begin{array}{l}\text { Student delivers disrespectful messages* (verbal or gestural) to } \\
\text { another person that includes threats and intimidation, obscene } \\
\text { gestures, pictures, or written notes. } \\
\text { *Disrespectful messages include negative comments based on race, } \\
\text { religion, gender, age, and/or national origin; sustained or intense verbal } \\
\text { attacks based on ethnic origin, disabilities or other personal matters. }\end{array}$ \\
\hline $\begin{array}{l}\text { Inappropriate Display } \\
\text { of Affection } \\
\text { (Inapp affection) }\end{array}$ & $\begin{array}{l}\text { Student engages in inappropriate, consensual (as defined by } \\
\text { school) verbal and/or physical gestures/contact, of a sexual } \\
\text { nature to another student/adult. }\end{array}$ \\
\hline $\begin{array}{l}\text { Inappropriate } \\
\text { Location/ Out of } \\
\text { Bounds Area } \\
\text { (Out Bounds) }\end{array}$ & $\begin{array}{l}\text { Student is in an area that is outside of school boundaries (as } \\
\text { defined by school). }\end{array}$ \\
\hline $\begin{array}{l}\text { Lying/Cheating } \\
\text { (Lying) }\end{array}$ & $\begin{array}{l}\text { Student delivers message that is untrue and/or deliberately } \\
\text { violates rules. }\end{array}$ \\
\hline $\begin{array}{l}\text { Other Behavior } \\
\text { (Other) }\end{array}$ & Student engages in problem behavior not listed. \\
\hline
\end{tabular}




\begin{tabular}{|c|c|}
\hline $\begin{array}{l}\text { Major Problem } \\
\text { Behavior }\end{array}$ & Definition \\
\hline $\begin{array}{c}\text { Property } \\
\text { Damage/Vandalism } \\
\text { (Prop dam) }\end{array}$ & $\begin{array}{l}\text { Student participates in an activity that results in destruction or } \\
\text { disfigurement of property. }\end{array}$ \\
\hline $\begin{array}{l}\text { Skip class } \\
\text { (Skip) }\end{array}$ & Student leaves or misses class without permission. \\
\hline $\begin{array}{l}\text { Truancy } \\
\text { (Truan) }\end{array}$ & Student receives an 'unexcused absence' for $1 / 2$ day or more. \\
\hline $\begin{array}{l}\text { Tardy } \\
\text { (Tardy) }\end{array}$ & $\begin{array}{l}\text { Student is late (as defined by the school) to class or the start up } \\
\text { of the school day (and Tardy is not considered a minor problem } \\
\text { behavior in the school). }\end{array}$ \\
\hline $\begin{array}{c}\text { Technology Violation } \\
\text { (Tech) }\end{array}$ & $\begin{array}{l}\text { Student engages in inappropriate (as defined by school) use of } \\
\text { cell phone, pager, music/video players, camera, and/or } \\
\text { computer. }\end{array}$ \\
\hline $\begin{array}{l}\text { Use/Possession of } \\
\text { Alcohol } \\
\text { (Alcohol) }\end{array}$ & Student is in possession of or is using alcohol. \\
\hline $\begin{array}{l}\text { Use/Possession of } \\
\text { Combustibles } \\
\text { (Combust) }\end{array}$ & $\begin{array}{l}\text { Student is in possession of substances/objects readily capable of } \\
\text { causing bodily harm and/or property damage (matches, lighters, } \\
\text { firecrackers, gasoline, lighter fluid). }\end{array}$ \\
\hline $\begin{array}{l}\text { Use/Possession of } \\
\text { Drugs } \\
\text { (Drugs) }\end{array}$ & $\begin{array}{l}\text { Student is in possession of or is using illegal drugs/substances } \\
\text { or imitations. }\end{array}$ \\
\hline $\begin{array}{l}\text { Use/Possession of } \\
\text { Tobacco } \\
\text { (Tobacco) }\end{array}$ & Student is in possession of or is using tobacco. \\
\hline
\end{tabular}




\begin{tabular}{|c|l|}
\hline $\begin{array}{c}\text { Major Problem } \\
\text { Behavior }\end{array}$ & \multicolumn{1}{c|}{ Definition } \\
\hline $\begin{array}{c}\text { Use/Possession of } \\
\text { Weapons } \\
\text { (Weapons) }\end{array}$ & $\begin{array}{l}\text { Student is in possession of knives or guns (real or look alike), or } \\
\text { other objects readily capable of causing bodily harm. }\end{array}$ \\
\hline Extra Info & $\begin{array}{l}\text { Extra Info is a field that SWIS TM offers for schools to more clearly } \\
\text { define categories within SWIS. Schools have three options available } \\
\text { for Extra Info codes. Examples are listed below. }\end{array}$ \\
\hline $\begin{array}{c}\text { Extra Info 1: } \\
\text { Harassment }\end{array}$ & $\begin{array}{l}\text { Type of harassment observed during the incident (e.g. racial, } \\
\text { sexual, religious, gender). }\end{array}$ \\
\hline Extra Info. 2: & $\begin{array}{l}\text { Specific location of 'hallway' where the incident occurred (e.g. } \\
\text { west wing). }\end{array}$ \\
\hline Hallway & Additional administrative decision regarding the incident. \\
\hline $\begin{array}{c}\text { Extra Info. 3: } \\
\text { Administrative } \\
\text { Decision }\end{array}$ & \\
\hline
\end{tabular}




\begin{tabular}{|c|l|}
\hline $\begin{array}{c}\text { Locations } \\
\text { Bathroom/Restroom } \\
\text { (Bathrm) }\end{array}$ & Definition \\
\hline $\begin{array}{c}\text { Bus } \\
\text { (Bus) }\end{array}$ & The area inside the bus. \\
\hline $\begin{array}{c}\text { Bus Loading Zone } \\
\text { (Bus zn) }\end{array}$ & The area used for bus loading and unloading. \\
\hline $\begin{array}{c}\text { Cafeteria } \\
\text { (Café) }\end{array}$ & The area used for breakfast and lunch. \\
\hline $\begin{array}{c}\text { Classroom } \\
\text { (Class) }\end{array}$ & Areas used for instructional purposes. \\
\hline $\begin{array}{c}\text { Commons/Common } \\
\text { area }\end{array}$ & Areas shared by students and staff for specific activities. \\
\hline $\begin{array}{c}\text { (Common) } \\
\text { (Music rm) }\end{array}$ & $\begin{array}{l}\text { The area used by students for music activities (e.g. music class, } \\
\text { choir, band) }\end{array}$ \\
\hline $\begin{array}{c}\text { Gym } \\
\text { (Gym) }\end{array}$ & Areas used for physical education activities. \\
\hline $\begin{array}{c}\text { Hallway/Breezeway } \\
\text { (Hall) }\end{array}$ & Areas designated for passing from one activity/class to another. \\
\hline pher & The area used by students to prepare for and completing \\
\hline
\end{tabular}




\begin{tabular}{|c|c|}
\hline Off-Campus & $\begin{array}{l}\text { An area beyond the property boundary of the school and not } \\
\text { affiliated with a school activity. }\end{array}$ \\
\hline $\begin{array}{l}\text { Office } \\
\text { (Office) }\end{array}$ & $\begin{array}{l}\text { The area used by school staff for primary school business and } \\
\text { management. }\end{array}$ \\
\hline $\begin{array}{l}\text { Other Location } \\
\text { (Other) }\end{array}$ & $\begin{array}{l}\text { The location for problem behavior event occurs in a location } \\
\text { that is not listed }\end{array}$ \\
\hline $\begin{array}{l}\text { Parking Lot } \\
\text { (Park lot) }\end{array}$ & Areas used for parking vehicles during school hours. \\
\hline $\begin{array}{l}\text { Playground } \\
\text { (Plygd) }\end{array}$ & The outside area used for recess breaks. \\
\hline $\begin{array}{c}\text { Special Event/ } \\
\text { Assembly/Field Trip } \\
\text { (Special evt) }\end{array}$ & $\begin{array}{l}\text { Areas used for infrequent activities that occur in and/or out of } \\
\text { school. }\end{array}$ \\
\hline Stadium & Area used for athletic/special events. \\
\hline $\begin{array}{l}\text { Unknown Location } \\
\text { (Unknown) }\end{array}$ & $\begin{array}{l}\text { The location of problem behavior event is not known or } \\
\text { undetermined. }\end{array}$ \\
\hline
\end{tabular}




\begin{tabular}{|c|c|}
\hline Possible Motivation & Definition \\
\hline $\begin{array}{l}\text { Avoid Adult } \\
\text { (Avoid a) }\end{array}$ & $\begin{array}{l}\text { Student engages in problem behavior(s) to get away from } \\
\text { adult(s). }\end{array}$ \\
\hline $\begin{array}{c}\text { Avoid Peer(s) } \\
\text { (Avoid p) }\end{array}$ & $\begin{array}{l}\text { Student engages in problem behavior(s) to get away } \\
\text { from/escape peer(s). }\end{array}$ \\
\hline $\begin{array}{l}\text { Avoid Tasks/Activities } \\
\text { (Avoid task) }\end{array}$ & $\begin{array}{l}\text { Student engages in problem behaviors(s) to get away/escape } \\
\text { from tasks and/or activities. }\end{array}$ \\
\hline $\begin{array}{l}\text { Obtain Adult Attention } \\
\qquad \text { (Ob a attn) }\end{array}$ & $\begin{array}{l}\text { Student engages in problem behavior(s) to gain adult(s) } \\
\text { attention. }\end{array}$ \\
\hline $\begin{array}{c}\text { Obtain items/Activities } \\
\text { (Ob itm) }\end{array}$ & $\begin{array}{l}\text { Student engages in problem behavior(s) to gain items and/or } \\
\text { activities. }\end{array}$ \\
\hline $\begin{array}{l}\text { Obtain Peer Attention } \\
\qquad \text { (Ob p attn) }\end{array}$ & $\begin{array}{l}\text { Student engages in problem behavior(s) to gain peer(s) } \\
\text { attention. }\end{array}$ \\
\hline $\begin{array}{l}\text { Other } \\
\text { (Other) }\end{array}$ & $\begin{array}{l}\text { Possible motivation for referral is not listed above. Staff using } \\
\text { this area will specify the possible motivation for this student's } \\
\text { problem behavior. }\end{array}$ \\
\hline $\begin{array}{l}\text { Unknown Motivation } \\
\text { (Unknown) }\end{array}$ & Student engages in problem behavior(s) for unclear reasons. \\
\hline Others Involved & Definition \\
\hline $\begin{array}{l}\text { None } \\
\text { (None) }\end{array}$ & Student engages in problem behavior incident alone. \\
\hline $\begin{array}{l}\text { Other } \\
\text { (Other) }\end{array}$ & $\begin{array}{l}\text { Student engages in problem behavior with person not listed } \\
\text { above. }\end{array}$ \\
\hline
\end{tabular}




\begin{tabular}{|c|l|}
\hline $\begin{array}{c}\text { Peers } \\
\text { (Peers) }\end{array}$ & Student engages in problem behavior incident with peer(s). \\
\hline $\begin{array}{c}\text { Staff } \\
\text { (Staff) }\end{array}$ & Student engages in problem behavior incident with staff. \\
\hline $\begin{array}{c}\text { Substitute } \\
\text { (Substitute) }\end{array}$ & Student engages in problem behavior incident with substitute. \\
\hline Teacher \\
(Teacher) & Student engages in problem behavior incident with teacher. \\
\hline Unknown & It is unclear if any others were involved in incident. \\
(Unknown) & \\
\hline
\end{tabular}




\begin{tabular}{|c|c|}
\hline $\begin{array}{l}\text { Administrative } \\
\text { Decision }\end{array}$ & Definition \\
\hline $\begin{array}{l}\text { Bus Suspension } \\
\text { (Bus susp) }\end{array}$ & $\begin{array}{l}\text { Consequence for referral results in 1-3 day period when } \\
\text { student not allowed on the bus. }\end{array}$ \\
\hline $\begin{array}{l}\text { Conference with } \\
\text { Student } \\
\text { (Conf) }\end{array}$ & $\begin{array}{l}\text { Consequence for referral results in student meeting with } \\
\text { administrator, teacher, and/or parent (in any combination). }\end{array}$ \\
\hline $\begin{array}{c}\text { Expulsion } \\
\text { (Expul) }\end{array}$ & $\begin{array}{l}\text { Consequence for referral results in student being dismissed } \\
\text { from school for one or more days. }\end{array}$ \\
\hline $\begin{array}{l}\text { Individualized } \\
\text { Instruction } \\
\text { (Intruct) }\end{array}$ & $\begin{array}{l}\text { Consequence for referral results in student receiving } \\
\text { individualized instruction specifically related to the student's } \\
\text { problem behaviors. }\end{array}$ \\
\hline $\begin{array}{l}\text { In-School Suspension } \\
\text { (In-sch susp) }\end{array}$ & $\begin{array}{l}\text { Consequence for referral results in a period of time spent away } \\
\text { from scheduled activities/classes during the school day. }\end{array}$ \\
\hline $\begin{array}{l}\text { Loss of Privilege } \\
\text { (Loss priv) }\end{array}$ & $\begin{array}{l}\text { Consequence for referral results in student being unable to } \\
\text { participate in some type of privilege. }\end{array}$ \\
\hline $\begin{array}{l}\text { Other Admin. Decision } \\
\text { (Other) }\end{array}$ & $\begin{array}{l}\text { Consequence for referral results in administrative decision that } \\
\text { is not listed. Staff using this area will specify the administrative } \\
\text { action taken. }\end{array}$ \\
\hline $\begin{array}{l}\text { Out-of-School } \\
\text { Suspension } \\
\text { (Out-sch susp) }\end{array}$ & $\begin{array}{l}\text { Consequence for referral results in a 1-3 day period when } \\
\text { student is not allowed on campus. }\end{array}$ \\
\hline $\begin{array}{l}\text { Parent Contact } \\
\text { (Parent) }\end{array}$ & $\begin{array}{l}\text { Consequence for referral results in parent communication by } \\
\text { phone, email, or person-to-person about the problem. }\end{array}$ \\
\hline
\end{tabular}




\begin{tabular}{|c|l|}
\hline $\begin{array}{c}\text { Restitution/Communit } \\
\text { y Service } \\
\text { (Restitution) }\end{array}$ & $\begin{array}{l}\text { Consequence for referral results in apologizing or } \\
\text { compensating for loss, damage, or injury; community services. }\end{array}$ \\
\hline $\begin{array}{c}\text { Saturday School } \\
\text { (Sat sch) }\end{array}$ & $\begin{array}{l}\text { Consequence for referral results in student attending classes on } \\
\text { a Saturday. }\end{array}$ \\
\hline $\begin{array}{c}\text { Time in Office } \\
\text { (Office) }\end{array}$ & $\begin{array}{l}\text { Consequence for referral results in student spending time in the } \\
\text { office away from scheduled activities/classes. }\end{array}$ \\
\hline $\begin{array}{c}\text { Time Out/Detention } \\
\text { (Detent) }\end{array}$ & $\begin{array}{l}\text { Consequence for referral results in student spending time in a } \\
\text { specified area away from scheduled activities/classes. }\end{array}$ \\
\hline $\begin{array}{c}\text { Unknown Admin. } \\
\text { Decision }\end{array}$ & Consequence is not known or undetermined. \\
(Unknown) & \\
\hline
\end{tabular}




\section{APPENDIX C}

Permission for Using Summary of Features on PBS at Each Level of Implementation

Glen Dunlap [glendunlap@sbcglobal.net]

To: Becker, Colleen M. (MU-Student) Saturday, December 17, 2011 5:25 PM

Colleen:

As far as I am concerned, you have permission.

Best wishes,

Glen Dunlap

Glen Dunlap, Ph.D.

Division of Applied Research and Educational Support

Department of Child and Family Studies, FMHI

College of Behavioral and Community Sciences

University of South Florida

2778 Mayberry Drive

Reno, NV 89509

$775-786-9319$

--- On Sat, 12/17/11, Becker, Colleen M. (MU-Student)

$<\mathrm{cmbm8d@mail.missouri.edu>} \mathrm{wrote:}$

From: Becker, Colleen M. (MU-Student)<cmbm8d@mail.missouri.edu>

Subject: ABD Doctoral Student Request

To: "glendunlap@sbcglobal.net" glendunlap@sbcglobal.net

Date: Saturday, December 17, 2011, 2:20 PM

Hello Dr. Dunlap!

My name is Colleen Becker and I am an ABD doctoral candidate at the University of Missouri-Columbia. I am currently working on my dissertation. My focus is in SchoolWide Positive Behavior Support. I just read your article "Positive Support Strategies for Students with Behavioral Disorders in General Education Settings" (2005).

I am requesting permission to use your Table 1 "Summary of Features on PBS at Each Level of Implementation" found on page 784 in Psychology in the Schools, 42(8).

In my dissertation I will indicate permission was granted to use the Table and I will be sure to cite the source as well. Please let me know whether or not I will be able to use this information. Thank you so much!

Colleen Becker 


\section{APPENDIX D}

Permission for Using the Essential Dimensions of School Climate Chart dfaster@csee.net on behalf of Darlene Faster [dfaster@schoolclimate.org]

To: Becker, Colleen M. (MU-Student) Monday, December 05, 2011 10:11 AM

Hi Colleen,

Thank you for your interest in NSCC and our work. Yes, you are approved to use the "12 Dimensions of School Climate Measured" Chart. Please be sure to cite the National School Climate Center (NSCC), for the Comprehensive School Climate Inventory (CSCI), www.schoolclimate.org, New York, NY; 2007.

Best of luck with your dissertation, and please keep us posted on your work as it relates to school climate.

Darlene

Forwarded message

From: Darlene Faster dfaster@csee.net Date: Sun, Dec 4, 2011 at 7:13

PMSubject: New lead assigned to you: Colleen Becker from University of Missouri Columbia

To: dfaster@schoolclimate.org dfaster@schoolclimate.org

$* * *$ NEW LEAD ASSIGNMENT NOTIFICATION ***

The following lead has been assigned to you.

Name: Colleen Becker

E-mail: cmbm8d@,mail.missouri.edu

Organization: University of Missouri - Columbia

City: Columbia

State: Missouri

Interest: Research

Comments: I am currently an ABD doctoral candidate and I am requesting permission to use the figure of "The 12 Dimensions of School Climate Measured" in my dissertation. I will be sure to cite the source as well as indicate permission was granted to use the information.

Please feel free to contact me if you have any questions or are in need of any additional information. Thank you!

Colleen Becker 


\section{APPENDIX E}

Permission for Using the Three-Tiered PBIS Triangle, the Four PBS Integrated Elements, and the PBIS Systems of Support Diagram

From: Laura A Riffel [tacenterpbis@gmail.com]

Sent: Monday, December 05, 2011 6:22 AM

To: Becker, Colleen M. (MU-Student)

Subject: Re: ABD doctoral candidate requesting permission

Dear Colleen

You have permission to use the items listed under the parameters defined in your email

Best wishes,

Laura A. Riffel, Ph. D.

Sent from my iPhone

On Dec 4, 2011, at 5:33 PM, "Becker, Colleen M. (MU-Student)"

cmbm8d@mail.missouri.edu wrote:

Hello!

My name is Colleen Becker and I am an ABD doctoral student at the University of Missouri - Columbia. I am requesting permission to use several diagrams from OSEP to use in my dissertation. I will be sure to acknowledge the "granted permission" in my dissertation. I am requesting to be able to use:

1. The three-tiered triangle showing the continuum of PBIS

2. The circle with the 4 PBS Integrated Elements

3. The circle with PBS Systems of Support

Thank you so much for your consideration as it is greatly appreciated! If you have any questions or are in need of additional information, please feel free to contact me.

Thank you!

\section{Colleen Becker}




\section{APPENDIX F}

Permission for Using "Decision-making in Secondary and Tertiary Interventions of School-Wide Systems of Positive Behavior Support"

Scott,Terry M [t.scott@louisville.edu]

To: Becker, Colleen M. (MU-Student)

Saturday, December 17, 2011 1:28 PM

Colleen,

You are very welcome to use anything I have or have done if it helps you to do your research. Good luck and let me know if there is anything I can do to be of assistance.

Thanks,

Terry

Terrance M. Scott, Ph.D

Professor and Distinguished University Scholar

Department of Special Education

158A Porter Education Bldg.

University of Louisville

Louisville, KY 40292

502-852-0576

Becker, Colleen M. (MU-Student) Friday, December 16, 2011 6:27 PM

Hello Dr. Scott!

My name is Colleen Becker and I am an ABD doctoral candidate at the University of Missouri-Columbia. I am currently working on my dissertation. My focus is in SchoolWide Positive Behavior Support. I just read your article "Decision-making in Secondary and Tertiary Interventions of School-Wide Systems of Positive Behavior Support" (2010).

I am requesting permission to use your Table 1 "Summary Table of Interventions Continuum at the Secondary and Tertiary Levels of PBS" found on page 529 in the Journal of Education and Treatment of Children, 33 (4).

In my dissertation I will indicate permission was granted to use the Table and I will be sure to cite the source as well. Please let me know whether or not I will be able to use this information. Thank you so much!

Colleen Becker 


\section{VITAE}

Colleen Gilday Becker was born and raised in Kansas City, Missouri. She is an identical twin and the oldest of five siblings. Colleen started playing the accordion at age five and took lessons at a local music store and then at age 14 began accordion lessons at the Conservatory of Music at the University of Missouri-Kansas City. After graduating from O'Hara High School in 1972 she began her studies at the Conservatory and continued with accordion studies and performing with the UMKC Accordion Orchestra as part of her degree program. She received a double major Bachelor of Music Education - Music Therapy (Vocal Music K-12) degree in 1977 and was recognized for being on the Dean's List. She also became a Registered Music Therapist. Her husband was transferred to Iowa and Colleen got her first teaching job as a Music Teacher/Music Therapist at a Special Education Public School in Ottumwa, Iowa. They then returned to Missouri and Colleen got a job as a Board Certified-Registered Music Therapist at the St. Joseph State Psychiatric Hospital in St. Joseph, Missouri where she later became the Director of the Music Therapy Department and Internship Training Director. She trained new students from across the country during six-month internships. She also started working on her Master's degree and she and her husband started a family. She received a Master of Science degree in Counseling/Psychology from Northwest Missouri State University in Maryville, Missouri in 1985. She remained working full time at the St. Joseph State Psychiatric Hospital, however changed job classifications and worked as a Psychologist.

Colleen then earned her certification as a Licensed Professional Counselor and 
started a small part time Private Practice business. As she continued to work at the State Hospital she also returned to the University of Missouri-Kansas City and completed an Educational Specialist degree in Guidance/Counseling in 1990 and received an award for four years of academic excellence (4.0 GPA). She then received certification as a Cognitive Behavioral Therapist. Colleen became a single parent and raised her three children while she maintained her Private Practice and worked full time for the Department of Corrections as a Substance Abuse Counselor and then as the Director of the Therapeutic Community Program at the prison involving approximately 500 inmates. After leaving her job at the prison she maintained a full time Private Practice and achieved Diplomate status as a psychotherapist with the American Psychotherapy Association.

Colleen returned to Northwest Missouri State University for two years and received her Certification as a Professional School Counselor. During this time at NWMSU she was hired by the local school district where she has now been employed full time for the past eight years as the Professional School Counselor/Licensed Professional Counselor at the K-12 Alternative School and also at the Alternative High School. She continues working fulltime at the school district while completing her doctorate at the University of Missouri-Columbia. Colleen also continues her education and training to receive her certification as a Trauma and Loss Specialist.

Colleen lives in St. Joseph, Missouri and helps her 26-year-old daughter Amy who is a single parent. Amy has Cystic Fibrosis and Colleen helps her to manage her home and her four-year-old son, and her seven-year-old son who is disabled. 